RAFAEL GUIMARÃES SAVIOLI

AVALIAÇÃO DOS PARÂMETROS CTOD E INTEGRAL $J$ EM JUNTAS SOLDADAS UTILIZANDO CORPOS-DE-PROVA COMPACTOS C(T)

São Paulo

2011 
RAFAEL GUIMARÃES SAVIOLI

\title{
AVALIAÇÃO DOS PARÂMETROS CTOD E INTEGRAL $J$ EM JUNTAS SOLDADAS UTILIZANDO CORPOS-DE-PROVA COMPACTOS C(T)
}

\author{
Dissertação Apresentada à Escola \\ Politécnica da Universidade de São \\ Paulo para a obtenção do Título de \\ Mestre em Engenharia.
}

Área de Concentração:

Engenharia Naval e Oceânica

Orientador: Professor Titular Claudio Ruggieri

São Paulo 
Este exemplar foi revisado e alterado em relação à versão original, sob responsabilidade única do autor e com a anuência de seu orientador.

São Paulo, de dezembro de 2011.

Assinatura do autor

Assinatura do orientador

FICHA CATALOGRÁFICA

Savioli, Rafael Guimarães

Avaliação dos parâmetros CTOD e integral- $J$ em juntas sol dadas utilizando corpos-de-prova compactos C(T) / R.G. Savioli. -- ed.rev. -- São Paulo, 2011. $136 \mathrm{p}$.

Dissertação (Mestrado) - Escola Politécnica da Universidade de São Paulo. Departamento de Engenharia Naval e Oceânica.

1. Juntas soldadas 2. Integridade estrutural 3. Mecânica da fratura 4. Propriedades dos materiais I. Universidade de São Paulo. Escola Politécnica. Departamento de Engenharia Naval e Oceânica II. t. 
Aos meus irmãos Daniela e Victor pelos momentos de descontração. Ao meu avô Cesar pela inspiração e exemplo de inteligência. À minha querida Nathália por me confortar e me encorajar.

Aos meus pais Jofre e Marcia por me apoiarem incondicionalmente em tudo. 


\section{AGRADECIMENTOS}

Ao Prof. Dr. Claudio Ruggieri pela orientação, crédito, exemplo de profissionalismo e pela oportunidade da participação em um projeto inesquecível;

Aos colegas do NAMEF: Diego Sarzosa, Luís Parise, Marcelo Lenin Paredes, Mario Chiodo, Paulo Eduardo Fernandes, pelo companheirismo e amizade;

Ao Sr. José Hernani Arrym responsável por viabilizar e incentivar o meu mestrado; Ao departamento de Engenharia Naval e Oceânica

À CAPES pela bolsa concedida. 


\section{RESUMO}

Este trabalho visa o refinamento do procedimento para estimativa dos parâmetros elasto-plásticos de tenacidade à fratura, integral $J$ e CTOD, incorporando o efeito de dissimilaridade mecânica devido à introdução de juntas soldadas utilizando a metodologia eta, tal efeito não é previsto na formulação das atuais normas de avaliação de tenacidade à fratura, porém a dissimilaridade mecânica afeta fortemente a relação entre o carregamento global do espécime e as forças motrizes na ponta da trinca. Para o desenvolvimento das análises foi empregada a geometria normalizada $\mathrm{C}(\mathrm{T})$, compacta, pois esta pode apresentar potencias vantagens sobre a geometria $\mathrm{SE}(\mathrm{B})$, flexão três pontos, como menor consumo de material para a confecção dos espécimes, menor capacidade do aparato experimental e fácil manipulação na prática dos testes laboratoriais, porém carece de fatores eta quando comparados ao tradicional espécime $\mathrm{SE}(\mathrm{B})$.

Os principais objetivos deste trabalho são gerar um compêndio de fatores eta e propor uma formulação robusta que incorpore os efeitos de dissimilaridade mecânica para o cálculo de integral $J$ e CTOD. Para tal intento a matriz de análise deste trabalho abrange diferentes comprimentos de trinca, níveis de dissimilaridade mecânica e larguras de cordão de solda, $0.45 \leq a / W \leq 0.6$ e $1 \leq M_{y} \leq 1.3,10 \mathrm{~mm} \leq 2 h \leq 20$ $\mathrm{mm}$ respectivamente. As análises numéricas foram realizadas nas condições de estado plano de deformação (2D) e tridimensional (incluindo o efeito acoplado entre os campos de tensões e deformações no plano e fora do plano), os resultados fornecem um bom suporte ao uso da geometria $\mathrm{C}(\mathrm{T})$ com trinca central no cordão de solda para avaliação de tenacidade à fratura em juntas soldadas de materiais comumente aplicados na construção de dutos e vasos de pressão.

Palavras-chave: Juntas Soldadas. Dissimilaridade Mecânica. Espécime Compacto. $\mathrm{C}(\mathrm{T})$. Método eta. Integral J. CTOD. 


\begin{abstract}
This work focuses on the evaluation procedure to determine the elastic-plastic $J$ integral and CTOD fracture toughness based upon the eta-method for $\mathrm{C}(\mathrm{T})$ fracture specimens including overmatched weldments. Since fracture toughness test protocols do not address weld strength mismatch effect, this effect strongly alters the relationship between global loads and crack driving forces.

The objectives of this investigation are to enlarge plastic eta-factor data base for $\mathrm{C}(\mathrm{T})$ specimen and to develop a robust formulation to address weld strength mismatch. The present analyses enable the introduction of a larger set of plastic eta-factors for a wide range of crack sizes (as measured by the $a / W$-ratio) and material properties, including different levels of weld strength mismatch, applicable to structural, pipeline and pressure vessel steels. Very detailed non-linear finite element analyses for plane-strain and full 3D models of standard $C(T)$ fracture specimens provide the evolution of load with increased crack mouth opening displacement (and LLD) required for the estimation procedure. The results provide a strong support to use the plastic eta-factor in $J$ integral and CTOD estimation procedures for center notch welded $\mathrm{C}(\mathrm{T})$ fracture specimen.
\end{abstract}

Keywords: Weldments. Weld Strength Mismatch. Compact Specimen. C(T). eta Method. $J$ integral. CTOD. 


\section{SUMÁRIO}

ÍNDICE DE FIGURAS

LISTAS DE TABELAS

LISTA DE ABREVIATURAS E SIGLAS.

LISTA DE SÍMBOLOS

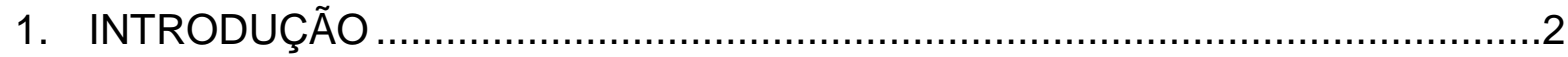

1.1 MOTIVAÇÃO E OBJETIVOS DO TRABALHO ….....................................

2. CONCEITOS DE MECÂNICA DA FRATURA …......................................10

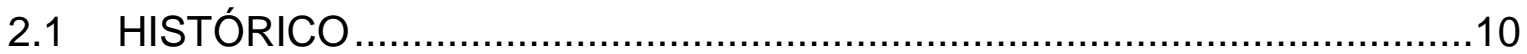

2.2 MECÂNICA DA FRATURA ELÁSTICA LINEAR ......................................13

2.3 LIMITAÇÕES DA MECÂNICA DA FRATURA ELÁSTICA LINEAR .............16

2.4 MECÂNICA DA FRATURA ELASTO-PLÁSTICA....................................18

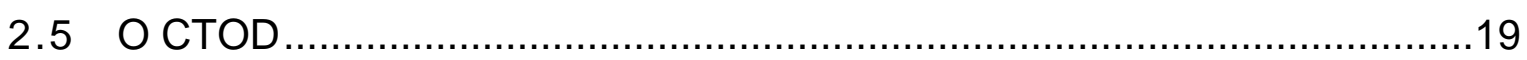

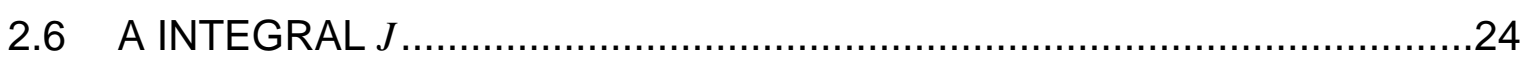

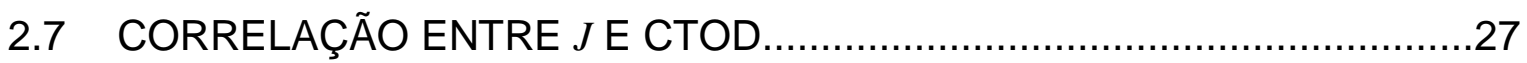

3. PROCEDIMENTOS DE AVALIAÇÃO DO CTOD E INTEGRAL $J$ UTILIZANDO MEDIÇÕES EXPERIMENTAIS DE CARGA E DESLOCAMENTO …................30

3.1 METODOLOGIA DA RÓTULA PLÁSTICA …............................................

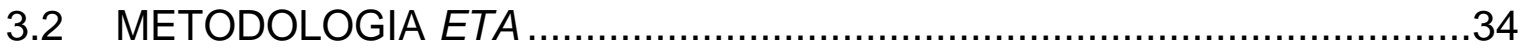

3.2.1 METODOLOGIA ETA - MATERIAIS HOMOGÊNEOS ...............................34

3.2.2 EXTENSÃO DA METODOLOGIA ETA PARA JUNTAS SOLDADAS COM

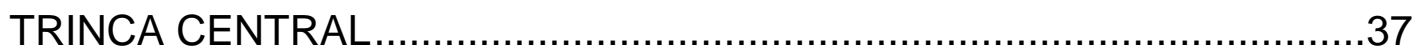

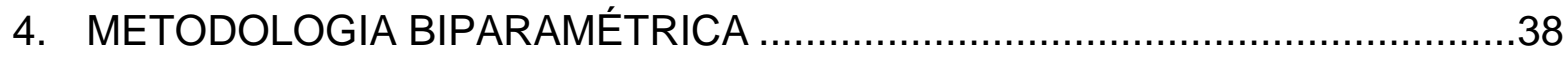

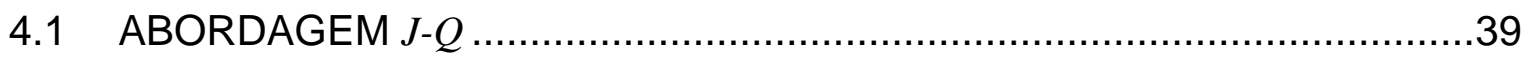

4.2 EXTENSÃO DA METODOLOGIA $J$ - $Q$ PARA JUNTAS SOLDADAS ….......41

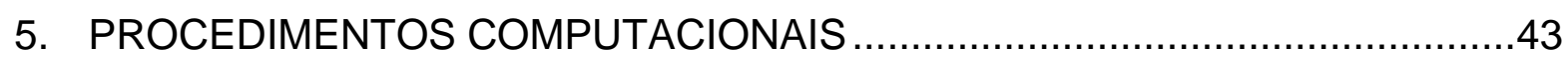

5.1 MODELOS GEOMÉTRICOS PARA OS CORPOS-DE-PROVA …..............43 
5.2 ANÁLISES PELO MÉTODO DOS ELEMENTOS FINITOS .........................45

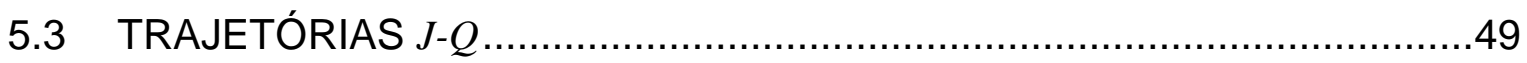

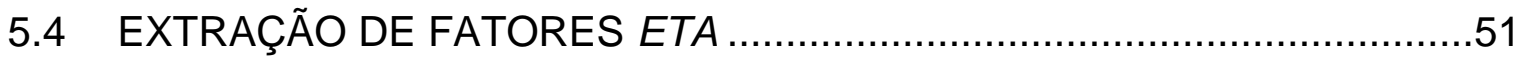

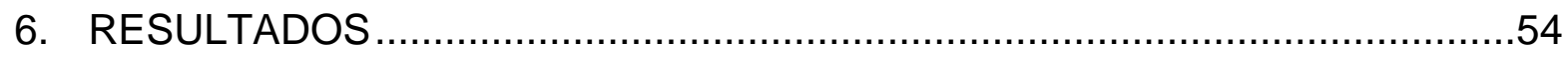

6.1 EFEITO DA DISSIMILARIDADE MECÂNICA NA TRAJETÓRIA $J-Q$ DE

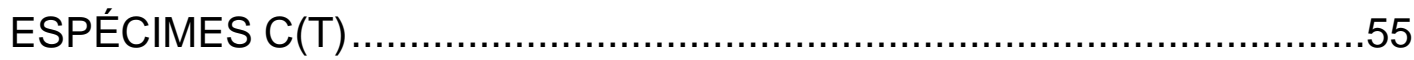

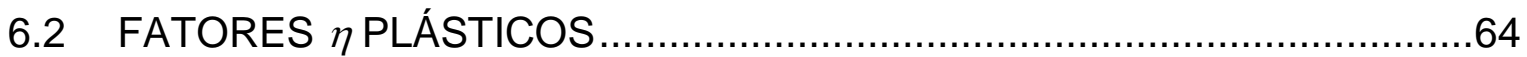

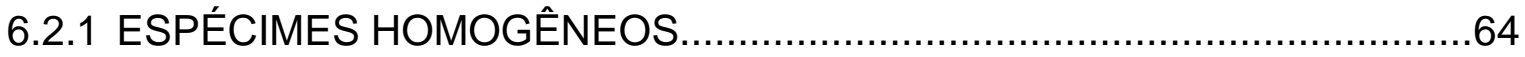

6.2.2 ESPÉCIMES COM DISSIMILARIDADE MECÂNICA: ANÁLISES 2D..........67

6.3 INFLUÊNCIA DA LARGURA DO CORDÃO DE SOLDA SOBRE OS FATORES $\eta$ EM ESTADO PLANO DE DEFORMAÇÃO ...........................73

6.4 ESPÉCIMES COM DISSIMILARIDADE MECÂNICA: ANÁLISES 3D.........80

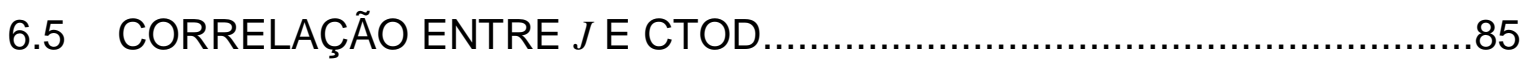

6.6 COMPARAÇÃO ENTRE OS VALORES DE CTOD NUMÉRICO E

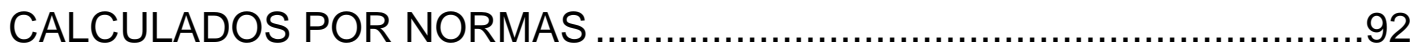

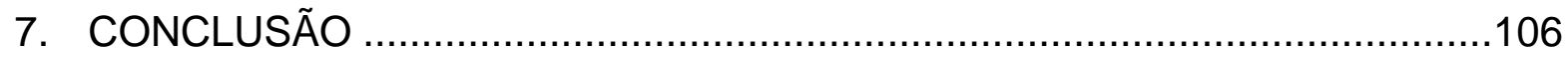

8. SUGESTÃO PARA TRABALHOS FUTUROS...........................................108

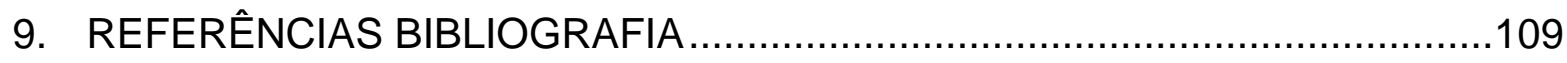

APÊNDICE A - FATORES ETA OBTIDOS NO TRABALHO ….........................114 


\section{ÍNDICE DE FIGURAS}

Figura 1 (a) Efeito da explosão de um gasoduto sobre o seu leito de passagem no solo com conseqüente ruptura e falha catastrófica da tubulação. (b) Detalhe do defeito precursor da ruptura e falha catastrófica [2]. ............... 3

Figura 2 Navio da série Liberty, exemplo de falha catastrófica com separação total do casco e convés [17]. 11

Figura 3 Esquema representativo da condição de similitude onde corpo-de-prova e estrutura estão carregados sob mesma condição de intensidade de tensões.

Figura 4 Representação da trinca estudada por Williams em coordenadas polares [29].

Figura 5 Modos de carregamento aplicados a uma trinca. (a) Modo I - Abertura; (b) Modo II - Cisalhamento no Plano; (c) Modo III - Cisalhamento Fora do Plano. [17] 16

Figura 6 Variação de $K_{I c}$ com a temperatura para o aço ASTM A533B de baixa liga utilizado na construção de vasos de pressão nucleares [17]. 17

Figura 7 Deslocamento dos flancos da trinca e arredondamento da ponta ("blunting") [33]. . 19

Figura 8 Representação da zona plástica de Irwin [17] 20

Figura 9 Representação da trinca utilizada pelo modelo de faixa de escoamento (a). Medição do CTOD $(\boldsymbol{\delta})$ para o modelo de faixa de escoamento (b) [17]... 21

Figura 10 (a) Deslocamento dos flancos da trinca. (b) Definição de CTOD 90 [17].

Figura 11 Representação do Modelo da Rótula Plástica [20]. 24

Figura 12 Representação de curva tensão deformação para materiais elastoplásticos e elásticos não lineares [33]. ......................................... 25

Figura 13 Representação do contorno arbitrário ao redor da trinca [33]. 25

Figura 14 Valores de $d n$ para a relação de $J$ vs. CTOD sob condição de estado plano de tensões e estado plano de deformações, respectivamente com $\alpha=1$. Para $\alpha \neq 1$ os valores acima devem ser multiplicados por $\alpha 1 / n$ [39]. 29

Figura 15 Representação do modelo da rótula plástica para um espécime $C(T)$ [41]

Figura 16 Definição de área plástica e elástica sob a curva de carga vs. deslocamento (CMOD ou LLD) [38]

Figura 17 Representação da curva de carga deslocamento com as representações da parcela plástica e elástica para um corpo-de-prova $\mathrm{C}(\mathrm{T})$ contendo cordão de solda.

Figura 18 Representação esquemática para a avaliação do parâmetro $Q$ incorporando os efeitos de dissimilaridade mecânica em um componente (corpo-de-prova) soldado. 
Figura 19 Representação comparativa em escala das dimensões apresentadas pelos espécimes $C(T)$ e $S E(B)$. (a) Comparativo no plano xy; (b) Extração dos espécimes de uma estrutura genérica. ......................................... 43

Figura 20 Representação das dimensões significativas para as geometrias compacta, (a); e flexão 3 pontos, (b). 45

Figura 21. Representação da simetria do corpo $\mathrm{C}(\mathrm{T})$ utilizada nos modelos para simulação 2D (a). Representação da ponta da trinca arredondada (b). .. 46

Figura 22 Modelo de elementos finitos tridimensional e representação dos cordões de solda com largura $2 h=10 \mathrm{~mm}, 15 \mathrm{~mm}$ e $20 \mathrm{~mm}$.

Figura 23 Gráfico de tensão vs. deformação de aços ferríticos com diferentes valores de encruamento e tensão de escoamento. 48

Figura 24 Representação de um corpo-de-prova com geometria compacta, C(T), (a) solicitado sob Modo I de carregamento. (b) Representação do modelo MBL. 49

Figura 25 Representação da tensão de abertura adimensional vs. distância adimensional para a solução de referência $\mathrm{MBL}$ e um componente estrutural genérico [38] 50

Figura 26 Influência da geometria do corpo-de-prova na trajetória $J-Q$ para espécimes $\mathrm{C}(\mathrm{T}), \mathrm{SE}(\mathrm{B}) \mathrm{SE}(\mathrm{T})$ e duto [29].... 51

Figura 27 Representação da curva de carga vs. deslocamento (LLD, CMOD) obtida computacionalmente para incrementos discretos de carga [38]............. 52

Figura 28 Influência da geometria do corpo-de-prova e da dissimilaridade mecânica do material na trajetória $J-Q$ para espécimes $\mathrm{SE}(\mathrm{B})$ e $\mathrm{C}(\mathrm{T})$ com mesmo comprimento de trinca adimensional $(a / W)$. [4] 56

Figura 29 Trajetória $J-Q$ para diferentes níveis de dissimilaridade mecânica. $a / W=\mathbf{0 . 4 5}$. (a) cordão de solda com largura $2 h=10 \mathrm{~mm}$; (b) cordão de solda com largura $2 h=15 \mathrm{~mm}$;(c) cordão de solda com largura $2 h=20$ $\mathrm{mm}$. 58

Figura 30 Trajetória $J-Q$ para diferentes níveis de dissimilaridade mecânica. $\boldsymbol{a} / \boldsymbol{W}=\mathbf{0 . 5}$. (a) cordão de solda com largura $2 h=10 \mathrm{~mm}$; (b) cordão de solda com largura $2 h=15 \mathrm{~mm}$;(c) cordão de solda com largura $2 h=20 \mathrm{~mm} \ldots . .59$

Figura 31 Trajetória $J-Q$ para diferentes níveis de dissimilaridade mecânica. $a / W=\mathbf{0 . 5 5}$. (a) cordão de solda com largura $2 h=10 \mathrm{~mm}$; (b) cordão de solda com largura $2 h=15 \mathrm{~mm}$;(c) cordão de solda com largura $2 h=20$ $\mathrm{mm}$.

Figura 32 Trajetória $J-Q$ para diferentes níveis de dissimilaridade mecânica. $a / W=\mathbf{0 . 6}$. (a) cordão de solda com largura $2 h=10 \mathrm{~mm}$; (b) cordão de solda com largura $2 h=15 \mathrm{~mm}$;(c) cordão de solda com largura $2 h=20 \mathrm{~mm} \ldots . .61$

Figura 33 Trajetória $J-Q$ para diferentes níveis de dissimilaridade mecânica. $a / W=\mathbf{0 . 6 5}$. (a) cordão de solda com largura $2 h=10 \mathrm{~mm}$; (b) cordão de solda com largura $2 h=15 \mathrm{~mm}$;(c) cordão de solda com largura $2 h=20$ $\mathrm{mm}$. 62

Figura 34 Trajetória $J-Q$ para diferentes níveis de dissimilaridade mecânica. $\boldsymbol{a} / W=\mathbf{0 . 7}$. (a) cordão de solda com largura $2 h=10 \mathrm{~mm}$; (b) cordão de solda com largura $2 h=15 \mathrm{~mm}$;(c) cordão de solda com largura $2 h=20 \mathrm{~mm} \ldots . .63$ 
Figura $35 \mathrm{O}$ gráfico de carga $(\mathrm{P})$ vs. deslocamento pode ser contruído em relação

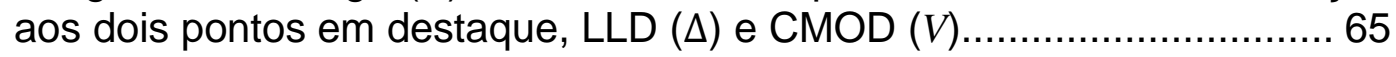

Figura 36 Representação das três geometrias apresentadas pelas normas da

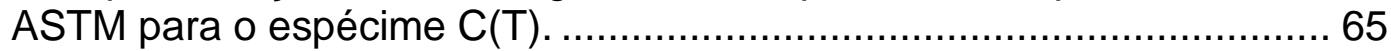

Figura 37 Comparação dos fatores $\eta_{J}^{L L D}$ obtidos por norma e por simulação numérica para corpos-de-prova homogêneos. 66

Figura 38 Fatores $\eta_{J}^{\text {CMOD }}$ para corpos-de-prova com diferentes níveis de dissimilaridade mecânica. (a) cordão de solda com largura $2 h=10 \mathrm{~mm}$; (b) cordão de solda com largura $2 h=15 \mathrm{~mm}$; (c) cordão de solda com largura $2 h=20 \mathrm{~mm}$. 69

Figura 39 Fatores $\eta_{J}^{\mathrm{LLD}}$ para corpos-de-prova com diferentes níveis de dissimilaridade mecânica. (a) cordão de solda com largura $2 h=10 \mathrm{~mm}$; (b) cordão de solda com largura $2 h=15 \mathrm{~mm}$; (c) cordão de solda com largura

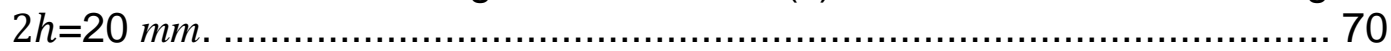

Figura 40 Fatores $\eta_{\delta}^{\text {CMOD }}$ para corpos-de-prova com diferentes níveis de dissimilaridade mecânica. (a) cordão de solda com largura $2 h=10 \mathrm{~mm}$; (b) cordão de solda com largura $2 h=15 \mathrm{~mm}$; (c) cordão de solda com largura

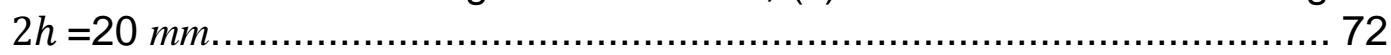

Figura 41 Influência da largura do cordão de solda sobre os fatores $\eta_{J}^{\text {CMOD }}$ para diferentes comprimentos de trinca adimensional, de raso a profundo. $0.45 \leq a / W \leq 0.7$. 74

Figura 42 Influência da largura do cordão de solda sobre os fatores $\eta_{J}^{\mathrm{LLD}}$ para diferentes comprimentos de trinca adimensional, de raso a profundo. $0.45 \leq a / W \leq 0.7$. 75

Figura 43 Influência da largura do cordão de solda sobre os fatores $\eta_{\delta}^{\mathrm{CMOD}}$ para diferentes comprimentos de trinca adimensional, de moderado a profundo. $0.45 \leq a / W \leq 0.7$ 76

Figura 44 Fatores $\eta_{J}^{\text {CMOD }} 3 \mathrm{D} 1 \mathrm{~T}$ para corpos-de-prova com diferentes níveis de dissimilaridade mecânica e cordão de solda com largura $2 h=15 \mathrm{~mm}$...... 81

Figura 45 Fatores $\eta_{J}^{\mathrm{LL}} 3 \mathrm{D}$ 1T para corpos-de-prova com diferentes níveis de dissimilaridade mecânica e cordão de solda com largura $2 h=15 \mathrm{~mm}$...... 81

Figura 46 Fatores $\eta_{\delta}^{\mathrm{CMOD}}$ 3D $1 \mathrm{~T}$ para corpos-de-prova com diferentes níveis de dissimilaridade mecânica e cordão de solda com largura $2 h=15 \mathrm{~mm}$...... 82

Figura 47 Gráficos comparativos entre fatores $\eta$ obtidos para os modelos tridimensionais e modelos sob a condição de estado plano de deformação. (a) $\eta_{J}^{\mathrm{CMOD}}$ (b) $\eta_{J}^{\mathrm{LLD}}$; (c) $\eta_{\delta}^{\mathrm{CMOD}}$

Figura 48 Gráficos comparativos entre fatores $\eta$ obtidos para os modelos tridimensionais com geometria $1 \mathrm{~T}$ e $0.5 \mathrm{~T}$. (a) $\eta_{J}^{\mathrm{CMOD}}$; (b) $\eta_{J}^{\mathrm{LLD}}$; (c) $\eta_{\delta}^{\mathrm{CMOD}} 85$

Figura 49 Relação entre $J$ vs. CTOD para a condição homogênea, $M_{y}=1.0$, com para diversos comprimentos de trinca. 86

Figura 50 Relação entre $J$ vs. CTOD sob efeito de dissimilaridade mecânica para diversos comprimentos de trinca. (a) $M_{y}=1.1$; (b) $M_{y}=1.2$; (c) $M_{y}=1.3 . \ldots .87$ 
Figura 51 Influência do nível de dissimilaridade e comprimento de trinca

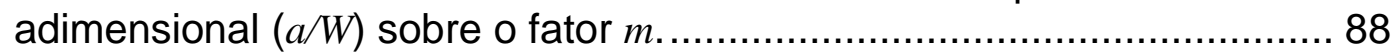

Figura 52 Gráficos para os valores de fator $\mathrm{m}$ utilizando $\sigma_{\text {FLOW }}$ como tensão de referência. (a) Utilizando a expressão analítica da API 579 para o cálculo do limite de resistência do material. (b) Utilizando a expressão analítica da DVN F-101 para o cálculo do limite de resistência do material. 91

Figura 53 Comparativo entre os valores de CTOD obtidos das análises numérica (CTOD $90^{\circ}$ ) e os valores de CTOD obtidos pelas formulações da norma BS 7448 [18]; (a) $a / W=0.45$; (b) $a / W=0.5$. 93

Figura 54 Comparativo entre os valores de CTOD obtidos das análises numérica (CTOD $90^{\circ}$ ) e os valores de CTOD obtidos pelas formulações da norma BS 7448 [18]; (a) $a / W=0.55$; (b) $a / W=0.6$. 94

Figura 55 Comparativo entre os valores de CTOD obtidos das análises numérica (CTOD $90^{\circ}$ ) e os valores de CTOD obtidos pelas formulações da norma BS 7448 [18]; (a) $a / W=0.65$; (b) $a / W=0.7$. 95

Figura 56 Comparativo entre os valores de CTOD obtidos as análises numérica (CTOD $90^{\circ}$ ) e os valores de CTOD obtidos pelas formulações da norma ASTM 1290 [19]; (a); $a / W=0.45 ;$ (b) $a / W=0.5$. 97

Figura 57 Comparativo entre os valores de CTOD obtidos as análises numérica (CTOD $90^{\circ}$ ) e os valores de CTOD obtidos pelas formulações da norma ASTM 1290 [19]; (a); $a / W=0.55$; (b) $a / W=0.6$. 98

Figura 58 Comparativo entre os valores de CTOD obtidos as análises numérica (CTOD $90^{\circ}$ ) e os valores de CTOD obtidos pelas formulações da norma ASTM 1290 [19]; (a); $a / W=0.65 ;$ (b) $a / W=0.7$. 99

Figura 59 Comparativo entre os valores de CTOD obtidos pelas formulações da norma BS 7448 [18] e os valores de CTOD obtidos pelas formulações da norma ASTM 1290 [19]; (a); $a / W=0.45$; (b) $a / W=0.5$. 102

Figura 60 Comparativo entre os valores de CTOD obtidos pelas formulações da norma BS 7448 [18] e os valores de CTOD obtidos pelas formulações da norma ASTM 1290 [19]; (a); $a / W=0.55$; (b) $a / W=0.6$. 103

Figura 61 Comparativo entre os valores de CTOD obtidos pelas formulações da norma BS 7448 [18] e os valores de CTOD obtidos pelas formulações da norma ASTM 1290 [19]; (a); $a / W=0.65$; (b) $a / W=0.7$. 104 


\section{LISTAS DE TABELAS}

Tabela 1 Comparativo de alguns dos procedimentos mais comuns de análise de integridade estrutural. [16]

Tabela 2 Matriz de Análise e Dimensões dos Corpos-de-Prova C(T) e SE(B)...... 44

Tabela 3 Propriedade dos Materiais Ensaiados 48

Tabela 4 Diferença percentual entre os valores de $\eta_{J}^{\mathrm{LLD}}$ calculados pelas normas ASTM e a simulação computacional por elementos finitos.

Tabela 5 Coeficientes para aplicação no polinômio de regressão múltipla para 0 cálculo de $\eta_{J}^{\mathrm{CMOD}}$

Tabela 6 Coeficientes para aplicação no polinômio de regressão múltipla para o cálculo de $\eta_{J}^{\mathrm{LLD}}$

Tabela 7 Coeficientes para aplicação no polinômio de regressão múltipla para o cálculo de $\eta_{\delta}^{\mathrm{CMOD}}$

Tabela 8 Coeficientes para a regressão polinomial da Eq.43 para cálculo do fator $m$.

Tabela 9: Fatores $\eta$ 2D utilizados para gerar os gráficos da seção 6.2.2 para o espécime 1T com largura de cordão de solda $2 \mathrm{~h}=10 \mathrm{~mm}$.

Tabela 10: Fatores $\eta$ 2D utilizados para gerar os gráficos da seção 6.2.2 para o espécime 1T com largura de cordão de solda $2 h=15 \mathrm{~mm}$.................... 114

Tabela 11: Fatores $\eta$ 2D utilizados para gerar os gráficos da seção 6.2.2 para o espécime 1T com largura de cordão de solda $2 h=20 \mathrm{~mm}$.

Tabela 12: Fatores $\eta$ tridimensionais utilizados para gerar os gráficos da seção 6.4 para o espécime 1T com largura de cordão de solda $2 h=15 \mathrm{~mm}$......... 115

Tabela 13: Fatores $\eta$ tridimensionais utilizados para gerar os gráficos da seção 6.4 para o espécime $0.5 \mathrm{~T}$ com largura de cordão de solda $2 h=15 \mathrm{~mm} \ldots . . .116$ 


\section{LISTA DE ABREVIATURAS E SIGLAS}

2D: Bidimensional (no contexto se refere às análises computacionais em estado plano de deformação);

3D: Tridimensional (no contexto se refere às análises computacionais onde se considerou o efeito de espessura);

ECA: "Engineering Critical Assessment" - análise crítica de engenharia

ANP: Agência Nacional do Petróleo;

API: American Petroleum Institute;

ASME: "American Society of Mechanical Engineers";

ASTM: "American Society for Testing and Materials";

BS: British Standard;

CMOD: Abertura da boca da trinca (Crack Mouth Opening Displacement);

$\mathrm{C}(\mathrm{T})$ : Espécime compacto submetido à tração;

CTOD: Abertura da ponta da trinca (Crack Tip Opening Displacement);

DMS: Dissimilaridade Mecânica da Solda (weld strength mismatch);

ECA: Engineering Critical Assessment;

EPD: Estado Plano de Deformações;

EPT: Estado Plano de Tensões;

FFP: Fitness-for-Purpose;

FFS: Fitness-For-Service;

HRR: Solução analítica proposta por Hutchinson, Rice e Rosengren para o campo de tensões e deformações à frente de trincas dada pela integral $J$;

LLD: "Load Line Displacement" - deslocamento da linha de carga;

LSY: "Large Scale Yieding" - escoamento de grande monta;

MB: Metal de Base;

MBL: "Modified Boundary Layer" - solução de Camada de Contorno Limite Modificada;

MFEL: Mecânica da Fratura Elástica Linear;

MFEP: Mecânica da Fratura Elasto-Plástica;

MS: Metal de Solda;

$\mathrm{SE}(\mathrm{B})$ : Espécime com entalhe lateral submetido à flexão; 
$\mathrm{SE}(\mathrm{T})$ : Espécime com entalhe lateral submetido à tração;

SSY: "Small Scale Yielding" - escoamento de pequena monta;

U-O-E: Processo da fabricação de dutos com costura;

ZTA: Zona Termicamente Afetada;

ZFL: Zona de Fragilização Localizada; 


\section{LISTA DE SÍMBOLOS}

$a$ : Comprimento de trinca;

$A_{P l}$ : Área plástica sob a curva de carga $v s$ deslocamento;

$B$ : Espessura do corpo-de-prova;

$B_{N}$ : Espessura neta do corpo-de-prova;

$b$ : Ligamento remanescente $(b=W-a)$;

$d_{n}$ : Fator adimensional que correlaciona $J$ com CTOD;

$d s$ : Incremento do arco do contorno fechado;

$E$ : Modulo de elasticidade;

E': Modulo de elasticidade em estado plano de deformação;

$F$ : Trabalho realizado pelas forças externas;

$\mathcal{G}$ : Taxa de liberação de energia;

$H$ : Distância entre os centros dos furos do corpo-de-prova $\mathrm{C}(\mathrm{T})$;

$I_{n}$ : Constante de integração na solução do campo HRR;

$J$ : Amplitude da singularidade - Integral $J$;

$J_{I c}$ : Valor de integral $J$ que produz a iniciação de crescimento da trinca carregada em modo I;

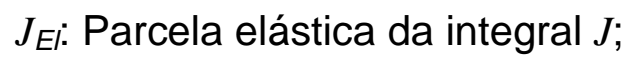

$J_{P l}$ : Parcela plástica da integral $J$;

$K_{I}$ : Fator de intensidade de tensões em Modo I de abertura;

$K_{I c}$ : Valor do fator de intensidade de tensões para o qual ocorre fratura sob modo I de carregamento;

$2 h$ : Largura do cordão de solda;

$h / W$ : Largura do cordão de solda normalizado;

$m$ : Fator de restrição plástica adimensional $\left(m=1 / d_{n}\right)$;

$M_{y}$ : Nível de dissimilaridade mecânica;

$n$ : Coeficiente de encruamento;

$\mathrm{P}$ : Carga imposta;

$\mathrm{P}_{0}$ : Carga Limite;

$r$ : Distância radial desde a ponta da trinca;

$r_{y}$ : Raio da zona plástico; 
$T_{i}$ : Vetor de tração $(i=1,2)$;

$U$ : Energia de deformação armazenada;

$u_{y}$ : Deslocamento vertical da face da trinca;

$u_{i}$ : Vetor de deslocamento $(i=1,2)$;

$V$ : Abertura da boca da trinca (CMOD);

$V_{E l}$ : Abertura elástica da boca da trinca $\left(\mathrm{CMOD}_{E l}\right)$;

$V_{P l}$ : Abertura plástica da boca da trinca $\left(\mathrm{CMOD}_{P l}\right)$;

w: Densidade de energia de deformação;

W: Largura do corpo-de-prova;

$\varepsilon_{i, j}$ : Tensor de deformação plástica;

$\varepsilon_{y s}$ : Deformação de referência ou escoamento $\left(\sigma_{y s} / E\right)$;

$\sigma_{0}:$ Tensão de referência;

$\sigma_{i, j:}:$ Tensor de tensão;

$\sigma_{y s}:$ Tensão de escoamento;

${\sigma_{y s}}^{M S}$ : Tensão de escoamento de material de solda ou adição;

$\sigma_{y s}{ }^{M B}$ : Tensão de escoamento de material de base;

$\left(\sigma_{y y}^{M B}\right)_{R e f}:$ Tensão de abertura desenvolvida na ponta da trinca para uma placa infinita (condição SSY);

$\left(\sigma_{i j}\right)_{\mathrm{SSY}}$ : Campo de tensões de referência;

$\alpha$ : Coeficiente de plasticidade;

П: Energia potencial do corpo trincado;

$\Delta$ : Deslocamento da linha de carga (LLD);

$\Delta_{E l}$ : Deslocamento elástico da linha de carga (LLD $\left.E l\right)$;

$\Delta_{P l}$ : Deslocamento plástico da linha de carga (LLD ${ }_{P l}$ );

$\Gamma$ : Caminho de integração usado para obtenção de $J$;

$\theta$ : Direção angular desde a ponta da trinca;

$\delta_{i, j}$ : Delta Kronecker;

$\delta$ : Abertura da ponta da trinca (CTOD);

$\delta_{E l}$ : Parcela elástica da abertura da ponta da trinca;

$\delta_{P l}$ : Parcela plástica da abertura da ponta da trinca;

$\delta_{90^{\circ}}$ : Abertura da ponta da trinca obtida das análises numéricas;

$\delta_{\mathrm{BS}}$ : Abertura da ponta da trinca obtida da norma BS 7448;

$\delta_{\text {ASTM: }}$ Abertura da ponta da trinca obtida da norma ASTM 1290; 
$\eta_{J}^{\text {LLD }}$ : Fator adimensional derivado da curva P-LLD para calcular $J$;

$\eta_{J}{ }^{\mathrm{CMOD}}$ : Fator adimensional derivado da curva P-CMOD para calcular $J$;

$\eta_{\delta}^{\mathrm{CMOD}}$ : Fator adimensional derivado da curva P-CMOD para calcular $\delta$; 



\section{INTRODUÇÃO}

O atual cenário que surge com as novas perspectivas advindas da descoberta de petróleo na camada pré-sal é muito positivo para a economia e tecnologia brasileiras. Este cenário prevê um significativo aumento do transporte modal de petróleo, derivados leves e gás requerendo eficiência produtiva e segurança operacional da malha dutoviária. Portanto, será necessário o desenvolvimento de tecnologias adequadas para a robusta avaliação de defeitos e avaliação da integridade das estruturas de transporte e armazenagem visando prevenir e evitar acidentes com dutos e vasos de pressão. Vazamentos e acidentes, além de causarem enormes prejuízos financeiros, podem ser causadores de grandes danos ambientais ou catástrofes sem precedentes se ocorrerem em regiões metropolitanas.

Estimativas recentes sugerem que $40 \%$ das malhas de dutos já ultrapassaram a vida útil de projeto (20 anos) o que motiva a tendência em estender a vida operacional e reabilitar estruturas antigas [1]. Os programas de avaliação de integridade estrutural objetivam primariamente 0 aumento da confiabilidade operacional de dutos, prevenção de vazamentos, aumento da vida útil da malha existente; melhoria da tecnologia de reabilitação de dutos; etc. Embora gasodutos e oleodutos possuam elevada segurança operacional e relativamente poucos registros estatísticos de acidentes, falhas operacionais devido à presença de defeitos não detectados ou formados em regiões de difícil acesso podem resultar em eventos catastróficos, particularmente no caso de dutos de transporte de gás em áreas densamente povoadas. A Figura 1 ilustra um acidente típico decorrente da explosão de um gasoduto com destaque para a abertura de uma grande cratera no solo por onde passa o duto e um defeito típico precursor da falha catastrófica [2].

Os dutos utilizados na construção de linhas dutoviárias geralmente são fabricados com aços microligados especificação API (Americam Petroleum Institute) com média e alta resistência mecânica (tensão de escoamento de 290 - 552 MPa). Esses dutos são usualmente fabricados em comprimentos de 6 a 12 metros por processo de conformação mecânica U-O-E [3] que consiste nas etapas de dobramento de uma chapa plana conferindo o formato de "U" seguido do 
prensamento até o formato de "O", soldagem longitudinal por processo de arco submerso e expansão mecânica a frio, "E". Uma vez prontos, estes dutos são levados até o local de montagem da linha onde são unidos por meio de soldagem manual com eletrodo revestido ou processo semi-automático em todo o seu perímetro (soldagem circunferencial).

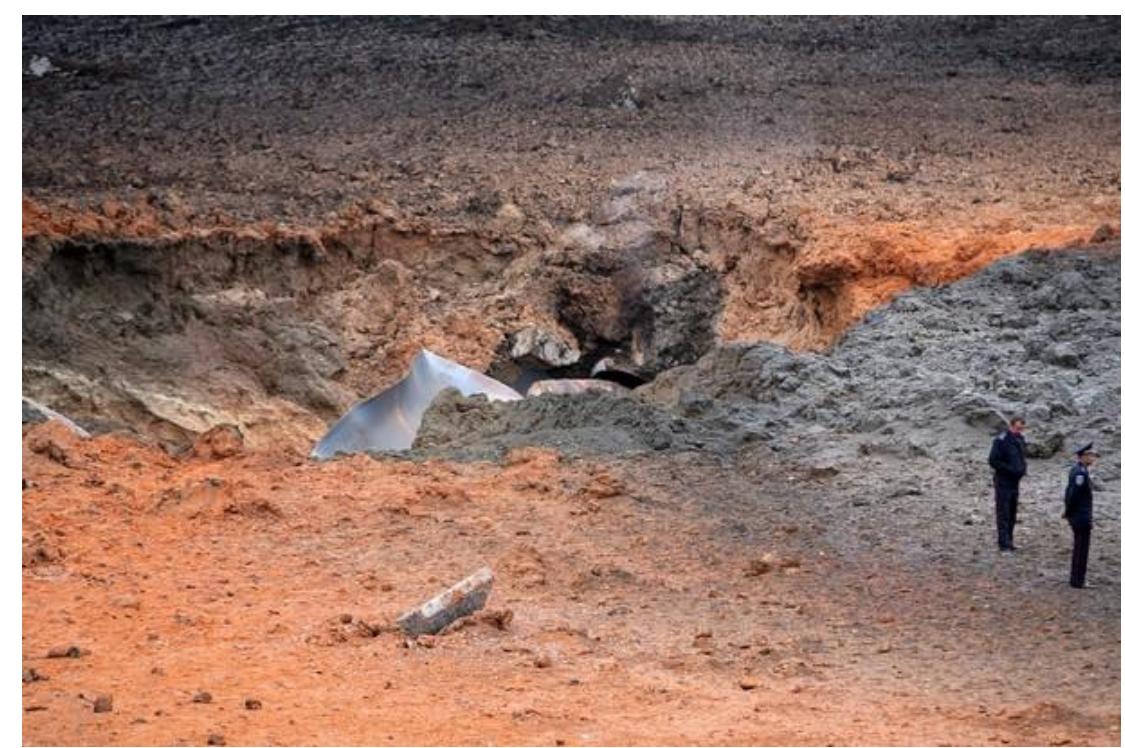

(a)

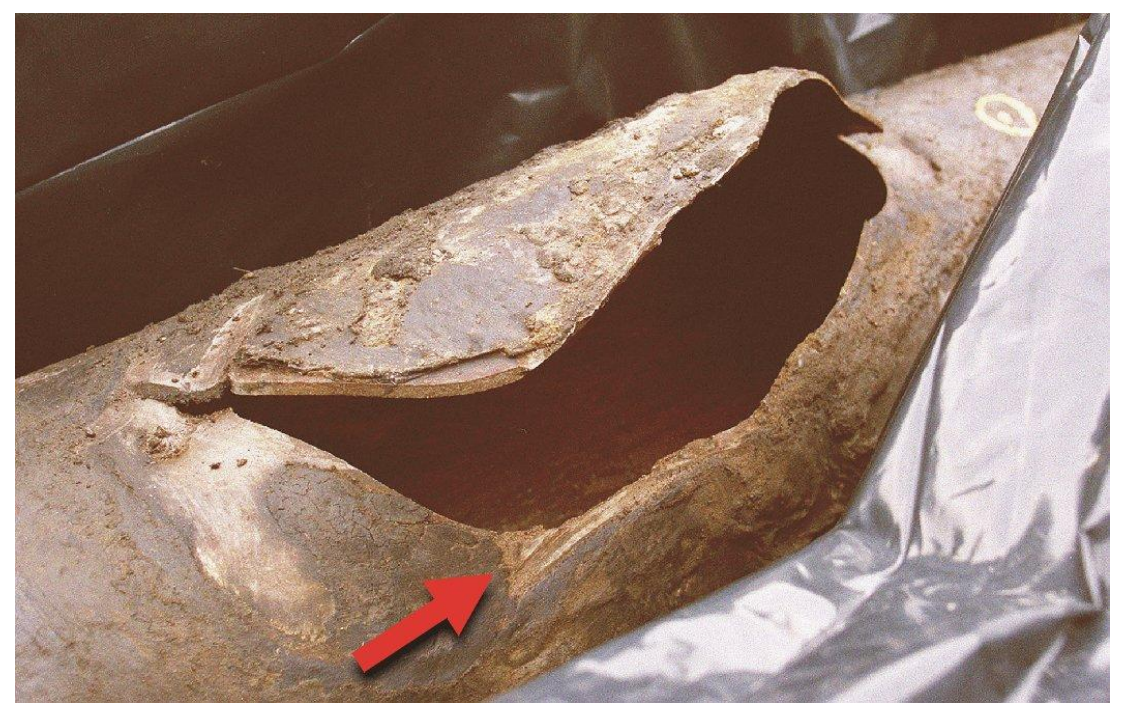

(b)

Figura 1 (a) Efeito da explosão de um gasoduto sobre o seu leito de passagem no solo com conseqüente ruptura e falha catastrófica da tubulação. (b) Detalhe do defeito precursor da ruptura e falha catastrófica [2]. 
A região soldada (cordão de solda + zona termicamente afetada (ZTA)) é particularmente crítica, pois o metal dessa região tem sua resistência à fratura afetada aumentando o risco de falha e, portanto, merecendo a avaliação de sua integridade estrutural. É prática comum (recomendada por normas e procedimentos de fabricação) a utilização de metais de solda com resistência mecânica mais elevada para preservar e proteger a junta soldada resultando, portanto, em uniões soldadas com dissimilaridades mecânicas entre o metal de solda e o metal base.

Esta prática afeta macroscopicamente o comportamento mecânico da estrutura acarretando em campos de tensão e forças motrizes nas proximidades de um defeito diferentes daqueles encontrados em uma estrutura homogênea [4]. Consequentemente, metodologias mais precisas para a avaliação de defeitos em juntas soldadas devem, portanto, considerar a influência da heterogeneidade mecânica no cálculo dos parâmetros convencionalmente utilizados pelos procedimentos de avaliação de tenacidade e resistência à fratura $\left(K_{c}, J_{c}\right.$ e CTOD $\left(\delta_{c}\right)$ ), em aços ferríticos aplicados na fabricação de tubulações, vasos de pressão dentre outros.

Muitas das análises de engenharia (Engineering Critical Assessment (ECA), Fitness for Service (FFS)) recomendam que as avaliações de aceitabilidade de defeitos em estruturas, como dutos e vasos de pressão, sejam feitas com base em valores de tenacidade à fratura conservadores (lower bound values). Dentre os parâmetros de tenacidade à fratura, o CTOD (Cack Tip Opening Displacement) é amplamente difundido e utilizado nos procedimentos de avaliação de integridade estrutural de dutos soldados e na qualificação de procedimentos de soldagem (e.g. BS 7910 [5], API 579 [6], SINTAP [7] DNV-F-101 [8], DNV-F-108 [9], API RP $2 Z$ [10] e API 1104 [11]) devido à sua relativa simplicidade de medição.

O conceito de CTOD como parâmetro de tenacidade à fratura foi introduzido inicialmente por Wells [12] em 1961 a partir de suas tentativas de medição do fator de intensidade de tensões, $K$, em aços com tenacidade elevada. Para esses materiais, Wells observou que a abertura da ponta da trinca (CTOD) sob condições de deformação plástica intensa (além, portanto, do regime elástico linear) fornecia uma melhor caracterização da sua tenacidade. Em meados da década de 1960 e início da década de 1970, Burdekin, Stone [13] e Dawes [14], desenvolveram o conceito de curva de projeto baseada no CTOD para seleção de materiais e otimização de tratamento térmico para aços soldados. 
Particularmente, um grande número de procedimentos de avaliação de integridade estrutural tem como base o procedimento pioneiro de avaliação de defeitos em estruturas metálicas PD6493 [15] e seu sucessor BS 7910 [5]. Tais procedimentos foram concebidos com base nas proposições das referências [13] e [14] sendo este mais um motivo para a ampla utilização do CTOD como parâmetro de tenacidade à fratura [16].

A medição experimental de valores críticos de CTOD $\left(\delta_{c}\right)$ é usualmente conduzida utilizando-se corpos-de-prova de flexão em três pontos $\mathrm{SE}(\mathrm{B})$. A motivação principal para a utilização desta configuração geométrica é a relativa facilidade de medição do valor de abertura da boca da trinca (CMOD) para determinação do parâmetro de tenacidade à fratura, CTOD (abertura da ponta da trinca), a partir de uma formulação simples baseada no modelo da rótula plástica [17]. Este modelo assume que o espécime rotaciona em torno de um ponto fixo (rótula plástica) permitindo, portanto, a relação geométrica entre CTOD com o CMOD. Porém, as normas para cálculo de CTOD (BS 7448[18], ASTM E1290 [19]) permitem a utilização de outras configurações geométricas que podem apresentar-se vantajosas em relação à geometria $\mathrm{SE}(\mathrm{B})$ sob determinadas condições motivando o esforço de expandir as bases de dados para estas outras configurações de corpos-de-prova.

\subsection{MOTIVAÇÃO E OBJETIVOS DO TRABALHO}

Não é foco deste trabalho explorar com detalhes todos os modos de falha e os vários tipos de defeitos abordados pelos procedimentos de análise de integridade estrutural correntes, conforme exemplifica a Tabela 1. Porém este trabalho tem como objetivo o refinamento de alguns parâmetros de cálculo utilizados por tais procedimentos de avaliação de tenacidade à fratura abordando o caso de juntas soldadas, principalmente naquilo que tange o efeito da dissimilaridade mecânica entre o metal de solda e o metal base. 
Tabela 1 Comparativo de alguns dos procedimentos mais comuns de análise de integridade estrutural. [16]

\begin{tabular}{cccc}
\hline Procedimento & Ano & Modos de Falha & Indústria \\
BS7910 & 2005 & Fratura; Fadiga; Fluência, Corrosão & Geral \\
API579 & 2007 & Fratura; Fadiga; Fluência, Corrosão & Geral \\
FITNET & 2008 & Fratura; Fadiga; Fluência, Corrosão & Geral \\
SINTAP & 1999 & Fratura & Geral \\
R6 & 2001 & Fratura & Nuclear \\
\hline
\end{tabular}

A detecção de trincas em estruturas ou em equipamentos não implica necessariamente que estes devam ser reparados ou retirados de operação imediatamente. Para estes casos, procedimentos de engenharia, conhecidos por Engineering Critical Assessment (ECA) do tipo Fitness-For-Service (FFS) ou Fitness-for-Purpose (FFP), devem ser aplicados para a avaliação quantitativa da integridade estrutural do componente visando determinar níveis seguros de operação, tempo de vida restante e criticidade do defeito encontrado (possibilidade de falha catastrófica). Ou seja, em uma análise ECA, o objetivo principal é estabelecer critérios seguros de aceitabilidade de defeitos (trinca) levando-se em consideração os carregamentos atuantes sobre a estrutura nas condições de operação na tentativa de estender a vida ou planejar uma parada para manutenção.

Procedimentos de análise de integridade estrutural também servem como ferramenta de auxílio na tomada de decisão sobre a troca ou reparo de estruturas defeituosas. As práticas e abordagens utilizadas nos vários procedimentos de análise de integridade estrutural podem variar de acordo com a função dos componentes, ramo da indústria para o qual os componentes foram projetados e até mesmo devido à legislação local de cada país, porém um ponto comum em todos estes procedimentos é o zelo pela segurança.

Para avaliar a criticidade de defeitos do tipo trincas e mitigar a possibilidade de falha por clivagem, os procedimentos de análise ECA determinam um valor mínimo 
de CTOD para a qualificação do material. Esta avaliação do CTOD é na maioria dos casos realizada com base nas normas ASTM E1290 e BS 7448, dois dos principais procedimentos para a determinação de valores experimentais de CTOD e, portanto frequentemente recomendados pelos procedimentos de análise de integridade estrutural. Várias outras normas como (i.e. ISO 12135 e WES 1108 apud Tagawa [20]) fazem uso da mesma metodologia (rótula plástica) de cálculo de CTOD utilizada pela norma britânica BS7448.

Até o ano de 2002 ambos os procedimentos, ASTM e BS, utilizavam o modelo de rótula plástica em suas formulações para cálculo de CTOD. Mas em uma recente revisão sofrida pela norma da ASTM o modelo de rótula plástica deixou de ser utilizado e o CTOD passou a ser avaliado por meio da Integral $J$ e metodologia $\eta[21]$.

Apesar de diferirem em suas bases metodológicas, os valores de CTOD calculados pela aplicação do modelo da rótula plástica ou integral $J$ e metodologia $\eta$ não deveriam apresentar discrepâncias significantes entre si. Entretanto trabalhos recentes, de Tagawa [20] entre outros, têm demonstrado consideráveis diferenças entre os valores de CTOD obtidos por meio das normas BS 7448 e ASTM E 1290. A diferença encontrada entre estes dois procedimentos chega a $30 \%$ em alguns casos, sendo da ASTM os resultados mais conservadores [21]. Isto resulta em dúvidas na aplicação dos procedimentos de avaliação de integridade estrutural, pois estes deixam a critério do usuário qual norma utilizar para a avaliação da tenacidade à fratura, como é o caso do procedimento FFS API-579 [6] que permite o uso de ambas as normas.

Outro ponto relevante é que apesar do CTOD ser utilizado como um parâmetro de tenacidade à fratura também para juntas soldadas e códigos correntes de projeto, não há nas normas de ensaio, formulações específicas para abordar os potenciais efeitos de dissimilaridade mecânica sobre as forças motrizes na região da ponta da trinca. A condição de dissimilaridade mecânica, conhecida, também na literatura como "weld strength mismatch", quando comparada à condição homogênea, altera os campos de tensão atuantes nas proximidades de um defeito e pode impactar significativamente a avaliação da criticidade de trincas nucleadas ao longo da vida de uma estrutura.

Especificamente sobre os códigos convencionais para avaliação de defeito e medição de tenacidade à fratura citados a cima, estes adotam extensivamente 
corpos-de-prova em flexão três pontos, geometria $S E(B)$, para medição dos parâmetros $J$ e CTOD. A geometria $\mathrm{SE}(\mathrm{B})$ é largamente utilizada na indústria de óleo e gás por razões históricas que datam da década de 1970 e a introdução da curva de projeto baseada no CTOD. Portanto, existe na literatura uma vasta base de dados a respeito da utilização de espécimes laboratoriais com esta geometria para a medição de tenacidade à fratura.

No entanto, corpos-de-prova SE(B) possuem grandes dimensões planares exigindo maior quantidade de material para a sua confecção, o posicionamento das amostras no dispositivo de ensaio de flexão 3 pontos necessita de maior acuidade visto que pequenos desvios no posicionamento dos corpos-de-prova podem influenciar a medição de tenacidade à fratura, por exemplo, além exigir um aparato experimental de grande capacidade. Consequentemente, corpos-de-prova com geometria reduzida, como as apresentadas pelo espécime compacto, $\mathrm{C}(\mathrm{T})$, tornamse uma alternativa atrativa para os testes de tenacidade à fratura, porém estes não apresentam uma base de dados tão extensa quanto a do espécime $S E(B)$.

Motivado pelas observações anteriores, este trabalho explorará a utilização de corpos-de-prova com geometria compacta, $\mathrm{C}(\mathrm{T})$ visando à obtenção de fatores $\eta$ para cálculo analítico de Integral $J$ e CTOD em juntas. O trabalho também contemplará um estudo exploratório dos efeitos da dissimilaridade mecânica sobre a restrição plástica na ponta da trinca por meio de metodologia biparamétrica $J-Q$ e realizará um comparativo entre os resultados obtidos pelas normas BS 7448 [18], ASTM E1290 [19] e o método de elementos finitos.

Os estudos serão conduzidos por meio de simulações computacionais e modelos numéricos 2D (sob condição de estado plano de deformação) e 3D (para avaliação do efeito de espessura). Para avaliar o efeito dos níveis de dissimilaridade mecânica (weld strength mismatch) sobre a tenacidade à fratura de juntas soldadas será simulado um cordão de solda com geometria de chanfro reta e uma trinca passante central ao cordão.

As atividades e objetivos do trabalho são resumidamente apresentados a seguir:

1. Construção trajetórias $J-Q$ para avaliar o comportamento dos espécimes com geometria compacta, $\mathrm{C}(\mathrm{T})$, sob diferentes níveis de dissimilaridade mecânica, em comparação às tendências observadas para o espécime $S E(B)$. Incluindo efeitos da largura do cordão de solda e comprimento de trinca. 
2. Determinação dos fatores $\eta$ para avaliação da Integral $J$ e CTOD na presença de dissimilaridade mecânica.

3. Obtenção de expressões analíticas a partir dos resultados numéricos para o cálculo dos fatores $\eta$ em função do comprimento de trinca e nível de dissimilaridade mecânica.

4. Análise comparativa normas BS 7448, ASTM E 1290 e a metodologia por elementos finitos aplicada neste trabalho para obtenção de valores CTOD.

5. Avaliação da correlação entre a Integral $J$ e o CTOD por meio do fator de restrição plástica, $m$. 


\section{CONCEITOS DE MECÂNICA DA FRATURA}

\subsection{HISTÓRICO}

Os primeiros relatos noticiados do estudo da mecânica da fratura pertencem a Leonardo da Vince [17]. Ele realizou estudos qualitativos em arames de ferro demonstrando que sua resistência era inversamente proporcional ao seu comprimento, pois com o aumento do volume de material aumentava-se a probabilidade da ocorrência de defeitos no mesmo. Séculos à frente, porém agora com resultados quantitativos correlacionando características dimensionais de um defeito com a tensão de falha, Griffith [22] baseou-se na primeira lei da termodinâmica e em 1913 estruturou uma teoria para prever a instabilidade devido a defeitos (trincas) em sólidos frágeis. A mesma teoria veio a ser aplicada em metais, mas devido à natureza dúctil do material os resultados não foram satisfatórios.

Novos avanços sobre os conceitos fundamentais da mecânica da fratura surgiram após o término da Segunda Guerra Mundial a partir das diversas falhas ocorridas em navios da série Liberty [17]. A construção destes navios incorporou o processo de soldagem em escala industrial, considerado novo e pioneiro na época. Diversos navios apresentaram sérios problemas de falha catastrófica onde trincas iniciavam em "cantos vivos" de grandes aberturas no convés (concentradores de tensão) junto às áreas soldadas e se propagavam por toda a seção transversal do navio conforme ilustrado na Figura 2 


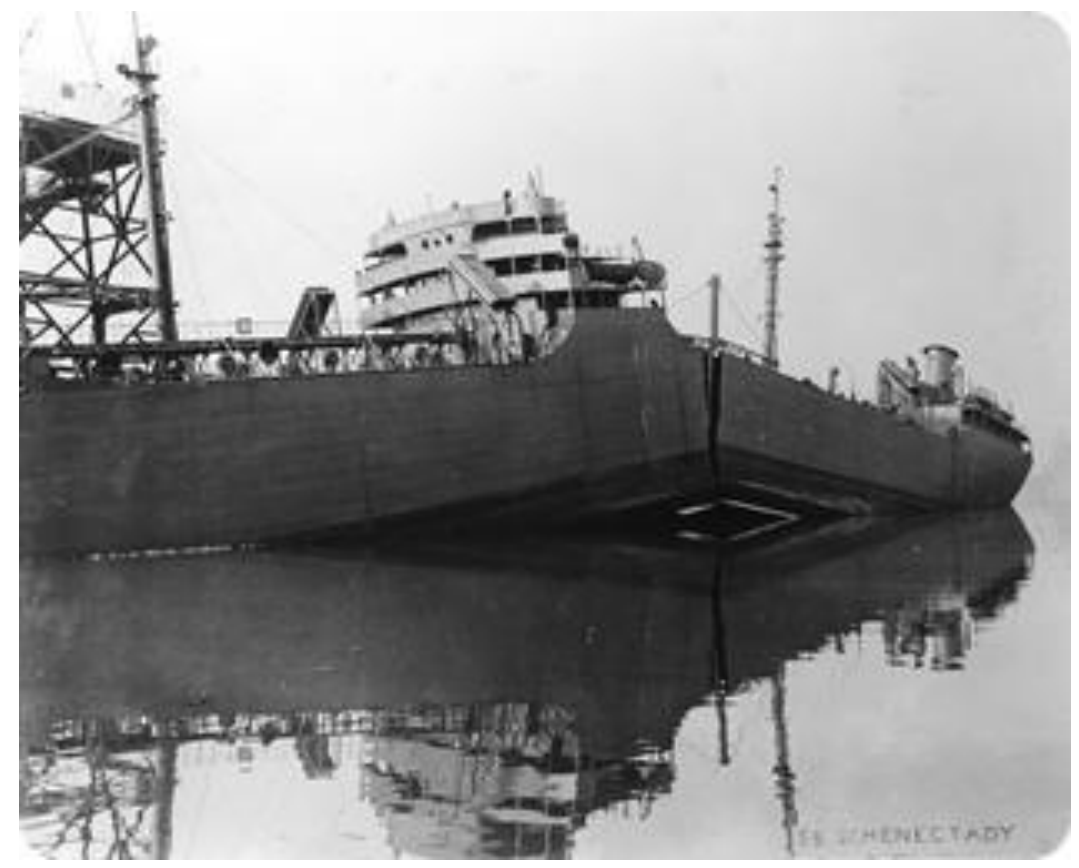

Figura 2 Navio da série Liberty, exemplo de falha catastrófica com separação total do casco e convés [17].

Em estudo patrocinado pela Marinha Americana, Irwin [23] [24] expandiu a teoria de Griffith utilizando a abordagem de Westergaard [25], permitindo sua aplicação a materiais metálicos, Irwin propôs um parâmetro único para descrever os campos de deformações e tensões na região próxima à ponta de uma trinca, este parâmetro veio mais tarde a ser conhecido como o fator de intensidade de tensões $(K)$.

Em meados dos anos 60, os fenômenos e os conceitos da mecânica da fratura linear elástica (MFLE) estavam praticamente consolidados. Os esforços então passam a ser focados no desenvolvimento de conceitos e parâmetros para o estudo da plasticidade desenvolvida na ponta da trinca onde a MFLE não mais descreve com precisão os campos de tensão.

Wells, durante o seu período de visita ao Laboratório de Pesquisa da Marinha Americana, teve contato, com as metodologias da mecânica da fratura elástica linear. Em seu retorno ao Britsh Welding Reseach Association, tentou aplicar o fator de intensidade de tensões em aços de baixa e média resistência, mas não obteve sucesso, pois estes aços desenvolvem grande plasticidade à frente da trinca antes da falha. Entretanto, Wells observou que, ao desenvolver esta plasticidade, os flancos da trinca se afastavam ocasionando um arredondamento ("blunting") na ponta da trinca. A medição deste distanciamento entre os flancos da 
trinca deu origem a um dos parâmetros mais utilizados na avaliação de tenacidade à fratura, o CTOD $(\delta)[17]$.

Rice, em 1968, apresenta mais um parâmetro para avaliação de tenacidade à fratura, a integral $J$, utilizando uma abordagem energética onde a taxa de liberação de energia de deformação para um material elástico não linear podia ser expressa por uma integral de linha para um contorno contendo a trinca. E Hutchinson, Rice e Rosengren [26] [27] desenvolvem um modelo conhecido como solução HRR que permite a caracterização do campo de tensão e deformação em regime elastoplástico para a condição de escoamento de pequena monta relacionado à integral $J$ transformando-a em um parâmetro elasto-plástico análogo ao fator de intensidade de tensão $(K)$.

Neste momento, já nos anos 70, havia, basicamente na mecânica da fratura, duas frentes de desenvolvimento. A frente norte americana, financiada fortemente pelas forças armadas e pela indústria nuclear e a frente britânica que dirigia seus esforços à exploração de petróleo no Mar do Norte. Por meio delas, a integral $J$ e CTOD respectivamente foram se consolidando como parâmetros para avaliação de integridade estrutural.

A passagem acima formou a base da mecânica da fratura monoparamétrica ou clássica que emprega um parâmetro único para descrever as condições de propagação instável de uma trinca. Assim, sob condições de plasticidade restrita nas vizinhanças da trinca ou fissura (e.g., condição de escoamento de pequena monta ou Small Scale Yielding (SSY) Conditions), estabelece-se uma correlação direta entre valores de tenacidade à fratura medidos experimentalmente $\left(K_{c}, J_{c}\right)$ e o comportamento à fratura de um componente estrutural em serviço. $O$ conceito fundamental que permite o emprego deste procedimento é a existência de similaridade dos campos de tensões e deformações entre corpos-de-prova, (CP), com dimensões reduzidas, e o componente estrutural em serviço. As condições da fratura devem ser iguais no componente estrutural e no corpo-de-prova o que implica que a zona plástica deve ter dimensões desprezíveis em relação às dimensões dos componentes (estrutura e CP). Para caracterizar as condições da fratura no caso monoparamétrico, podem ser empregados diversos parâmetros, sendo os mais utilizados os parâmetros $K$, CTOD $(\delta)$ e $J$. O parâmetro $K$ é baseado em considerações lineares elásticas, restringindo sua aplicação na presença de 
grandes deformações. Os parâmetros CTOD e $J$ são baseados em considerações elásticas não-lineares e elasto-plásticas tendo sua aplicação estendida além dos limites de $K$.

\subsection{MECÂNICA DA FRATURA ELÁSTICA LINEAR}

O mecanismo de fratura frágil é de grande interesse nos procedimentos de análise de integridade estrutural uma vez que o colapso ocasionado por esse mecanismo é catastrófico e ocorre em níveis globais de tensão inferiores ao limite de escoamento de aços comumente utilizados na construção de componentes e estruturas nas áreas oceânicas, nucleares e navais.

A mecânica da fratura elástica linear se baseia quantitativamente em um parâmetro local descritor das condições de falha nas vizinhanças de um defeito para a avaliação do problema de fratura por clivagem (frágil) sob determinadas condições. Este parâmetro, conhecido como fator de intensidade de tensões $(K)$, descreve o campo de tensões ao redor de uma trinca e permite a correlação entre defeitos encontrados em estruturas com espécimes laboratoriais para avaliação da integridade estrutural. Tal correlação é possível devido ao princípio da similitude ilustrado na Figura 3 que garante igualdade entre os campos de tensões desenvolvidos no espécime ensaiado e na estrutura. 


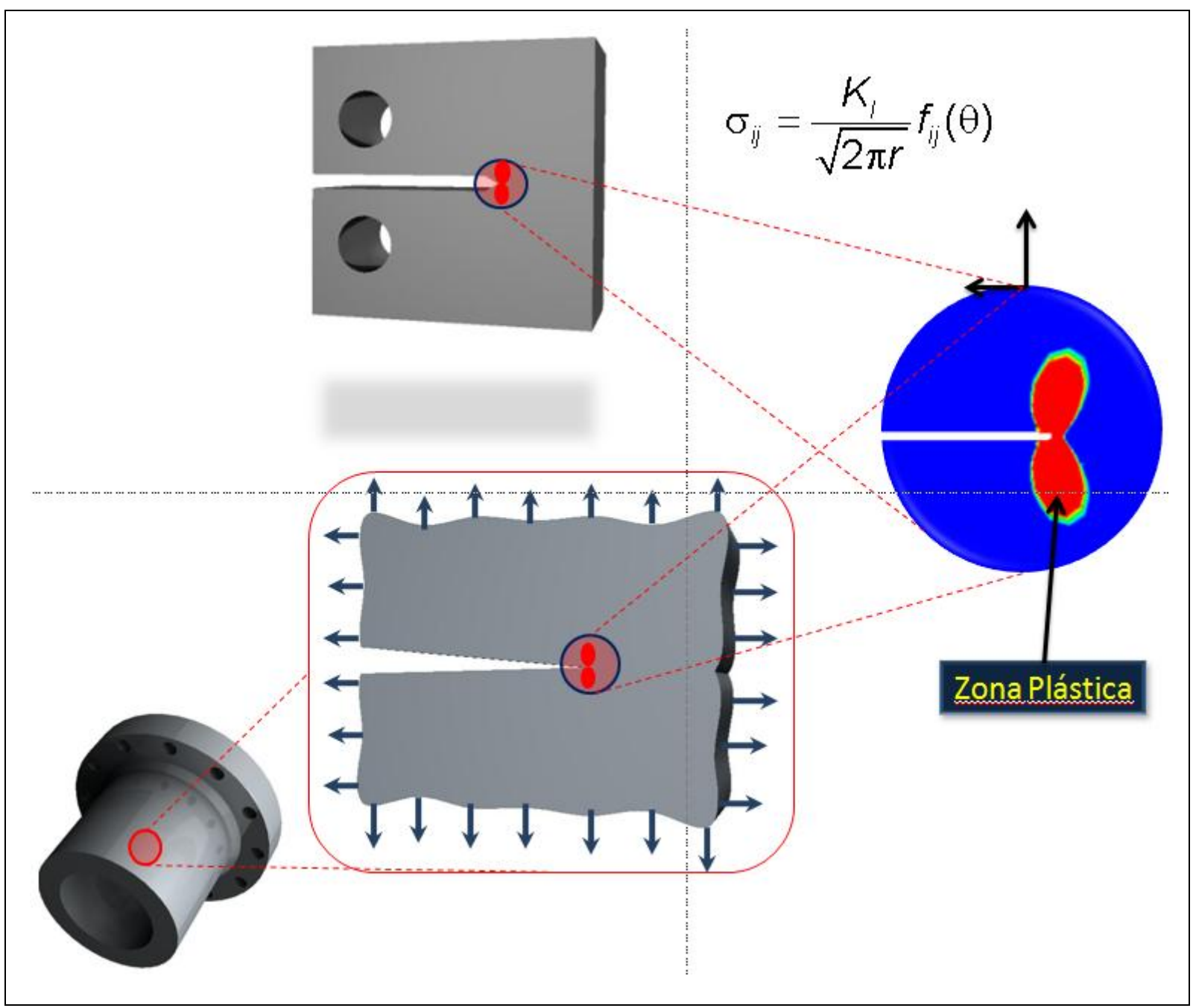

Figura 3 Esquema representativo da condição de similitude onde corpo-de-prova e estrutura estão carregados sob mesma condição de intensidade de tensões.

Os campos de tensões elásticas lineares podem ser avaliados por algumas soluções clássicas da teoria da elasticidade. Uma das mais conhecidas foi a desenvolvida por Williams [28] na qual a resposta elástica do material sob tensão possui uma singularidade, para regiões suficientemente próximas à ponta de uma trinca, na razão $1 / \sqrt{r}$, onde $r$ é a distância da ponta da trinca em coordenadas polares conforme Figura 4. 


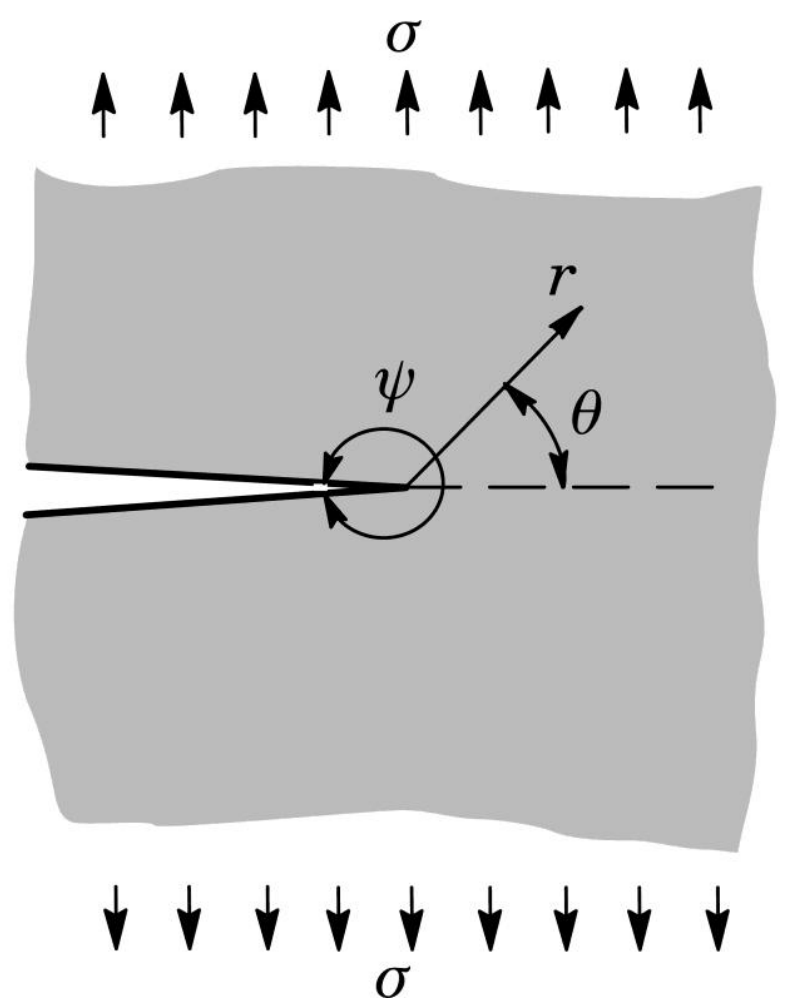

Figura 4 Representação da trinca estudada por Williams em coordenadas polares [29].

Posteriormente, Williams [30] descreveu matematicamente o campo de tensões elásticos na presença de uma trinca e Irwin [31] introduziu o parâmetro $K_{I}$ descritor do campo de tensões na ponta de trinca, Eqs. (1.1 - 1.3), submetida ao Modo I, ilustrado na Figura 5, para uma placa infinita baseando-se na função potencial desenvolvida por Williams.

$$
\begin{aligned}
& \sigma_{r r}=\frac{K_{I}}{\sqrt{2 \pi r}}\left[\frac{5}{4} \cos \left(\frac{\theta}{2}\right)+\frac{1}{4} \cos \left(\frac{3 \theta}{2}\right)\right]+O(r) \\
& \sigma_{\theta \theta}=\frac{K_{I}}{\sqrt{2 \pi r}}\left[\frac{3}{4} \cos \left(\frac{\theta}{2}\right)+\frac{1}{4} \cos \left(\frac{3 \theta}{2}\right)\right]+O(r) \\
& \tau_{r \theta}=\frac{K_{I}}{\sqrt{2 \pi r}}\left[\frac{1}{4} \sin \left(\frac{\theta}{2}\right)+\frac{1}{4} \sin \left(\frac{3 \theta}{2}\right)\right]+O(r)
\end{aligned}
$$


O segundo termo das equações, $(O(r))$, são soluções de maior ordem que exercem influência sobre os campos de tensão apenas em regiões afastadas da ponta da trinca e, por isso, são geralmente ignorados.

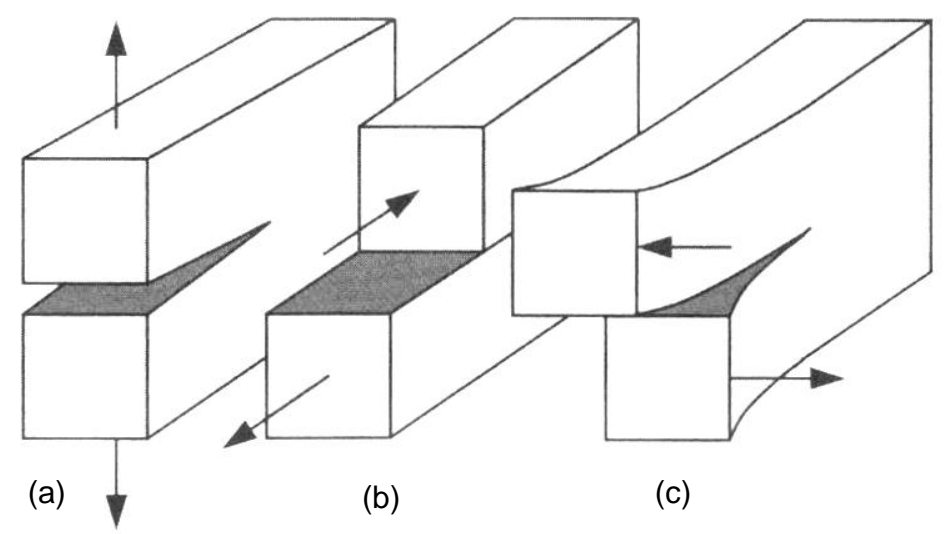

Figura 5 Modos de carregamento aplicados a uma trinca. (a) Modo I - Abertura; (b) Modo II Cisalhamento no Plano; (c) Modo III - Cisalhamento Fora do Plano. [17]

Portanto se for detectada falha do material por fratura frágil (clivagem transgranular) dentro do regime elástico linear do material, o valor do fator de intensidade de tensão para o qual isso acontece é crítico $\left(K_{I c}\right)$.

\subsection{LIMITAÇÕES DA MECÂNICA DA FRATURA ELÁSTICA LINEAR}

O fator de intensidade de tensões, $K_{I}$, somente descreve os campos de tensões e deformações à frente da trinca sob determinadas condições definidas pelas dimensões do espécime trincado e do seu nível de carregamento. Em materiais estruturais deformáveis como aços ferríticos soldáveis, a fratura geralmente é precedida por escoamento local considerável. Sob tais condições, o material apresenta o desenvolvimento de elevado nível de plasticidade à frente da trinca antes da ruptura frágil, violando, portanto, as hipóteses sob as quais o parâmetro elástico linear, $K$, é válido (dominância $K$ ). 
A dominância $K$ é especificada pela ASTM E399 [32] a qual estabelece que, para valores válidos de $K_{I c}$, a seguinte relação deve ser obtida.

$$
B, a,(W-a)>2.5 *\left(\frac{K_{I c}}{\sigma_{Y S}}\right)^{2}, \quad 0.45 \leq \frac{a}{W} \leq 0.55
$$

onde $\mathrm{B}$ é a espessura do corpo-de-prova, $a$ é o comprimento da trinca e $(W-a)$ é o ligamento remanescente. Os requisitos da ASTM E399, expressos pela Eq. (2), são extremamente rigorosos e aplicáveis a uma faixa bastante estreita de comprimentos de trinca. Aços de baixa e média resistência apresentam valores de $K_{I c}$ a temperaturas extremamente baixas, conforme ilustrado na Figura 6. Portanto, à temperatura ambiente, os espécimes laboratoriais deveriam ser fabricados com tamanhos impraticáveis na maior parte dos casos para atender aos requisitos da norma. Em vista destas limitações outros parâmetros e teorias devem ser utilizados na avaliação de tenacidade à fratura, quando existir o predomínio de plasticidade, no mecanismo de falha por fratura.

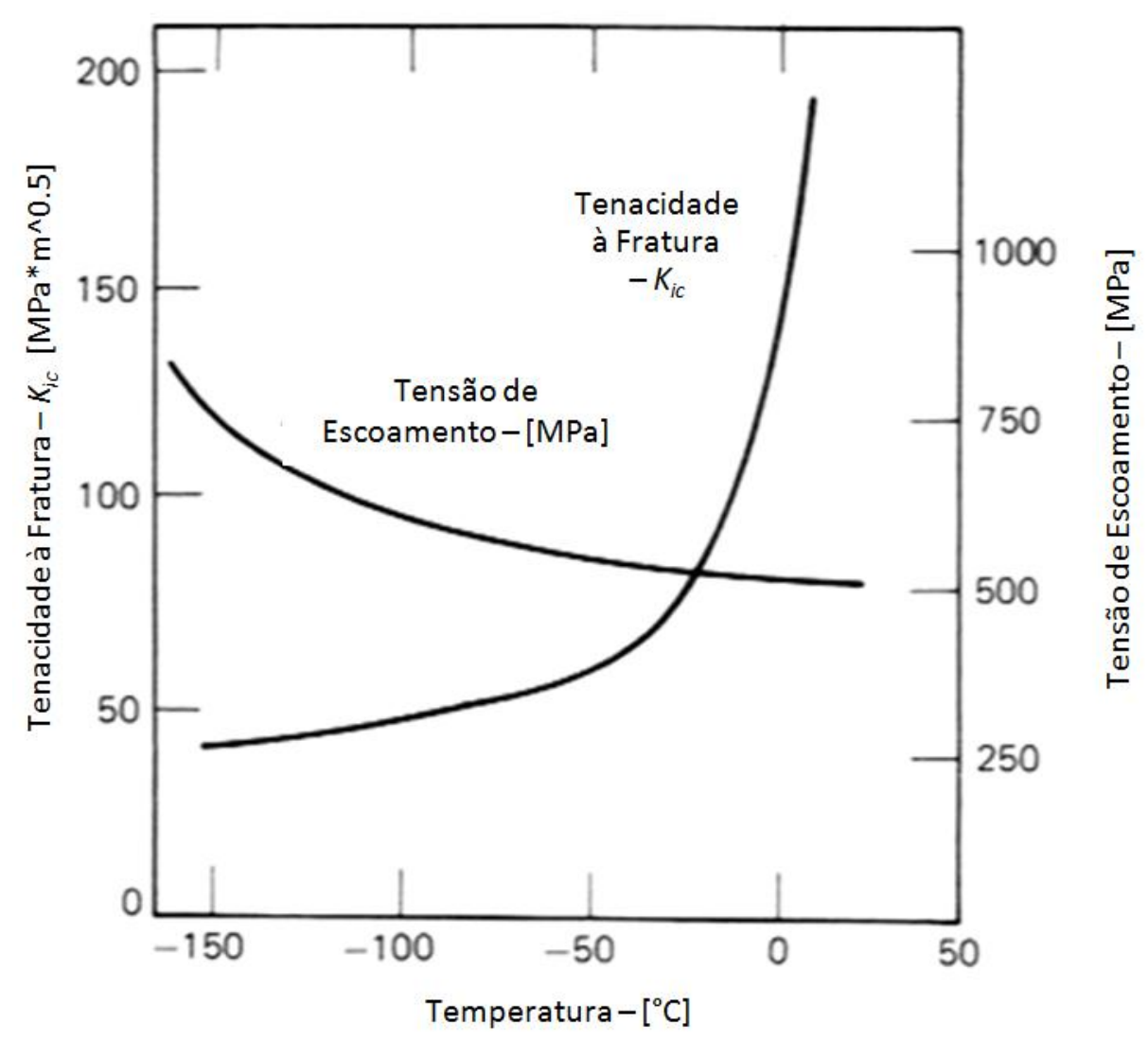

Figura 6 Variação de $K_{\mathrm{IC}}$ com a temperatura para o aço ASTM A533B de baixa liga utilizado na construção de vasos de pressão nucleares [17] 


\subsection{MECÂNICA DA FRATURA ELASTO-PLÁSTICA}

O desenvolvimento da mecânica da fratura elasto-plástica (MFEP) foi motivado pelas limitações da mecânica da fratura elástica linear (MFEL) em representar o comportamento à fratura de materiais estruturais com maior tenacidade. Sob ocorrência de escoamento e plasticidade limitados, a mecânica da fratura elástica linear permite descrever o comportamento à fratura de diversos materiais e ligas metálicas. Entretanto, com o desenvolvimento de aços de grande resistência e tenacidade, os quais apresentam grande plasticidade antes da fratura frágil, a MFEL encontra dificuldades em relação à sua aplicabilidade para caracterização dos campos de tensões e deformações. Os requisitos dimensionais da MFEL para estes tipos de aços exigem corpos-de-prova excessivamente grandes para obter valores válidos de tenacidade à fratura o que torna os ensaios potencialmente proibitivos.

Ainda assim, mesmo sendo possível a sua obtenção, estes não são aplicáveis à estruturas com espessura ou dimensões reduzidas. Portanto, a mecânica da fratura elástica linear, representada pelo parâmetro $K$ para avaliação de tenacidade, não reproduz os campos de tensões à frente da trinca para a avaliação de tenacidade de materiais submetidos a grandes carregamentos acompanhados de deformações plásticas generalizadas na ponta da trinca.

Isso motivou o desenvolvimento de metodologias que descrevessem com maior precisão o comportamento de materiais elasto-plásticos. Como resultado destes desenvolvimentos, Wells [12], em 1961, propõe um parâmetro conhecido como CTOD (Crack Tip Opennig Displacement) ao observar o deslocamento dos flancos da trinca seguido do arredondamento de sua ponta sem que a mesma se propagasse em aços de alta tenacidade, conforme ilustrado Figura 7. 


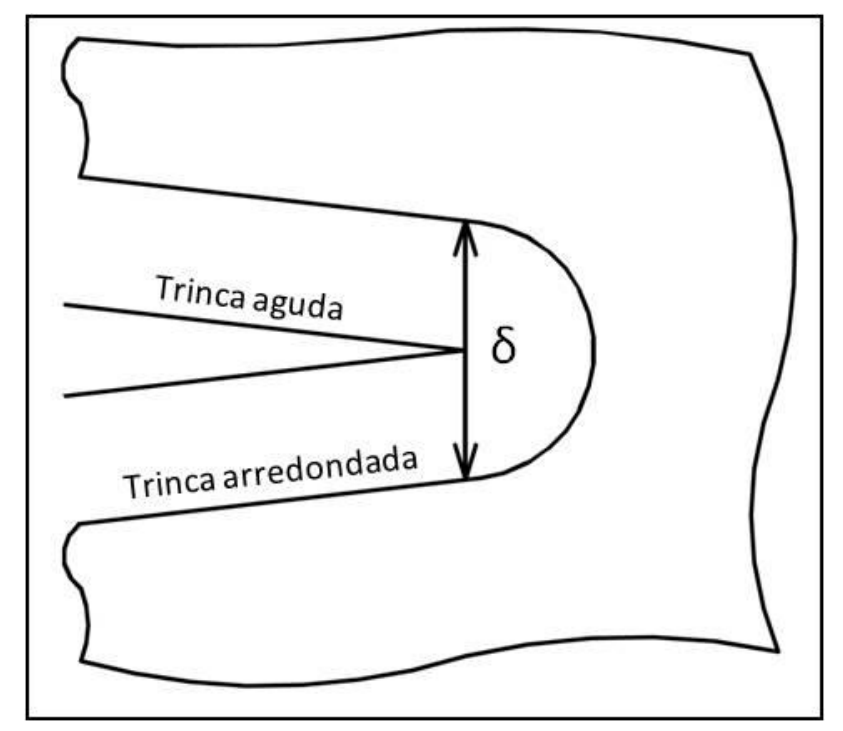

Figura 7 Deslocamento dos flancos da trinca e arredondamento da ponta ("blunting”) [33].

Posteriormente em 1968, Rice [34], propôs uma integral de linha independente do sentido de integração para caracterizar a resistência à fratura igualando o resultado desta integral à taxa de energia liberada por um sólido elástico não-linear contendo uma trinca, esta abordagem ficou conhecida como integral $J$. Nos capítulos seguintes haverá maiores explicações sobre os parâmetros $J$ e CTOD, assim como algumas abordagens para sua determinação experimental.

\subsection{O CTOD}

O CTOD apresenta diferentes definições, algumas abordagens são conceituais e outras geométricas. Serão apresentadas abaixo as abordagens conceituais de Irwin, o Modelo de Faixa de Escoamento e a abordagem geométrica $\left(90^{\circ}\right)$ comumente utilizada em medições por elementos finitos.

Irwin [35] demonstrou que a plasticidade na ponta da trinca faz com que ela se comporte como se fosse um pouco mais longa do que realmente é, como ilustrado na Figura 8. Então o CTOD deve ser estimado levando-se em consideração um comprimento efetivo de trinca $\left(a+r_{y}\right)$ onde $r_{y}$ é a representação da zona plástica de Irwin e o deslocamento $u_{y}$ é dado por: 


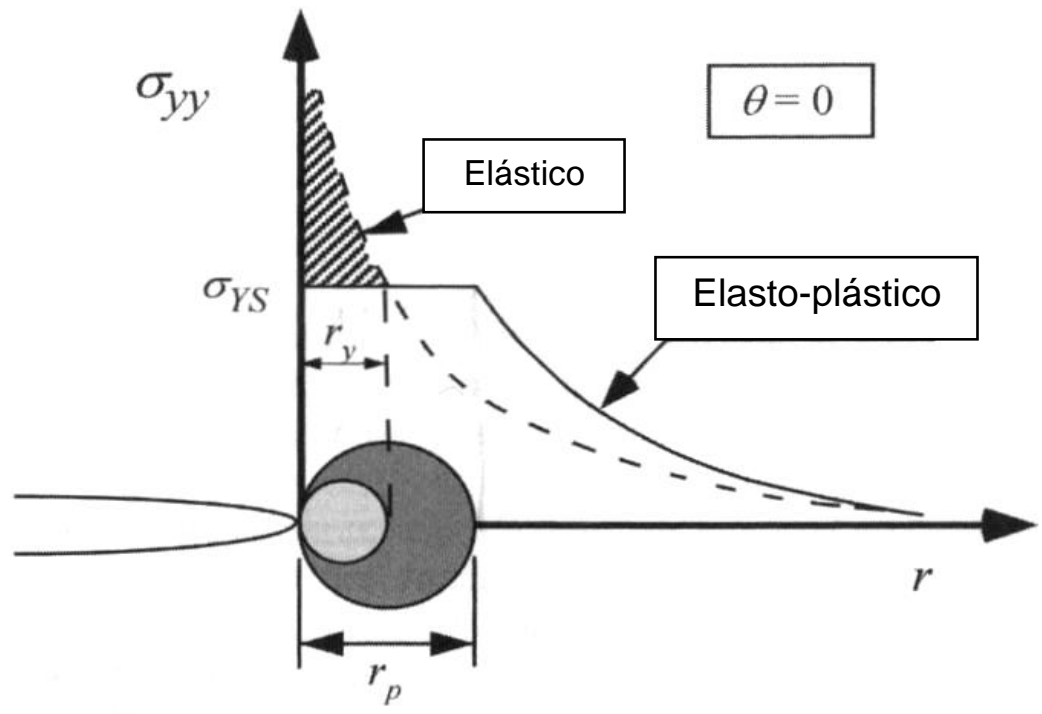

Figura 8 Representação da zona plástica de Irwin [17]

$$
u_{y}=\frac{\kappa+1}{2 \mu} K_{I} \sqrt{\frac{r_{y}}{2 \pi}}
$$

Onde $\kappa=3-4 v$ para estado plano de deformações (EPD), $\kappa=(3-v) /(1-v)$ para estado plano de tensões (EPT) e $v$ é o coeficiente de Poisson.

Para o estado plano de tensões, esta correção é dada por:

$$
r_{y}=\frac{1}{2 \pi}\left(\frac{K_{I}}{\sigma_{y s}}\right)^{2}
$$

Substituindo a Eq. (4) na Eq. (3), temos o CTOD calculado por:

$$
\delta=2 u_{y}=\frac{4 K_{I}^{2}}{\pi \sigma_{y s} E}
$$

O modelo de faixa de escoamento proposto por Dugdale [36] e Barenblatt [37] assume uma longa e fina faixa de zona plástica em um material que não sofre encruamento sob estado plano de tensão. Considerou-se para análise a geometria de uma placa infinita com trinca passante. A trinca é modelada assumindo um comprimento de $2 a+2 r$ onde $r$ é o comprimento da zona plástica sob a ação de 
uma tensão de fechamento igual a $\sigma_{y s}$, como apresentado na Figura 9 (a). Este modelo proporciona outra maneira de analisar o CTOD a qual pode ser definido como a abertura da ponta da trinca para o final da faixa de escoamento conforme a Figura 9(b).

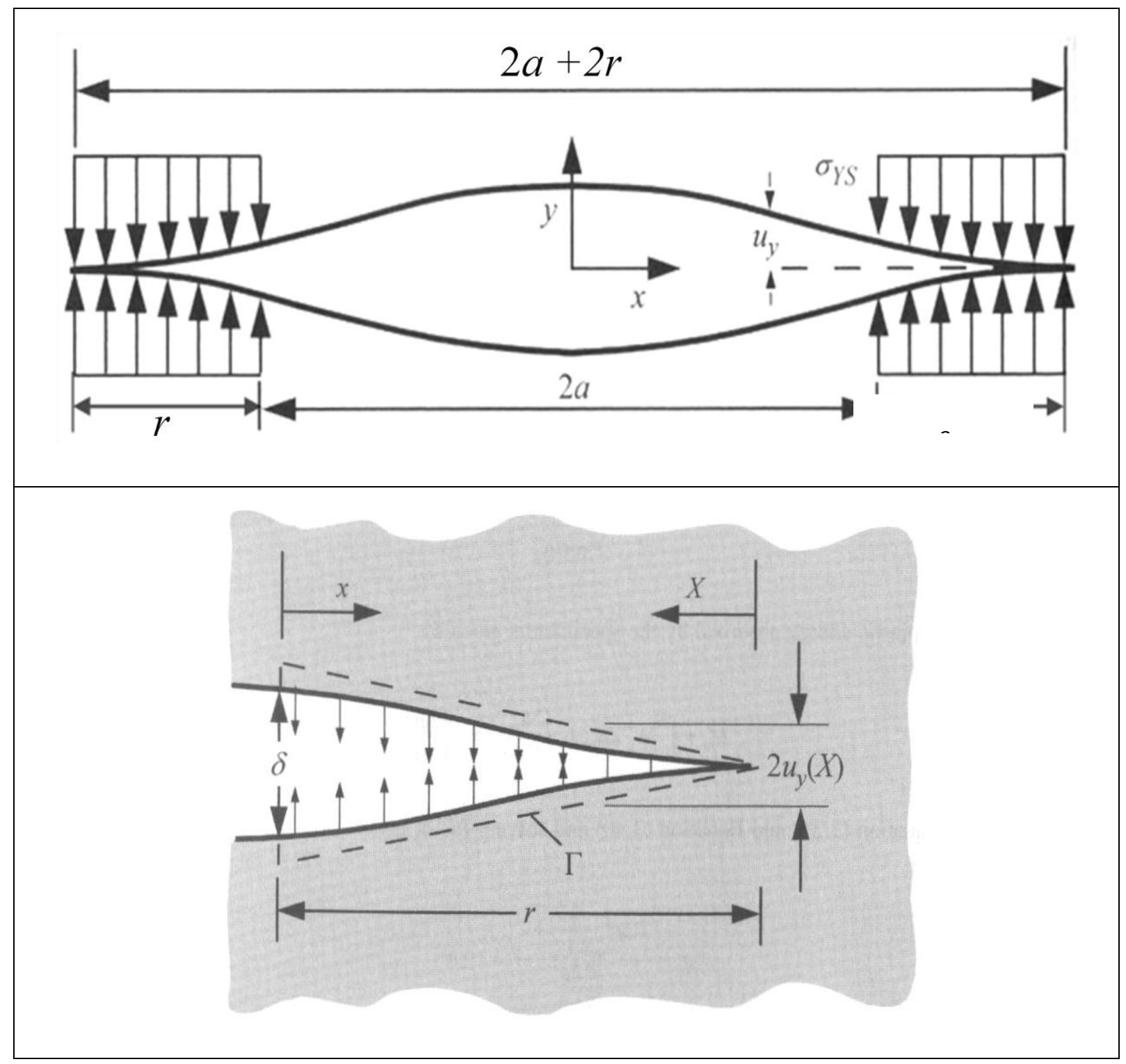

Figura 9 Representação da trinca utilizada pelo modelo de faixa de escoamento (a). Medição do CTOD $(\boldsymbol{\delta})$ para o modelo de faixa de escoamento (b) [17]

Para uma placa infinita com trinca passante o valor do CTOD é dado pela seguinte expressão

$$
\delta=\frac{8 \sigma_{y s} a}{\pi E} \ln \sec \left(\frac{\pi \sigma}{2 \sigma_{y s}}\right)
$$


Após uma expansão em série de ln sec da Eq. (6) e algumas manipulações temos:

$$
\delta=\frac{K_{I}^{2}}{\sigma_{y s} E}\left[1+\frac{1}{6}\left(\frac{\pi \sigma}{2 \sigma_{y s}}\right)^{2}+\cdots\right]
$$

onde os termos de ordem superior foram desprezados. E a relação pode ser escrita da seguinte forma

$$
\frac{K_{I}^{2}}{\sigma_{y s} E}=\frac{G}{\sigma_{y s}}
$$

A Eq. (8) difere da Eq. (5) proposta para o modelo de correção da zona plástica de Irwin uma vez que o Modelo de Faixa de Escoamento assume a condição de estado plano de tensões e o material sem encruamento (elástico-perfeitamente plástico). Porém a relação entre CTOD, $K_{I}$ e $G$ depende do estado de tensões e do encruamento do material [17] conforme propõe a expressão seguinte

$$
\delta=\frac{K_{I}^{2}}{m_{\mathrm{SSY}} \sigma_{y s} E^{\prime}}=\frac{G}{m_{\mathrm{SSY}} \sigma_{y s}}
$$

onde: $m_{\mathrm{SSY}}=1$ e $E^{\prime}=E$ para EPT; $m_{\mathrm{SSY}}=2$ e $E^{\prime}=E /\left(1-v^{2}\right)$ para EPD.

A abordagem geométrica (interseção a $90^{\circ}$ ) adota o valor de CTOD como o deslocamento da frente da trinca representado pela intersecção de duas retas ortogonais com origem na ponta da trinca e os flancos deformados [38], como mostrado na Figura 10. Esta última definição foi sugerida por Rice e é largamente utilizada na mensuração do CTOD em análises computacionais por elementos finitos [17]. 


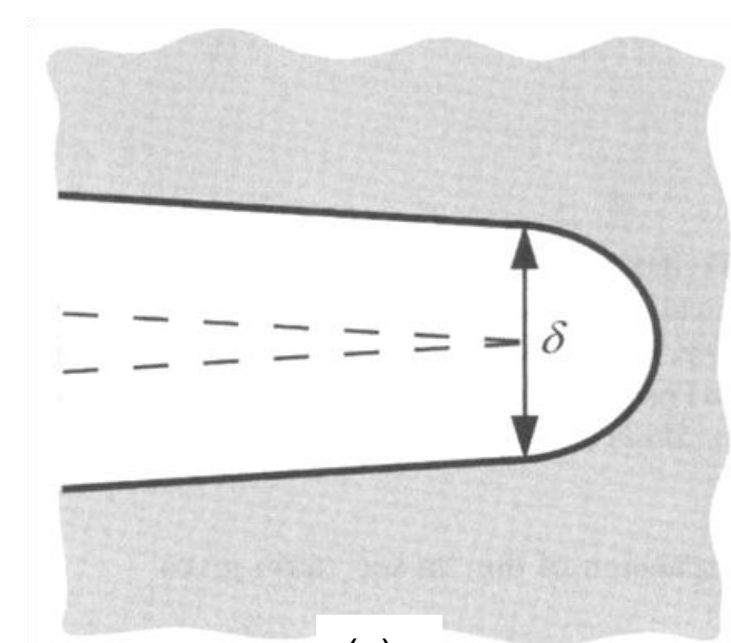

(a)

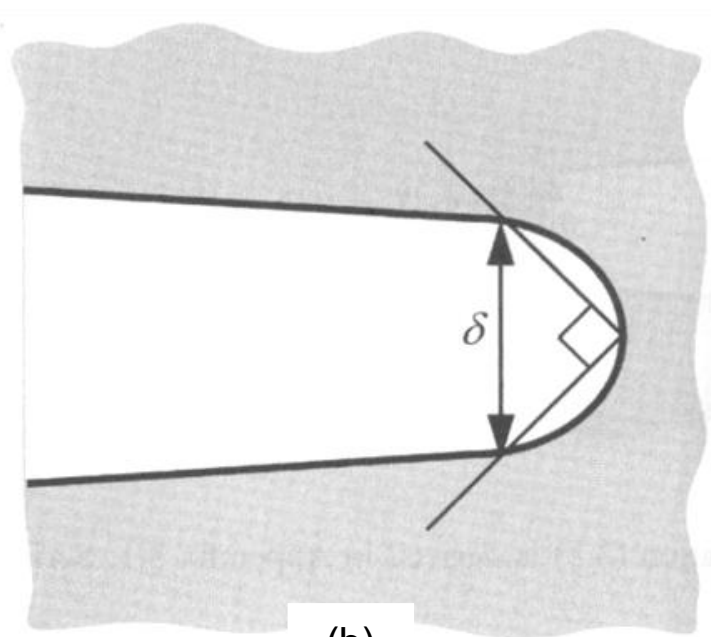

(b)

Figura 10 (a) Deslocamento dos flancos da trinca. (b) Definição de CTOD 90 [17].

O método de medição experimental direto da ponta da trinca é extremamente complicado e impreciso, pois exige a introdução de dispositivos de medição na ponta da trinca, região de pequena dimensão e difícil acesso. Devido à dificuldade e consequente imprecisão desta medição, foram desenvolvidos métodos indiretos de cálculo do CTOD que medem a abertura da "boca" da trinca, CMOD (Crack Mouth Open Displacement) e a correlacionam com a abertura da ponta da trinca (CTOD).

Um destes métodos, ilustrado na Figura 11, é conhecido como Modelo da Rótula Plástica e será descrito com maiores detalhes na seção 3.1. O outro, metodologia eta, será apresentado na seção 3.2. Ambos fazem uso de parâmetros adimensionais, $r_{p}$ e $\eta$ respectivamente, para o cálculo do CTOD. 


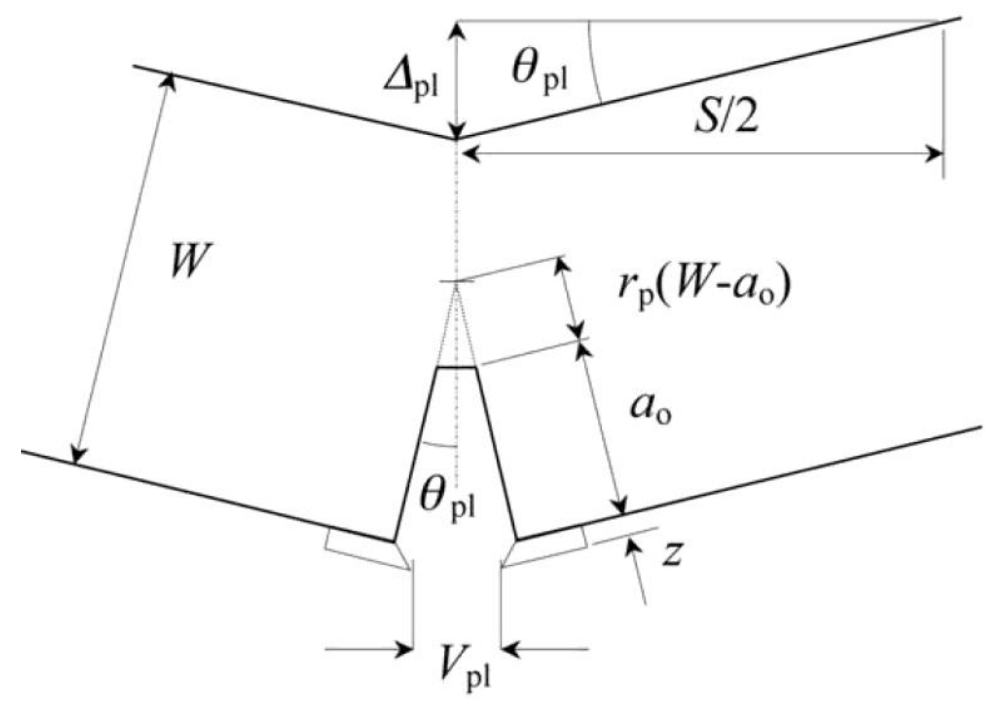

Figura 11 Representação do Modelo da Rótula Plástica [20].

\subsection{A INTEGRAL $J$}

Conforme citado anteriormente, Rice [34], introduziu a integral $J$ como parâmetro de avaliação de tenacidade à fratura utilizando a hipótese de elasticidade não linear, representado esquematicamente na Figura 12. Rice mostrou que a taxa de liberação de energia, denotada por $J$, em sólido pode ser descrita por uma integral de linha independente do caminho de integração na forma

$$
J=\int_{\Gamma}\left(W d y-T_{i} \frac{\partial u_{i}}{\partial x} d s\right)
$$

onde $\Gamma$ denota um contorno fechado e anti-horário definido sobre um plano normal à frente da trinca, iniciando na face inferior da trinca e terminando na sua face superior, ilustrado pela Figura 13, $W$ denota a energia de deformação por unidade de volume indeformado, $T_{i}$ e $u_{i}$ são as componentes cartesianas do tensor de tensões (assimétricas) e dos deslocamentos no sistema de coordenadas localizado na frente da trinca. 


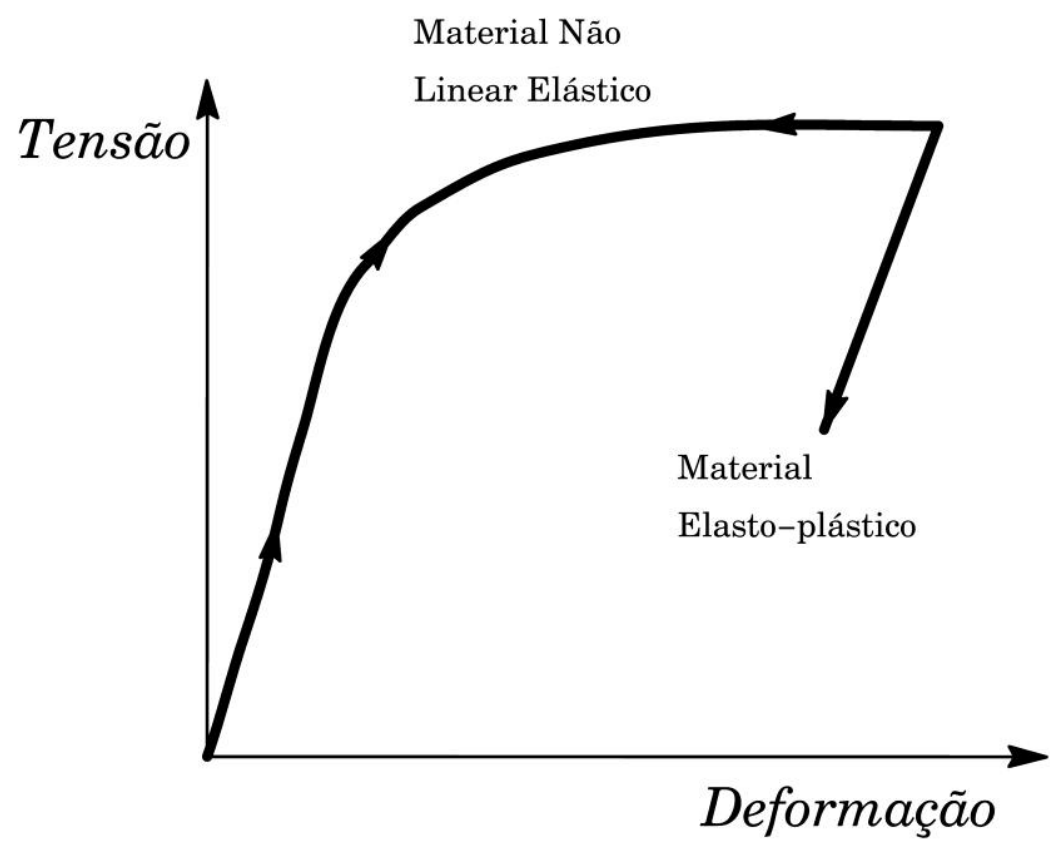

Figura 12 Representação de curva tensão deformação para materiais elasto-plásticos e elásticos não lineares [33].

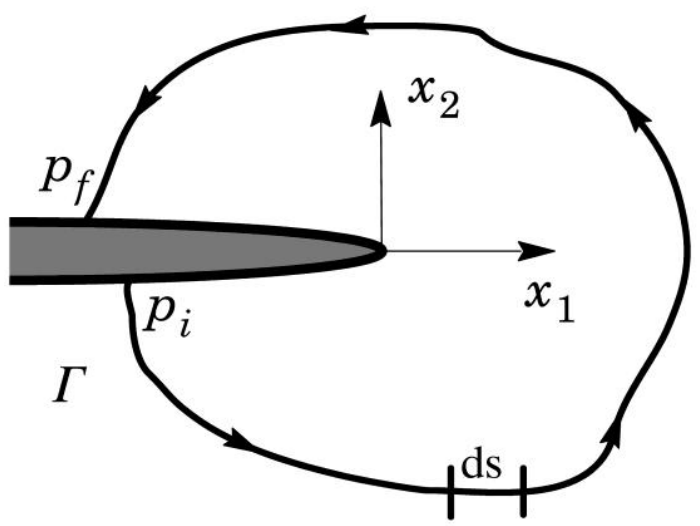

Figura 13 Representação do contorno arbitrário ao redor da trinca [33].

Para o caso especial de material com comportamento linear elástico, $J$ é equivalente à taxa de liberação de energia de Griffith [22], isto é, $J=G$. Esta equivalência permite obter a relação entre o fator de intensidade de tensões elásticas lineares e a integral $J$ como 


$$
J=\frac{K_{I}^{2}}{E^{\prime}}
$$

onde $E^{\prime}$ : é o módulo de elasticidade longitudinal do material, $E^{\prime}=E$ para EPT, $E^{\prime}=E /\left(1-v^{2}\right)$ para EPD e $v$ é o Coeficiente de Poisson.

Estudos subseqüentes de Hutchinson [26] e paralelamente Rice e Rosengren [27] mostraram a relação unívoca entre o campo de tensões e deformações atuantes nas vizinhanças de uma trinca contida em sólido elástico não-linear e a integral $J$ em materiais com resposta tensão-deformação obedecendo a uma lei de potência na forma

$$
\frac{\varepsilon}{\varepsilon_{0}}=\frac{\sigma}{\sigma_{0}}+a\left(\frac{\sigma}{\sigma_{0}}\right)^{n}
$$

onde, $\varepsilon$ e $\sigma$ são a deformação e tensão verdadeiras, a é uma constante adimensional e $n$ é o expoente de encruamento. O subscrito "0" para a tensão e deformação na Eq. (12) refere-se a valores de referência, usualmente associados tensão de escoamento $\left(\sigma_{y s}\right)$ e deformação de escoamento $\left(\varepsilon_{y s}\right)$. Hutchinson, Rice e Rosengren mostraram que para manter a integral de linha independente do caminho de integração é preciso que as tensões nas vizinhanças da ponta da trinca variem com $(1 / r)^{1 /(n+1)}$. Aplicando condições de contorno apropriadas, eles obtiveram os campos de tensões e deformações na forma

$$
\begin{gathered}
\sigma=\sigma_{0}\left(\frac{E J}{\alpha \sigma_{0}^{2} I_{n} r}\right)^{\frac{1}{n+1}} \sigma_{i j}^{\prime} \\
\varepsilon=\frac{\alpha \sigma_{0}}{\varepsilon_{0}}\left(\frac{E J}{\alpha \sigma_{0}^{2} I_{n} r}\right)^{\frac{n}{n+1}} \varepsilon^{\prime}{ }_{i j}(n, \theta)
\end{gathered}
$$

onde $I_{n}$ é uma constante de integração que depende do expoente de encruamento $n, \sigma^{\prime}{ }_{i j}$ e $\varepsilon^{\prime}{ }_{i j}$ são funções adimensionais de $\theta, n$ e do estado de tensões (estado plano de tensões ou estado plano de deformações). No caso elástico linear, $n=1$ 
e as tensões variam com $\sqrt{ }(1 / r)$, recuperando-se a singularidade caracterizada por $K_{I}$. As Eqs.(13 e 14) são conhecidas como solução HRR (iniciais de Hutchinson, Rice e Rosengren).

Assim a integral $J$ pode ser interpretada tanto como um parâmetro de variação de energia e como também um parâmetro de intensidade de tensões. Esta integral é completamente consistente com o parâmetro $K_{I}$ porque, no caso particular de sólido com comportamento elástico linear, fornece resultados equivalentes.

\subsection{CORRELAÇÃO ENTRE $J$ E CTOD}

Para o caso de haver condições apropriadas na região próxima à ponta da trinca onde a mecânica da fratura elástica linear seja descritora dos fenômenos que governam o modo de falha, a relação entre os valores de $J$ e CTOD se faz de maneira direta e pode ser calculada pela Eq. (9) uma vez que $J=G$.

Porém esta relação não se mantém quando há aumento da zona plástica e a conseqüente perda da validade da mecânica da fratura linear elástica. A extensão para casos elasto-plásticos de uma correlação entre $J$ e CTOD foi desenvolvida por Shih [39], em 1981, e é expressa por

$$
\delta=\frac{d_{n} J}{\sigma_{y s}}
$$

a qual incorpora os efeitos de encruamento e tensão de escoamento do material, representados por $n$ e $\sigma_{y s}$ respectivamente.

onde:

$$
d_{n}=2 u_{y}(\pi, n) \frac{\left[\frac{\alpha \sigma_{0}}{E}\left\{u_{x}(\pi, n)+u_{y}(\pi, n)\right\}\right]^{\frac{1}{n}}}{I_{n}}
$$


Utilizando a relação de tensão vs. deformação expressa pela Eq. (12) anterior com $\alpha=1$, Shih [39] obteve valores da constante adimensional $d_{n}$ em função de $N=1 / n$ para diversos níveis da relação $\sigma_{0} / E$ (ou $\sigma_{y s} / E$ ) como apresentado na Figura 14. Estes resultados revelam que $d_{n}$ é fortemente dependente do encruamento do material para ambas as condições EPT e EPD.

Recentemente, Kirk [40], propôs uma forma alternativa à Eq. (15) para representar a correlação entre $J$ e CTOD a qual é expressa por

$$
J=m \sigma_{0} \delta
$$

$\mathrm{Na}$ Eq. (16) o fator $m$ difere do fator $m_{\mathrm{ssy}}$, Eq.(9), pois neste caso estão sendo correlacionados valores de $J$ e CTOD totais (parcelas elástica e plástica) em regime elasto-plástico. Onde as condições do modelo de faixa de escoamento (estado plano de tensão e não encruamento) não se fazem mais presentes. 

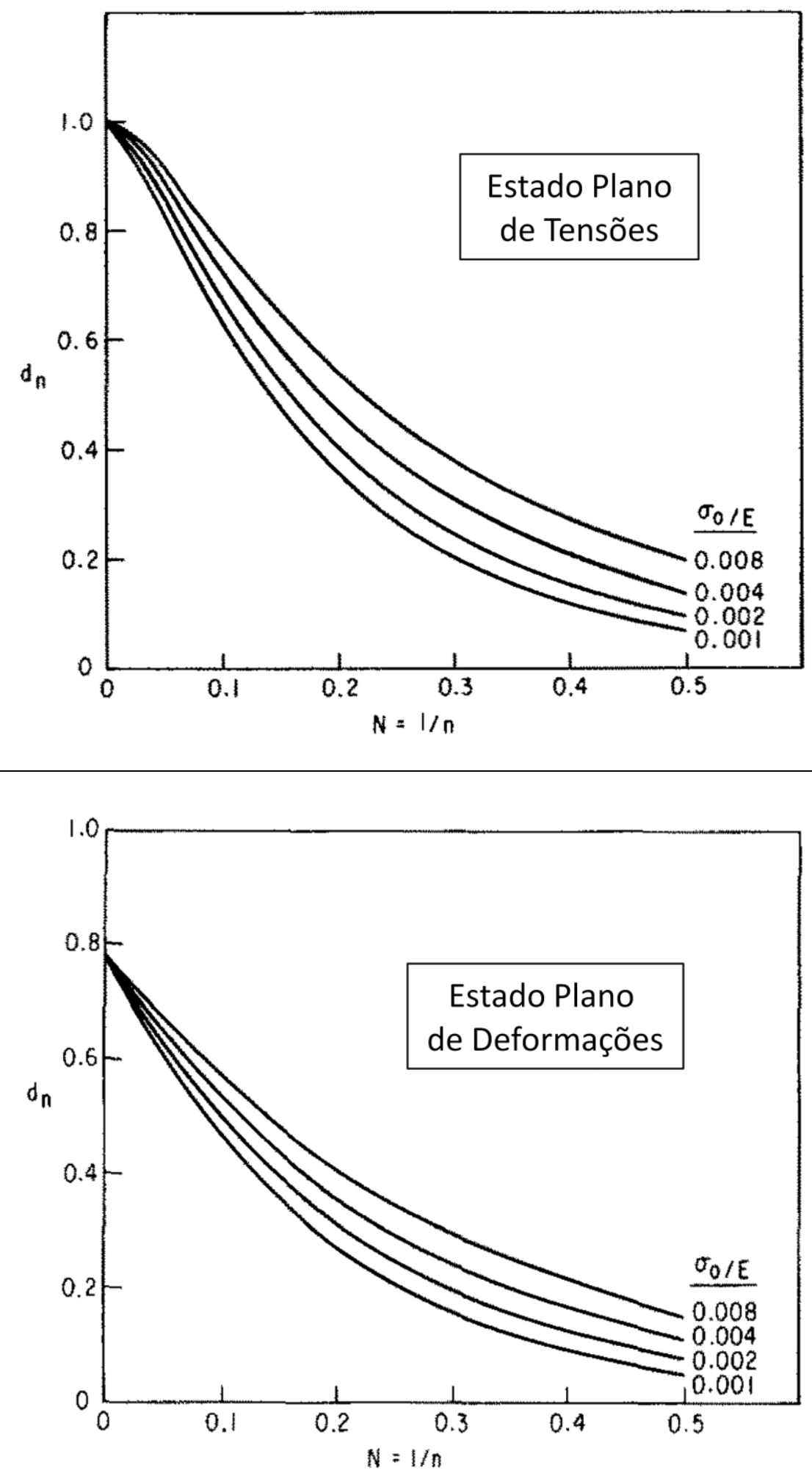

Figura 14 Valores de $d_{n}$ para a relação de $J v$ s. CTOD sob condição de estado plano de tensões e estado plano de deformações, respectivamente com $\alpha=1$. Para $\alpha \neq 1$ os valores acima devem ser multiplicados por $\alpha^{1 / n}[39]$. 


\section{PROCEDIMENTOS DE AVALIAÇÃO DO CTOD E INTEGRAL $J \quad$ UTILIZANDO MEDIÇÕES EXPERIMENTAIS DE CARGA E DESLOCAMENTO}

A determinação experimental de valores críticos de tenacidade à fratura, $J_{c} e \delta_{c}$, obedece à normas de ensaios de mecânica da fratura utilizando, geralmente, medições experimentais de carga e deslocamento em corpos-de-prova com geometria normalizada. Dentre as normas experimentais de testes existentes, destacam-se as normas BS 7448 [5] e ASTM E1290 [19], por serem amplamente recomendados pelos procedimentos de avaliação de criticidade de defeitos na avaliação de tenacidade à fratura.

Embora extensivamente adotadas para a determinação de valores críticos de $J$ e CTOD, estas normas baseiam-se em abordagens distintas e, consequentemente, não produzem valores únicos $\mathrm{e}$ independentes de tenacidade à fratura. Adicionalmente, e talvez mais importante, estas normas de testes não incorporam procedimentos analíticos específicos para determinação de $\delta_{c}$ e $J_{c}$ em juntas soldadas com dissimilaridade mecânica entre o metal de base e o metal de solda (condição de "weld strength mismatch"). Donato [33], por meio de análises numéricas, identificou que os parâmetros adimensionais, $r_{p}$ e $\eta$, utilizados por cada uma destas normas para obtenção de $\delta$ e $J$, são sensíveis aos níveis de dissimilaridade mecânica para espécimes com geometria $\mathrm{SE}(\mathrm{B})$ o que motiva a extensão desta investigação para outras geometrias normalizadas de corpos-deprova.

O nível de dissimilaridade mecânica, $M_{y}$, é definido como a relação entre a tensão de escoamento do metal de solda e a tensão de escoamento do metal de base, expresso por

$$
M_{y}=\frac{\sigma_{y s}^{M S}}{\sigma_{y s}^{M B}}
$$


onde $\sigma_{y s}^{M S}$ é a tensão de escoamento do metal de solda e $\sigma_{y s}^{M B}$ é a tensão de escoamento do metal base.

A norma britânica BS 7448 [5], é dividida em quatro partes e aborda em sua Parte 2 a avaliação de tenacidade à fratura em juntas soldadas. Entretanto, neste procedimento são reportados apenas os intervalos dos níveis de dissimilaridade mecânica para os quais a medição de $J$ e CTOD é válida, sem haver a proposição de quaisquer alterações nos parâmetros de fórmula na intenção de incorporar os efeitos de $M_{y}$ sobre esta medição. Segundo esta norma, são permitidos valores de dissimilaridade mecânica de $0.5 \leq M_{y} \leq 1.5$ para o cálculo de CTOD e $0.5 \leq M_{y} \leq 1.25$ para o cálculo de $J$. Níveis de dissimilaridade maiores que os limites superiores estabelecidos para cada caso podem levar a valores superestimados de tenacidade à fratura e valores menores ao limite inferior de dissimilaridade mecânica, $M_{y}<0.5$, podem gerar valores subestimados de tenacidade à fratura [18].

Em contraste, a norma da ASTM prevê o seu uso na avaliação da tenacidade à fratura de materiais soldados, porém, diferentemente da norma britânica, não estabelece limites para os níveis de dissimilaridade mecânica entre o metal de solda e o metal base para os quais suas formulações se mantêm precisas.

Este capítulo apresenta sucintamente os fundamentos metodológicos para avaliação de $J$ e CTOD utilizando medições experimentais de carga $v s$. deslocamento em corpos-de-prova convencionais de mecânica da fratura. Será mostrado brevemente o modelo de rótula plástica para a determinação do CTOD (para maiores detalhes consultar [33]). Em seguida será apresentada a metodologia $\eta$ aplicável à determinação experimental de $J$ e CTOD e sua extensão para juntas soldadas, objeto de estudo deste trabalho.

\subsection{METODOLOGIA DA RÓTULA PLÁSTICA}

Conforme citado anteriormente a medição direta do CTOD é bastante complicada e imprecisa devido às dimensões da ponta da trinca que dificultam o acesso desta região. Como o CTOD é um parâmetro físico, amplamente difundido na caracterização da tenacidade à fratura de materiais metálicos, foram desenvolvidas 
técnicas de medição indireta (e.g metodologia $\eta$ e modelo da rótula plástica) deste parâmetro que tomam como base a curva de carga vs. deslocamento e relações geométricas obtidas das dimensões dos corpos-de-prova. O modelo da rótula plástica, utilizando corpos-de-prova com geometria $\mathrm{C}(\mathrm{T})$, ilustrado na Figura 15, proporciona uma medição simples e fácil dos parâmetros para o cálculo do CTOD.

A norma BS 7448 [5] fornece as diretrizes do procedimento para o cálculo do CTOD de forma experimental e recomenda o valor de $r_{p}=0.4$, assim como a norma ASTM 1820 de 1999 sugere um valor de $r_{p}=0.44$ para o corpo-de-prova com a geometria $\mathrm{SE}(\mathrm{B})$. Ambas as normas sugerem o valor de $r_{p}=0.46$ para 0 espécime $\mathrm{C}(\mathrm{T})$.

Conforme é mostrado pela Eq. (18.1), o CTOD pode ser dividido em duas componentes uma referente à parte elástica, Eq. (18.2), e a outra referente à parte plástica, Eq. (18.3). O valor de $r_{p}$ será utilizado no cálculo da componente plástica do CTOD sendo este obtido por semelhança de triângulos relacionando a porção plástica da abertura da boca da trinca $\left(\mathrm{CMOD}_{P l}\left(\mathrm{~V}_{P l}\right)\right)$ com o ligamento remanescente $(W-a)$.

$$
\begin{gathered}
\delta=\delta_{E l}+\delta_{P l} \\
\delta_{E l}=\frac{K_{I}^{2}}{m \sigma_{y s} E} \\
\delta_{P l}=\frac{r_{p}(W-a) V_{P l}}{r_{p}(W-a)+a}
\end{gathered}
$$



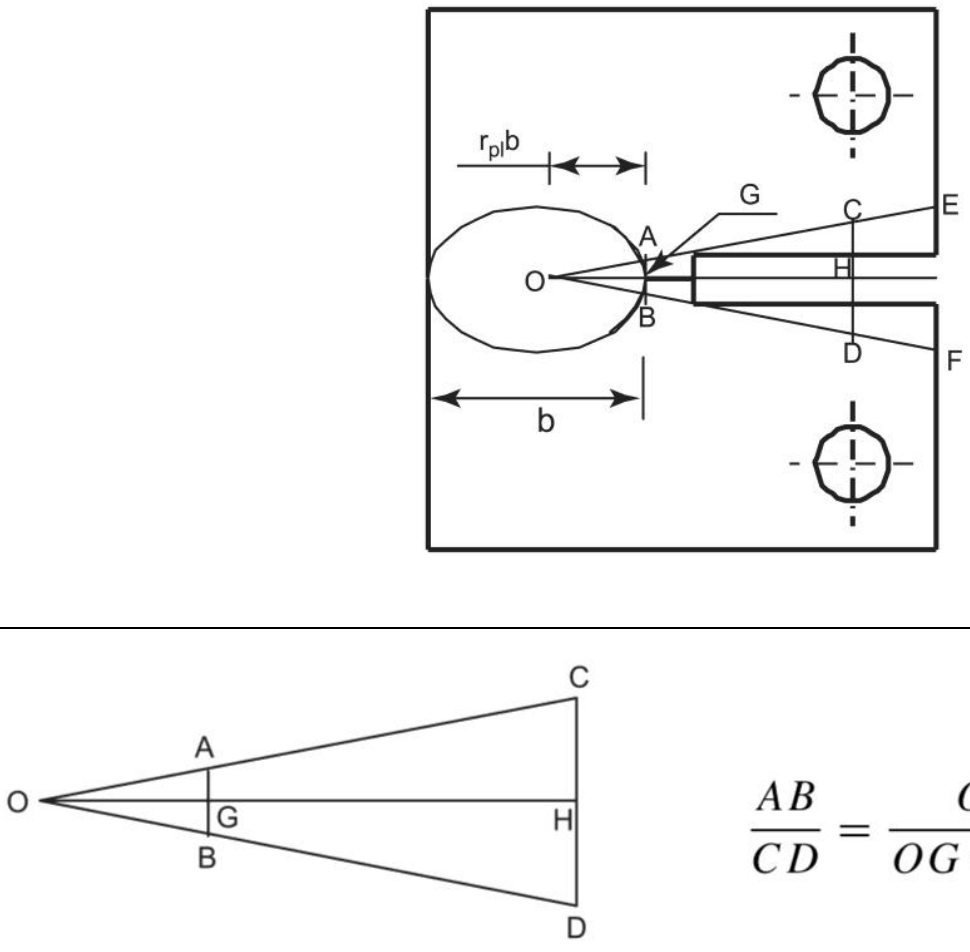

$$
\frac{A B}{C D}=\frac{O G}{O G+G H} \quad \frac{\delta_{p l}}{V_{p l}}=\frac{r_{p l} b}{r_{p l} b+a_{0}}
$$

Figura 15 Representação do modelo da rótula plástica para um espécime $\mathrm{C}(\mathrm{T})$ [41]

Como o nome sugere o $r_{p}$ define o ponto rotular sobre o qual as duas metades do corpo-de-prova irão rotacionar. O ponto rotular é utilizado apenas para o cálculo da componente plástica, pois durante a abertura da trinca, ainda dentro do regime elástico do material, $r_{p}$ varia muito de posição ao longo da região do ligamento remanescente e isso provocaria valores imprecisos no cálculo da componente elástica do CTOD [33]. Para o cálculo da componente plástica, agora dentro do regime plástico do material, a posição do ponto rotular tem uma variação bem menos significativa aumentando a precisão dos valores. 


\subsection{METODOLOGIA ETA}

\subsubsection{METODOLOGIA ETA - MATERIAIS HOMOGÊNEOS}

Proposta por Sumpter e Turner [43], em 1976, esta metodologia correlaciona por meio de um parâmetro adimensional a energia de deformação, dada pela Integral $J$, com o valor da área sob a curva do gráfico de carga vs. deslocamento obtida experimentalmente, conforme ilustra a Figura 16, para um corpo-de-prova trincado confeccionado com material homogêneo. Nesta metodologia, $J$ é dividido em duas componentes, uma elástica $\left(J_{E l}\right)$, e outra plástica $\left(J_{P l}\right)$, conforme a Eq. (19). Normas como ASTM E1290 [19] e ASTM E1820 [44] fazem uso desta metodologia para o cálculo dos parâmetros $J$ e CTOD.

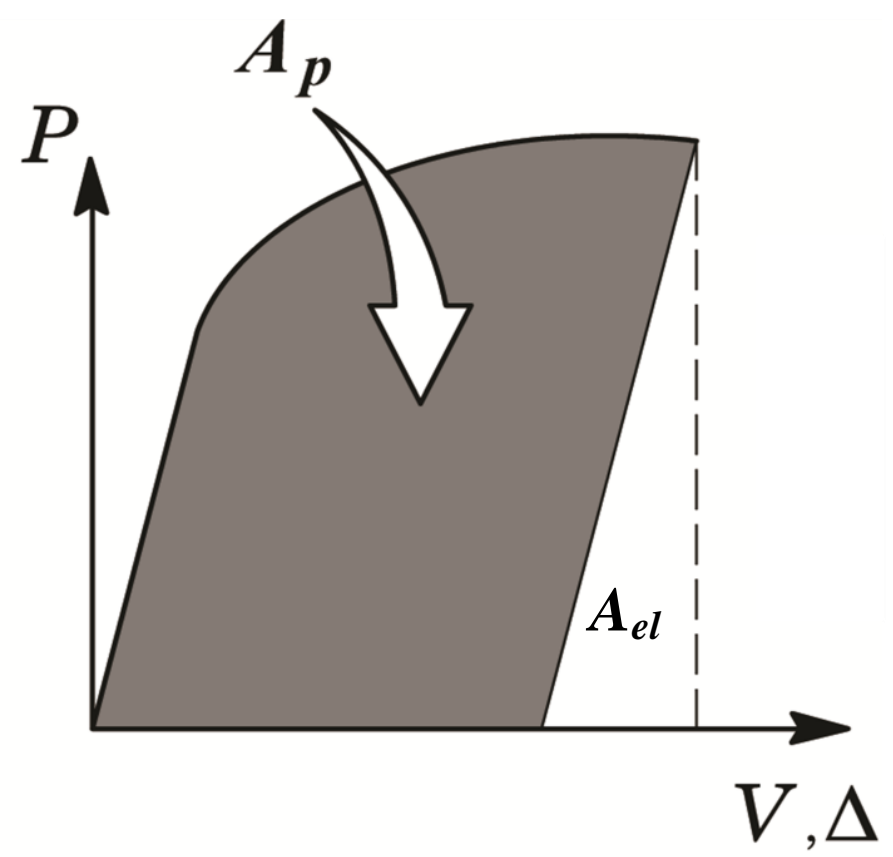

Figura 16 Definição de área plástica e elástica sob a curva de carga vs. deslocamento (CMOD ou LLD) [38] 


$$
J_{T o t a l}=J_{E l}+J_{P l}
$$

A componente elástica, $J_{E l}$ é dada por

$$
J_{E l}=\frac{K_{I}^{2}}{E^{\prime}}
$$

onde fator de intensidade de tensões, $K_{I}$, é definido analiticamente para 0 espécime $\mathrm{C}(\mathrm{T})$ como [17]

$$
K_{I}=\frac{P}{B \sqrt{W}} f\left(\frac{a}{w}\right)
$$

onde

$$
f\left(\frac{a}{W}\right)=\frac{2+\frac{a}{W}}{\left(1-\frac{a}{W}\right)^{3 / 2}}\left[0.886+4.64\left(\frac{a}{W}\right)-13.32\left(\frac{a}{W}\right)^{2}+14.72\left(\frac{a}{W}\right)^{3}-5.6\left(\frac{a}{W}\right)^{4}\right]
$$

A componente plástica, $J_{P l}$, pode ser convenientemente avaliada a partir da área plástica sob a curva carga vs. deslocamento como [4]

$$
J_{P l}=-1 / B \int_{0}^{\Delta_{p}}\left(\frac{\partial P}{\partial a}\right) d \Delta_{P l}=\frac{\eta_{J}}{B b} \int_{0}^{\Delta_{p}} P \Delta_{P l}=\frac{\eta_{J} A_{P l}}{B b}
$$

onde $A_{P l}$ é a área plástica da curva de carga vs. deslocamento (a qual representa o trabalho plástico, $\left.U_{p}\right), P$ denota o carregamento, $\Delta_{p l}$ define a componente plástica do deslocamento, $b$ é o ligamento remanescente inicial do corpo-de-prova, B é a espessura do espécime e $\eta_{J}$ é o fator adimensional que relaciona a contribuição plástica com a energia de deformação do sólido contendo uma trinca à integral $J$ As formulações acima apresentadas se mantêm válidas para o caso da medição do deslocamento ser realizada em relação à abertura da boca da trinca, CMOD (V), ou em relação ao deslocamento da linha de carga (LLD), e podem ser respectivamente denotadas nas seguintes maneiras 


$$
\begin{gathered}
J_{P l}=\frac{\eta_{J}{ }^{C M O D} A_{P l}^{C M O D}}{B b_{0}} \\
J_{P l}=\frac{\eta_{J}^{L L D} A_{P l}^{L L D}}{B b_{0}}
\end{gathered}
$$

onde os fatores $\eta_{J}^{\text {CMOD }}$ e $\eta_{J}^{\text {LLD }}$ representam os valores do fator adimensional tomando-se como referência para a medida do deslocamento a abertura da boca da trinca e o deslocamento da linha de carga, respectivamente.

Caso valores de CTOD sejam desejados para a caracterização da tenacidade à fratura, uma formulação análoga é adotada utilizando a relação entre $J$ e CTOD introduzida anteriormente (ver seção 2.7). Então valores experimentais de CTOD podem ser avaliados por:

$$
\begin{gathered}
\delta_{\text {Total }}=\delta_{E l}+\delta_{P l} \\
\delta_{E l}=\frac{K_{I}^{2}}{m \sigma_{y s} E^{\prime}} \\
\delta_{P l}=\frac{\eta_{\delta} A_{P l}}{B b \sigma_{y s}}
\end{gathered}
$$

Onde $\eta_{\delta}$ representa o fator adimensional que descreve os efeitos da energia de deformação plástica sobre o CTOD aplicado, $m$ representa o fator de restrição plástica, usualmente adotado como 2, [18] [45] e $\sigma_{y s}$ denota a tensão de escoamento do material. 


\subsubsection{EXTENSÃO DA METODOLOGIA ETA PARA JUNTAS SOLDADAS COM TRINCA CENTRAL}

Citado em seções anteriores, os procedimentos correntes de avaliação de criticidade de defeitos e as normas de teste para avaliação de tenacidade à fratura não incorporam em suas rotinas de cálculo os efeitos da dissimilaridade mecânica entre o metal de base e o metal de solda. Esta condição afeta significativamente a resposta mecânica global e local, em particular a relação entre o carregamento remoto aplicado e as forças motrizes na ponta da trinca da estrutura soldada.

A presença de dissimilaridade mecânica em um corpo-de-prova contendo uma trinca central no cordão de solda não invalida os conceitos previamente apresentados para a integral $J$ e o CTOD [33] e estes podem ser avaliados de maneira análoga ao apresentado na seção anterior para materiais homogêneos. Os efeitos da dissimilaridade são computados diretamente pela curva de carga vs. deslocamento, representada na Figura 17 para um espécime com trinca central ao cordão de solda.
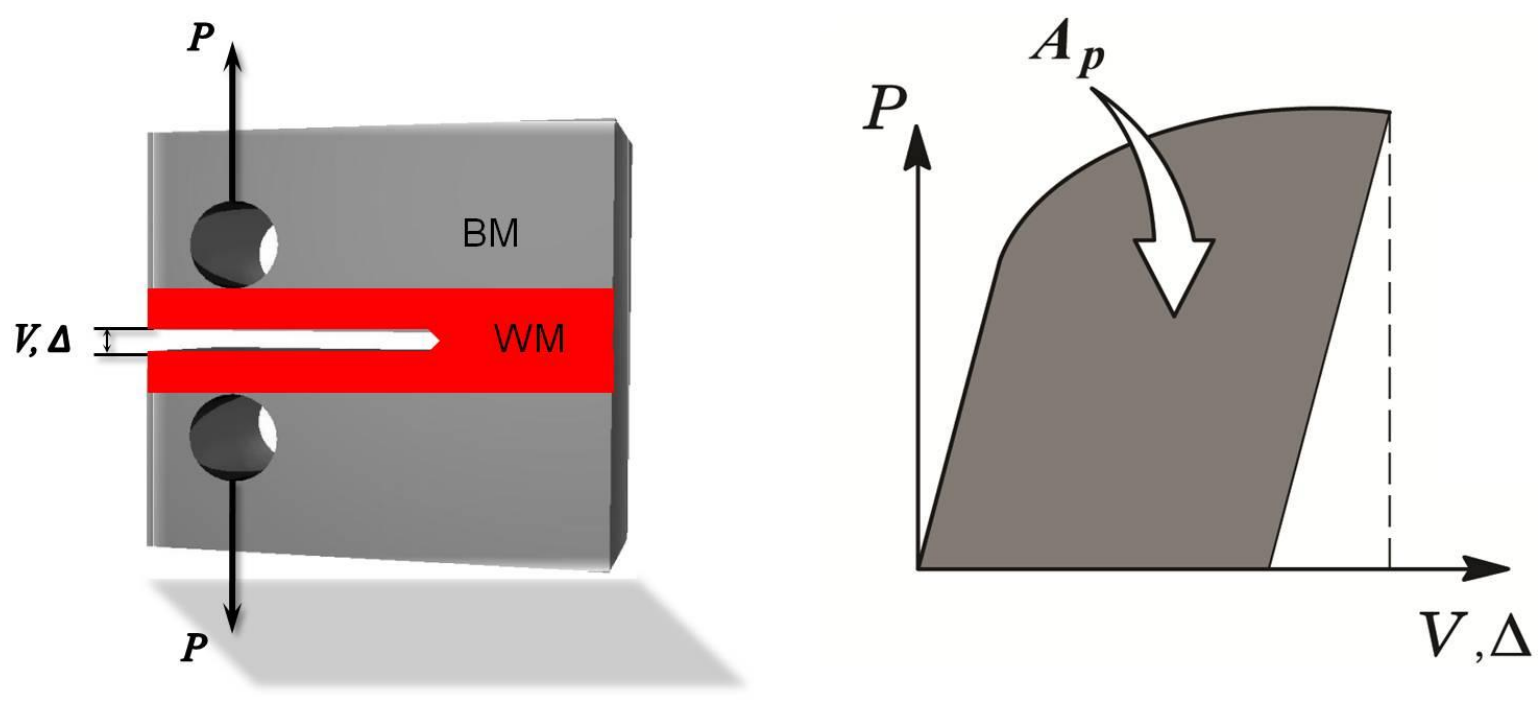

Figura 17 Representação da curva de carga deslocamento com as representações da parcela plástica e elástica para um corpo-de-prova C(T) contendo cordão de solda.

A área abaixo da curva de carga vs. deslocamento, assim como os valores do parâmetro $\eta$, podem ser fortemente afetados pelo do nível de dissimilaridade mecânica, $M_{y}$. Portanto, para a abordagem desta situação não se recomenda a 
aplicação estreita e direta das normas citadas anteriormente sem que sejam feitos os devidos refinamentos nos parâmetros de cálculo.

\section{METODOLOGIA BIPARAMÉTRICA}

Sob plasticidade restrita nas vizinhanças do defeito ou da trinca, garantida pela condição de escoamento de pequena monta (Small Scale Yielding), a mecânica monoparamétrica, representada pelos fatores CTOD, $J$ e $K$, permite correlacionar de maneira satisfatória os valores de tenacidade à fratura, medidos experimentalmente, com o comportamento à fratura de estruturas sob condições de serviço. [46]. Porém a validade da mecânica da fratura monoparamétrica pode ser violada sob condições de análise onde haja escoamento de grande monta. Variações geométricas dos espécimes ensaiados e condições de plasticidade generalizada causam o relaxamento das tensões nas proximidades da ponta da trinca podendo invalidar o conceito de parâmetro único para avaliação da tenacidade à fratura [17].

Em vista dos argumentos apresentados e da necessidade de uma avaliação precisa dos valores de tenacidade à fratura sob condições de plasticidade generalizada o desenvolvimento da mecânica biparamétrica foi motivado. As metodologias desenvolvidas assumem campos de tensões separáveis sendo um quantificador do nível de restrição plástica na ponta da trinca e outro quantificador do nível de tensão nesta mesma região [47] [48].

Estas metodologias seguem duas abordagens:

- Teoria $J-T^{l}$, construída com base na tensão elástica $T$.

- Teoria $J-Q$, desenvolvida utilizando o parâmetro hidrostático $Q$.

Ambas as teorias utilizam dois parâmetros escalares para descrição do campoelasto-plástico de tensões e quantificação do nível de triaxialidade para trincas estacionárias em materiais homogêneos em relação a uma solução de referência

\footnotetext{
${ }^{1}$ Não é foco deste trabalho a abordagem da metodologia $J-T$. Para maiores detalhes ver [17] e [29].
} 
[17]. Assim a integral $J$ mede os campos elasto-plásticos de tensão de alta triaxialidade próximos à trinca enquanto o segundo parâmetro mede o nível de triaxialidade associado à perda de restrição da ponta da trinca.

Neste trabalho será utilizada a abordagem $J-Q$ para uma análise qualitativa das alterações provocadas nos níveis de triaxialidade de um corpo-de-prova com geometria compacta $\mathrm{C}(\mathrm{T})$ devido à presença de uma junta soldada idealizada e a conseqüente introdução de dissimilaridades mecânicas entre metal de solda (MS) e metal base (MB).

\subsection{ABORDAGEM $J-Q$}

O’Dowd e Shih [47] [48], por meio de análises numéricas identificaram conjuntos de campos elasto-plásticos de tensões parametrizáveis, Eq. (27), utilizando outro parâmetro de triaxialidade, mais geral, aplicável em condições de escoamento generalizado (Large Scale Yieding (LSY)) que efetivamente mede os efeitos geométricos do corpo-de-prova, tamanho de trinca e modo de carregamento. Este parâmetro, representado por $Q$, é a diferença escalar de tensões relativas a um campo de elevada triaxialidade dentro de uma região microestruturalmente significativa (cerca de 5 10 CTOD’s em relação a ponta da trinca) [38] e uma solução de referência expressa por

$$
\sigma_{i j}=\sigma_{o} \hat{f} i j\left(\frac{r}{J / \sigma_{0}}, \theta, Q\right)
$$

onde $\sigma_{0}$ representa uma tensão de referência, geralmente a tensão de escoamento, e $Q$ define a diferença entre os campos de tensão de um corpo finito e a solução de referência. As componentes de tensão de cisalhamento do campo diferencial são desprezíveis quando comparadas as componentes normais deste mesmo campo, por isso $Q$ é tratado como parâmetro hidrostático. [29] 
A descrição $J-Q$ dos campos de tensão sob Modo I de carregamento, neste trabalho, deriva da solução MBL (Modified Boundary Layer), ou solução de Camada de Contorno Limite Modificada, similar à Eq. (28) abaixo, representada por uma placa infinita.

$$
\sigma_{i j}=\left(\sigma_{i j}\right)_{R e f}+Q \sigma_{0} \delta_{i j} ; \text { para } \quad r>\frac{\mathrm{J}}{\sigma_{0}}, \quad|\theta| \leq \frac{\pi}{2}
$$

onde $\left(\sigma_{i j}\right)_{\text {Ref }}=\left(\sigma_{i j}\right)_{\mathrm{SSY}}$, representa o campo de tensões de referência com alta restrição plástica, o segundo termo $Q \sigma_{0} \delta_{i j}$ é uma constante hidrostática independente da distância e ângulo em relação a ponta da trinca. Portanto operacionalmente $Q$ é definido como:

$$
Q \equiv \frac{\sigma_{y y}-\left(\sigma_{y y}\right)_{R e f}}{\sigma_{0}} ; \quad r=J * \frac{2}{\sigma_{0}}
$$

onde $\sigma_{y y} \mathrm{e}\left(\sigma_{y y}\right)_{R e f}$ são respectivamente as tensões de abertura da trinca do componente (corpo-de-prova) e as tensões de abertura da trinca da solução de referência avaliadas a uma distância $r$. A distância $r$ mostra pouca influência sobre os valores de $Q$ quando mantida no intervalo $J / \sigma_{0} \leq r \leq 5 * J / \sigma_{0}$ [29].

Neste trabalho, para a avaliação do parâmetro $Q$, serão realizadas análises aplicando o método de elementos finitos em modelos com geometria compacta e malha suficientemente refinada para uma significativa representação da região microestrutural de forma a permitir o cálculo da diferença entre os campos de tensões desenvolvidos na ponta da trinca para os modelos pretendidos, C(T) e para o modelo MBL. Maiores detalhes do procedimento de análise aplicado serão abordados nas próximas seções. 


\subsection{EXTENSÃO DA METODOLOGIA $J-Q$ PARA JUNTAS SOLDADAS}

A extensão da metodologia $J-Q$ para a avaliação de juntas soldadas é realizada de maneira direta, sem alterações significativas sobre a formulação previamente apresentada para materiais homogêneos utilizando a mesma abordagem para a medição diferencial dos campos de tensões. Para incorporar os efeitos de dissimilaridade mecânica, os modelos de elementos finitos foram desenvolvidos de forma a simular o efeito de maior resistência mecânica do metal de solda (condição de "overmatch") para o componente desejado (corpo-de-prova) enquanto para a solução de referência são mantidas as propriedades do metal de base. A Figura 18 representa esquematicamente a avaliação do parâmetro $Q$ para um corpo-de-prova com trinca central ao cordão de solda.

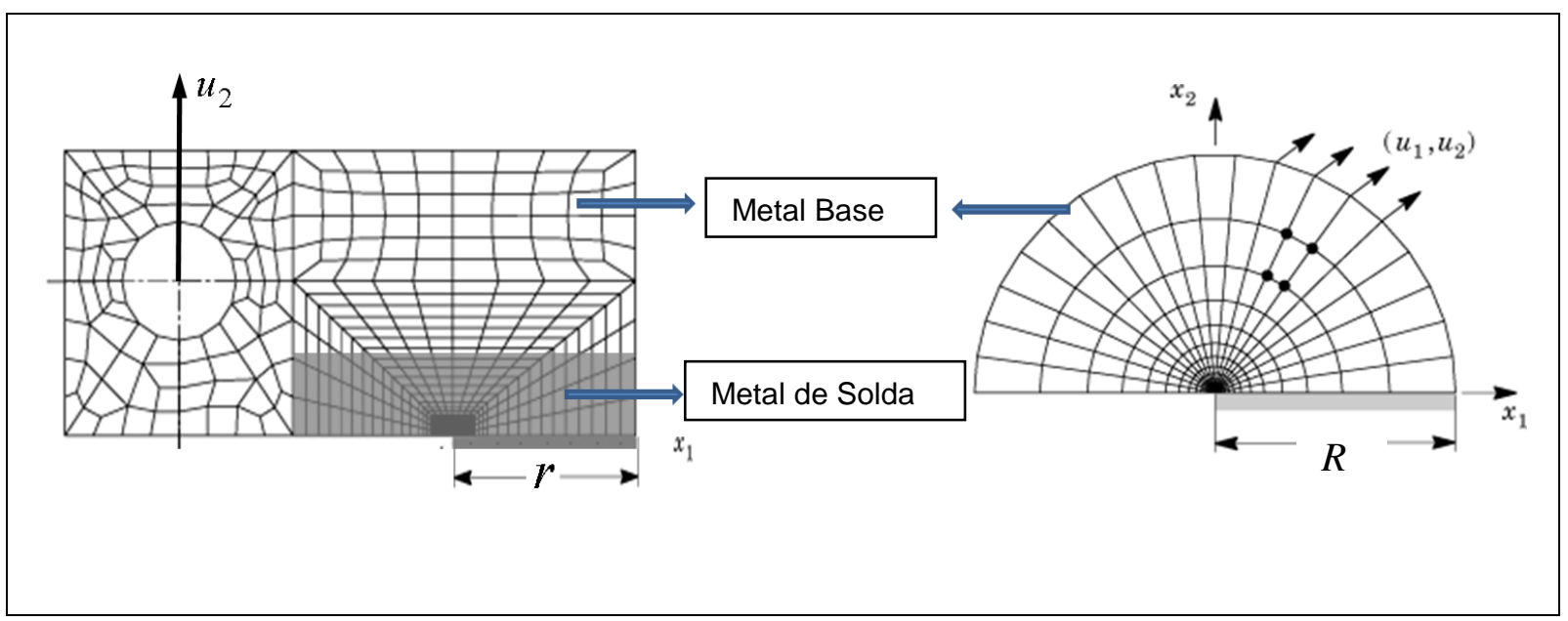

Figura 18 Representação esquemática para a avaliação do parâmetro $Q$ incorporando os efeitos de dissimilaridade mecânica em um componente (corpo-de-prova) soldado

Portanto para capturar o efeito acoplado da dissimilaridade mecânica com os efeitos de geometria sobre a restrição plástica, a expressão anteriormente apresentada para material homogêneo, Eq. (29), será utilizada na forma 


$$
Q \equiv \frac{\sigma_{y y}^{M S}-\left(\sigma_{y y}^{M B}\right)_{R e f}}{\sigma_{0}^{M S}} ; \quad r=J * \frac{2}{\sigma_{0}^{M S}}
$$

onde $\sigma_{y y}^{M S}$ é a tensão de abertura na ponta da trinca desenvolvida no metal de solda, $\left(\sigma_{y y}^{M B}\right)_{R e f}$ é a tensão de abertura desenvolvida na ponta da trinca para uma placa infinita com as propriedades mecânicas do metal base, $\sigma_{0}^{M S}$ é a tensão de referência (tensão de escoamento) do metal de solda e $r$ é a distância onde tais tensões de abertura são avaliadas. 


\section{PROCEDIMENTOS COMPUTACIONAIS}

\subsection{MODELOS GEOMÉTRICOS PARA OS CORPOS-DE- PROVA}

As análises numéricas deste trabalho foram realizadas utilizando-se basicamente duas geometrias de corpos-de-prova, $\mathrm{C}(\mathrm{T})$ e $\mathrm{SE}(\mathrm{B})$, representadas na Figura 19. Estas análises abrangem diversas configurações de tamanho de trinca, largura de cordão de solda e níveis de dissimilaridade mecânica.

(a)
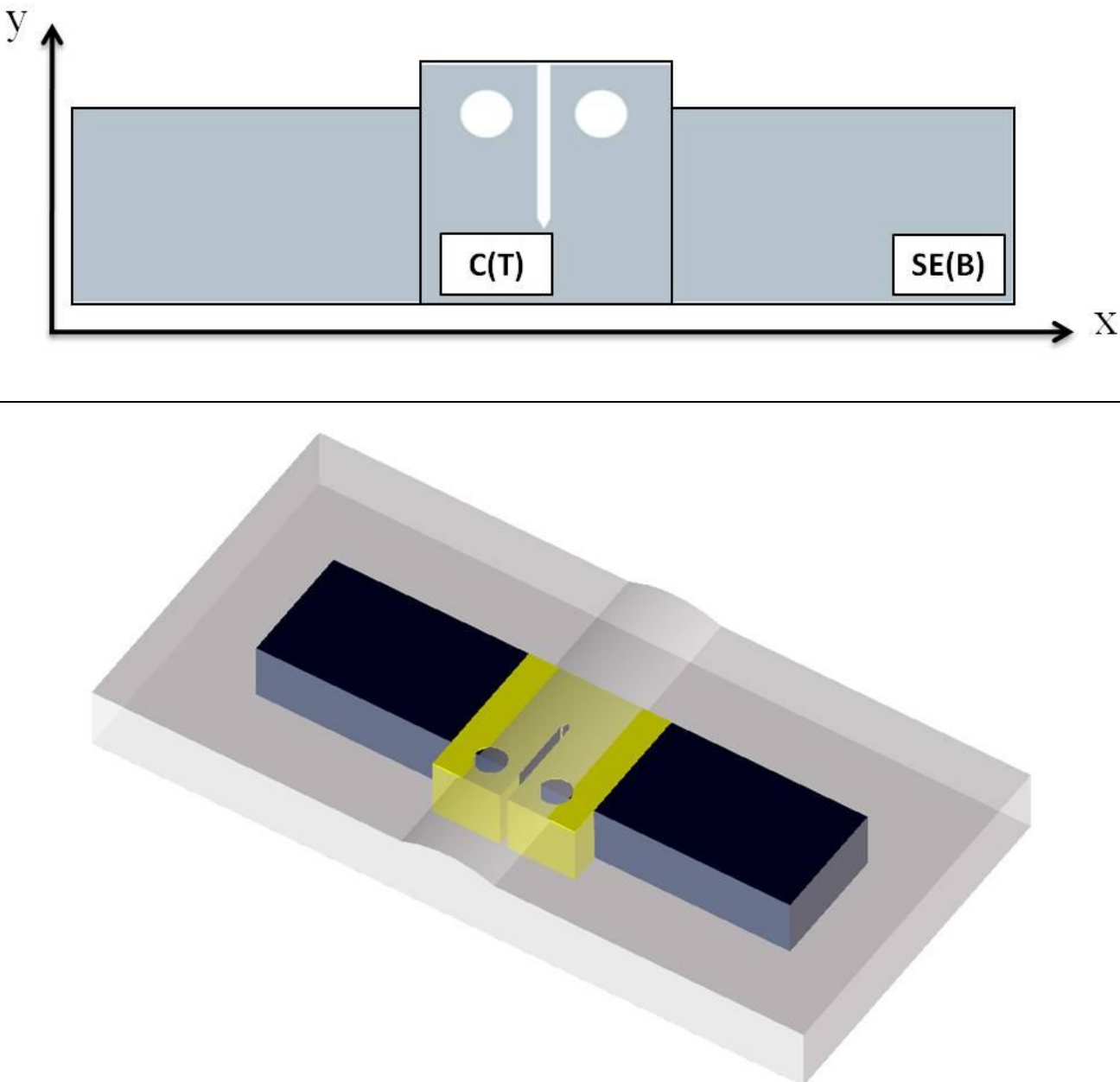

(b)

Figura 19 Representação comparativa em escala das dimensões apresentadas pelos espécimes $C(T)$ e $S E(B)$. (a) Comparativo no plano xy; (b) Extração dos espécimes de uma estrutura genérica. 
A matriz de análise desenvolvida está representada na Tabela 2. Os modelos computacionais dos corpos-de-prova têm as dimensões significativas ilustradas pela Figura 20 (a) e (b). O comprimento de trinca simulado abrange trincas intermediárias e profundas $(a / W=0.45 \sim 0.7)$. A largura do cordão de solda, assim como, o nível de dissimilaridade mecânica foram estipulados com base nas recomendações dos códigos de fabricação e procedimentos de soldagem (por exemplo, AWS D1.1 [49]). Os fatores eta 3D tiveram suas análises estendidas até $M_{y}=1.5$ a fim de investigar possíveis alterações de tendência e uma discussão em maior detalhe será feita na seção 6.4.

Tabela 2 Matriz de Análise e Dimensões dos Corpos-de-Prova C(T) e SE(B).

\begin{tabular}{|c|c|c|c|c|c|c|c|}
\hline & $2 h[\mathrm{~mm}]$ & $\boldsymbol{H}[\mathrm{mm}]$ & $W[\mathrm{~mm}]$ & $a[\mathrm{~mm}]$ & $a / W$ & \multicolumn{2}{|c|}{$M_{y}[\%]$} \\
\hline \multirow{7}{*}{$C(T)$} & $10 ; 15 ; 20$ & 33 & 50.8 & 22.84 & 0.45 & (2D) & (3D) \\
\hline & $10 ; 15 ; 20$ & 33 & 50.8 & 25.39 & 0.50 & 1.0 & 1.0 \\
\hline & $10 ; 15 ; 20$ & 33 & 50.8 & 27.94 & 0.55 & 1.1 & 1.1 \\
\hline & $10 ; 15 ; 20$ & 33 & 50.8 & 30.48 & 0.60 & 1.2 & 1.2 \\
\hline & $10 ; 15 ; 20$ & 33 & 50.8 & 33.02 & 0.65 & 1.3 & 1.3 \\
\hline & $10 ; 15 ; 20$ & 33 & 50.8 & 35.56 & 0.70 & & 1.5 \\
\hline & $2 h[\mathrm{~mm}]$ & $S$ [mm] & $W[\mathrm{~mm}]$ & $a[\mathrm{~mm}]$ & $a / W$ & \multicolumn{2}{|c|}{$M_{y}[\%]$} \\
\hline & & & & & & \multicolumn{2}{|c|}{ (2D) } \\
\hline $\mathrm{SE}(\mathrm{B})$ & 15 & 203.2 & 50.8 & 25.39 & 0.50 & \multicolumn{2}{|c|}{1.0} \\
\hline & & & & & & \multicolumn{2}{|c|}{1.1} \\
\hline & & & & & & \multicolumn{2}{|c|}{1.2} \\
\hline & & & & & & \multicolumn{2}{|c|}{1.3} \\
\hline
\end{tabular}




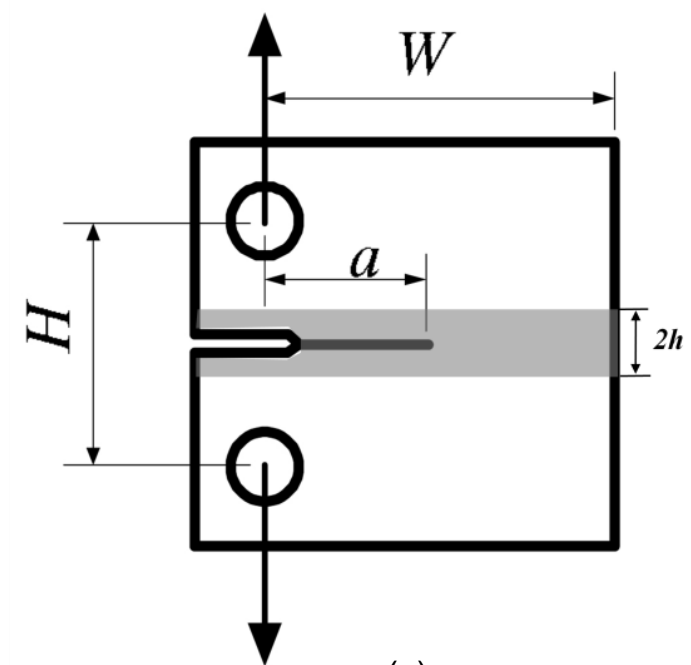

(a)

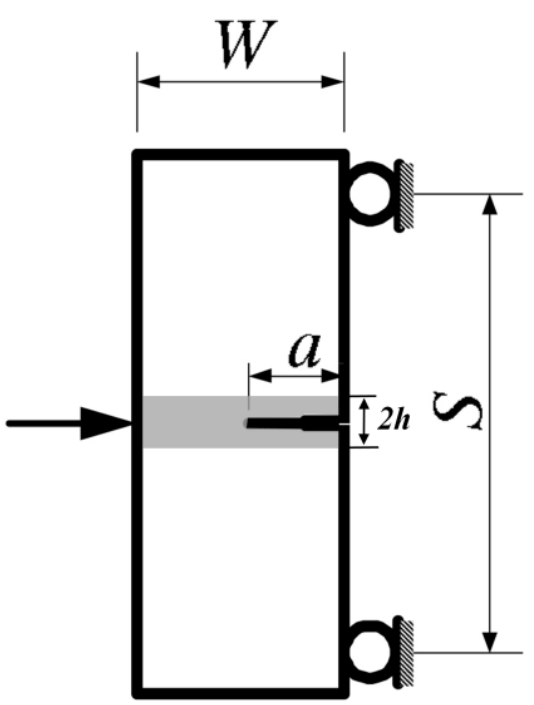

(b)

Figura 20 Representação das dimensões significativas para as geometrias compacta, (a); e flexão 3 pontos, (b).

As simulações computacionais permitiram obter e comparar os níveis de restrição plástica da ponta da trinca desenvolvidos para cada uma das configurações da matriz de análise utilizando-se as curvas $J-Q$, assim como gerar o compêndio de fatores $\eta$ para avaliar os parâmetros $J$ e CTOD. A geração das curvas $J-Q$ e a obtenção dos fatores $\eta$ foram realizadas com o auxílio dos programas FRACTUS 2D [38], WARP3D [50].

\subsection{ANÁLISES PELO MÉTODO DOS ELEMENTOS FINITOS}

As análises computacionais deste trabalho visam simular numericamente os campos de tensões de aços ferríticos em regime elásto-plástico para corpos-deprova com trinca central no cordão de solda. Para modelagem computacional dos corpos-de-prova $\mathrm{C}(\mathrm{T})$ foi utilizado o programa MSC PATRAN [51] como pré e pósprocessador. Devido à simetria dos espécimes, os modelos de elementos finitos foram construídos de forma a representar somente uma metade (caso 2D) e um quarto (caso 3D) do espécime para reduzir o esforço computacional. Nas análises 
submetidas ao estado plano de deformação (2D) foi imposta condição de contorno para restringir o deslocamento na direção $w$ (direção da espessura).

Na modelagem da trinca um pequeno raio $(\rho=0.0025)$ é utilizado para simular o "blunting" ou arredondamento observado em corpos-de-prova reais, como mostrado na Figura 21 (b). Além disto, este raio facilita a convergência das análises numéricas tornando mais rápida a simulação.

A aplicação do carregamento se dá por meio de passos incrementais de deslocamento. O WARP3D [50] permite a simulação de contato que para o caso do corpo-de-prova $\mathrm{C}(\mathrm{T})$ é realizado através de um pino passante pelo furo com centro localizado a uma distância $\mathrm{H} / 2$ do plano de simetria, conforme ilustrado na Figura 21 (a). O ponto de contato, representado por um nó, entre o pino e furo deve permanecer com sua movimentação restrita na direção $u$ durante os primeiros incrementos de deslocamento e depois deve ser liberado. Essa estratégia se faz necessária para evitar o movimento de corpo livre do modelo nos primeiros incrementos de deslocamento e a partir deles permitir a rotação do corpo-de-prova de maneira mais realista.

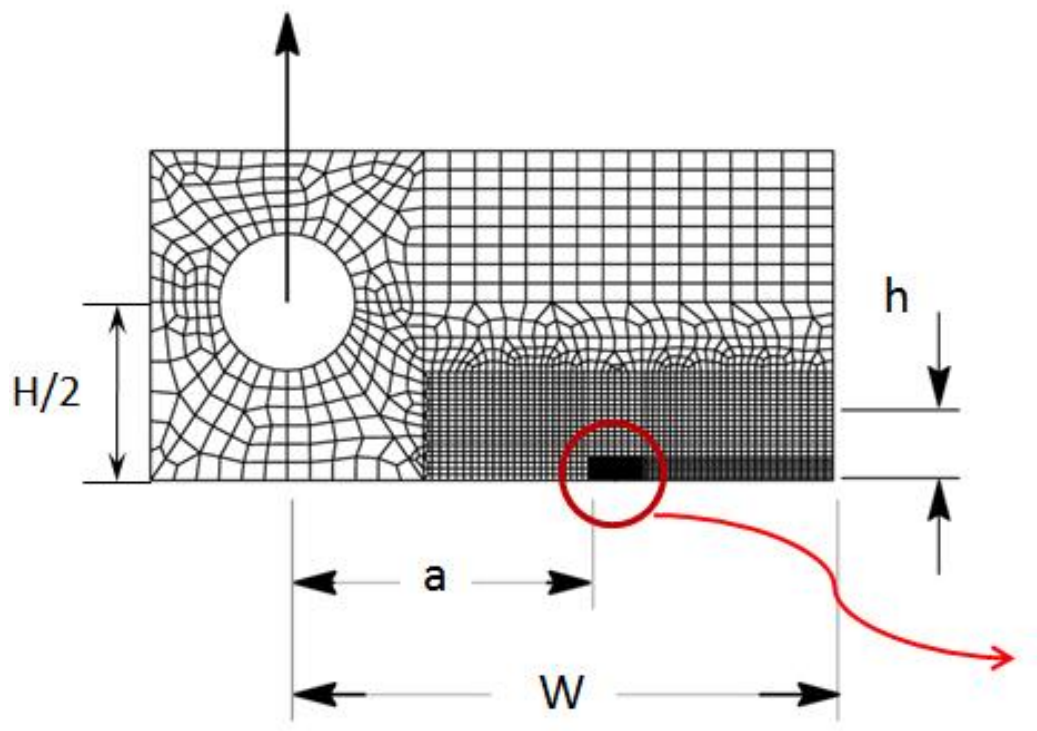

(a)
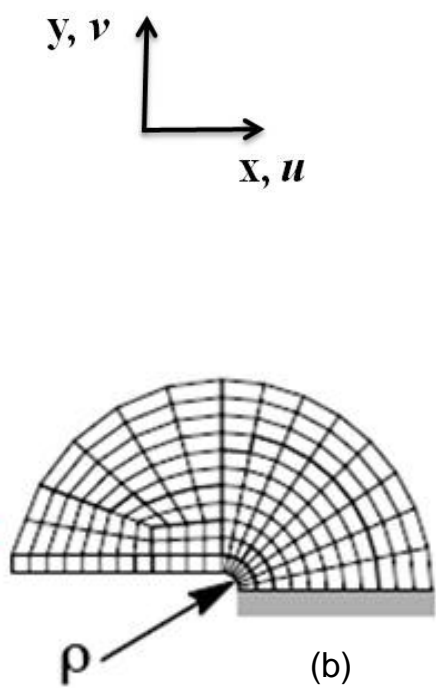

Figura 21. Representação da simetria do corpo $C(T)$ utilizada nos modelos para simulação 2D (a). Representação da ponta da trinca arredondada (b). 
A malha do modelo foi criada de maneira a comportar diferentes larguras de cordão de solda simulando cordões de $10 \mathrm{~mm}, 15 \mathrm{~mm}$ e $20 \mathrm{~mm}$, sem haver necessidade de alteração da mesma para cada uma das simulações. Os modelos simulados em estado plano de deformação, representados pela Figura 21 (a), possuem aproximadamente 5300 nós e 2500 elementos hexaédricos de 8 nós, este número de elementos e nós irá variar de acordo com o tamanho da trinca. Os modelos tridimensionais, representados pela Figura 22, possuem aproximadamente 46000 nós, 41000 elementos hexaédricos de 8 nós distribuídos em 15 camadas ao longo da espessura, podendo também variar de acordo com o tamanho da trinca.

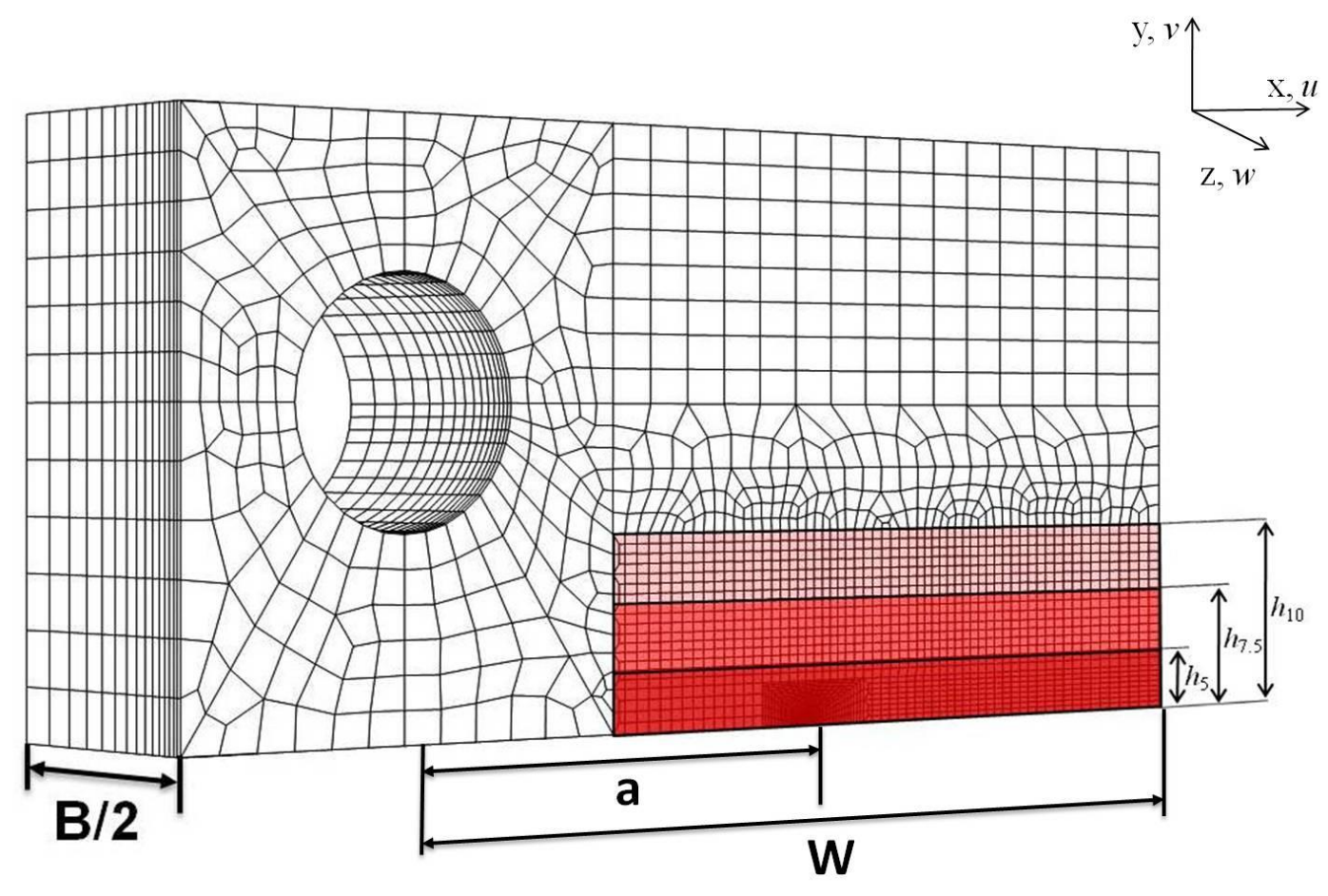

Figura 22 Modelo de elementos finitos tridimensional e representação dos cordões de solda com largura $2 h=10 \mathrm{~mm}, 15 \mathrm{~mm}$ e $20 \mathrm{~mm}$.

As análises foram conduzidas utilizando-se o código WARP3D [50]. Este código foi concebido para modelagens numéricas não-lineares em sólidos 3D com comportamento elasto-plástico e por meio dele a integral $J$ é calculada.

Para o cálculo de $J$ é utilizado o modelo constitutivo de Ramberg-Osgood, adequado para aços ferríticos, denotado pela Eq. 12. As propriedades dos materiais (módulo de elasticidade, coeficiente de Poisson, tensão de escoamento, fator de encruamento) simulados encontram-se na Tabela 3. Aços ferríticos 
apresentam uma diminuição no encruamento com o aumento da tensão de escoamento, lembrando que quanto maior for o valor do expoente de encruamento, $n$, menor é o encruamento do material, conforme mostrado na Figura 23. Os valores do expoente de encruamento foram obtidos por interpolação simples a partir dos valores representativos de uma ampla gama de materiais estruturais: $n=5\left(\mathrm{E} / \sigma_{\mathrm{ys}}=800\right) ; n=10\left(\mathrm{E} / \sigma_{\mathrm{ys}}=500\right)$ e $n=20\left(\mathrm{E} / \sigma_{\mathrm{ys}}=300\right)$.

Tabela 3 Propriedade dos Materiais Ensaiados

\begin{tabular}{cccc}
$\begin{array}{c}\text { Módulo de Elasticidade } \\
\text { [GPa] }\end{array}$ & $\boldsymbol{v}$ & $\boldsymbol{\sigma}_{\boldsymbol{y s}}[\mathrm{MPa}]$ & $\begin{array}{c}\text { Expoente } \\
\text { de Encruamento }(\boldsymbol{n})\end{array}$ \\
\hline \multirow{2}{*}{206} & & 412 & 10 \\
& \multirow{2}{*}{0.3} & 453 & 11.4 \\
& & 494 & 12.8 \\
& 536 & 14.2 \\
& 618 & 17.4 \\
\hline
\end{tabular}

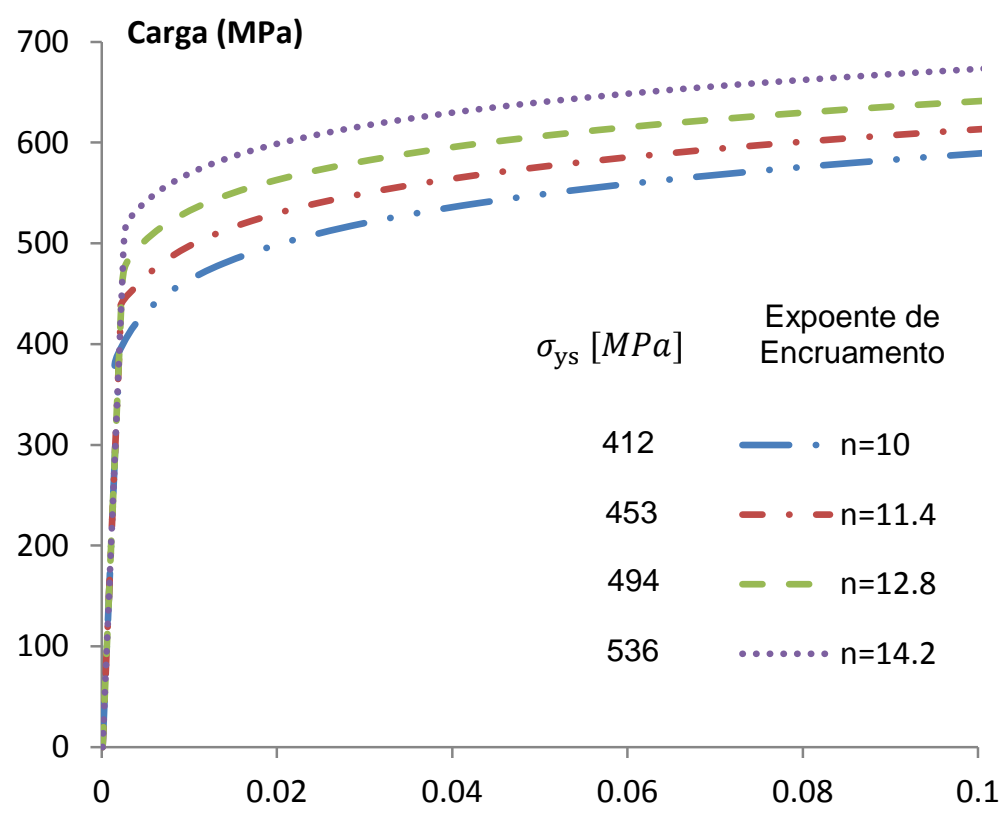

Figura 23 Gráfico de tensão vs. deformação de aços ferríticos com diferentes valores de encruamento e tensão de escoamento.

A medição da triaxialidade na ponta da trinca pelo cálculo do parâmetro $Q$ e 0 cálculo dos fatores $\eta$ relativos aos modelos ensaiados foram realizados com auxílio 
do programa Fractus 2D [38] e serão descritos com maiores detalhes nas seções 5.3 e 5.4 .

\subsection{TRAJETÓRIAS $J-Q$}

Para a obtenção de trajetórias $J-Q$ as Eq. (29) e (30) são resolvidas ponto a ponto computacionalmente calculando-se a diferença de tensões sob Modo I de carregamento a uma distância fixa da ponta da trinca, $r=J * 2 / \sigma_{0}$, entre 0 componente estrutural, neste trabalho representado por corpo-de-prova compacto e a solução de referência representada por uma placa infinita contendo uma trinca, representados pela Figura 24 (a) e (b) respectivamente.

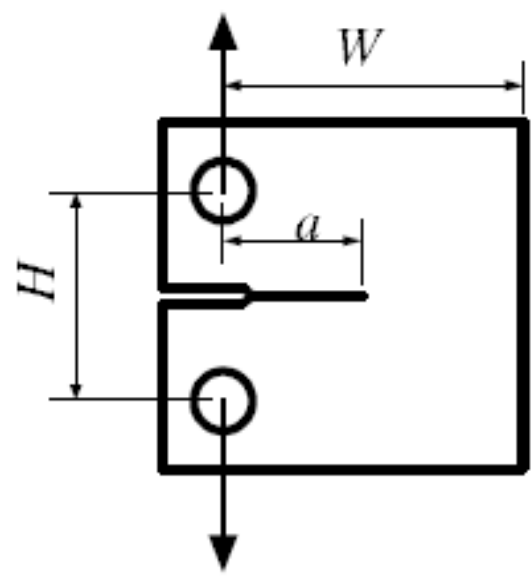

(a)

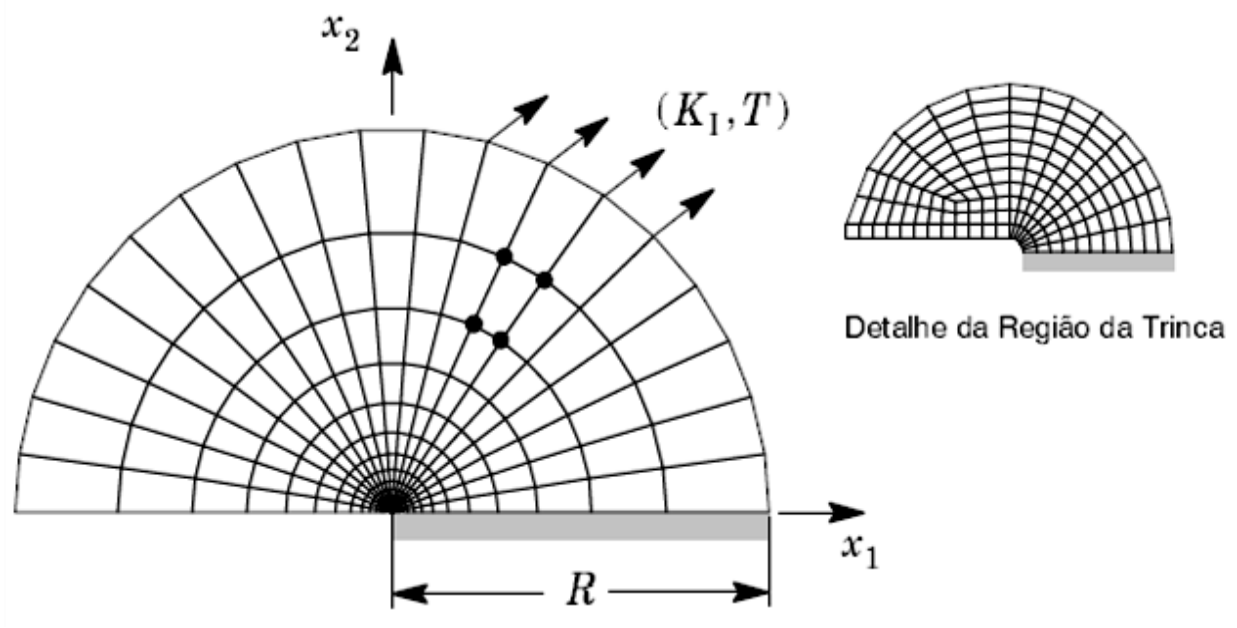

(b)

Figura 24 Representação de um corpo-de-prova com geometria compacta, $\mathrm{C}(\mathrm{T})$, (a) solicitado sob Modo I de carregamento. (b) Representação do modelo MBL. 
O gráfico da Figura 25 representa a diferença entre os campos de tensão, $Q * \sigma_{0}$, onde é plotada tensão de abertura adimensionalizada pela tensão de escoamento $\left(\sigma_{y y} / \sigma_{0}\right)$ do material vs. distância adimensional em relação à ponta da trinca $\left.\left(r / J / \sigma_{0}\right)\right)$. A linha tracejada representa a solução de referência e as linhas cheias referem-se ao componente estrutural objeto de estudo com diferentes níveis de carregamento $(J)$.

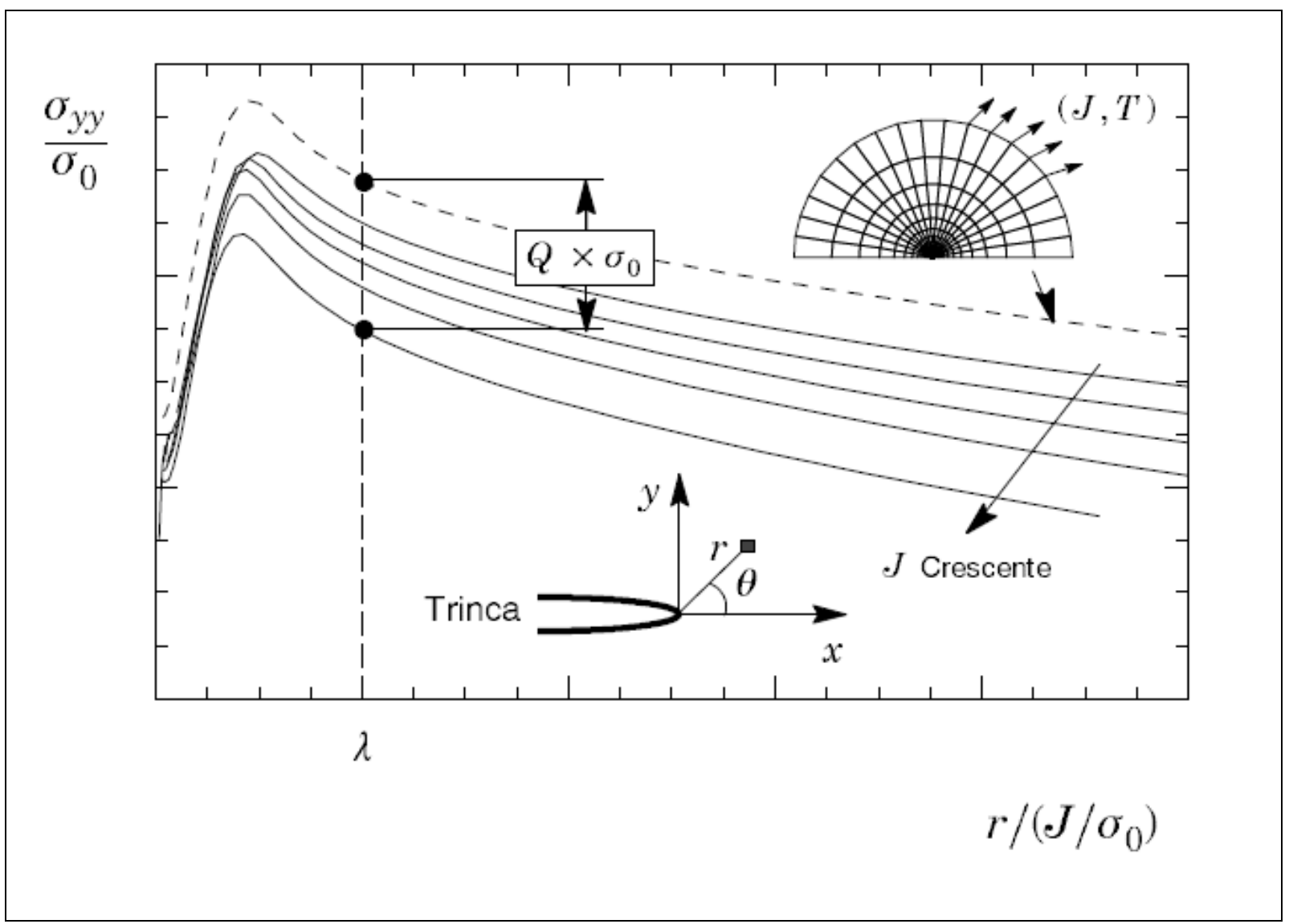

Figura 25 Representação da tensão de abertura adimensional vs. distância adimensional para a solução de referência MBL e um componente estrutural genérico [38].

Obtidos os valores de $Q$ na sequência são construídas as trajetórias $J-Q$, conforme ilustra o gráfico da Figura 26. Note como as trajetórias para as diversas geometrias são diferentes mostrando a forte influência da mesma na restrição plástica à frente da trinca. 


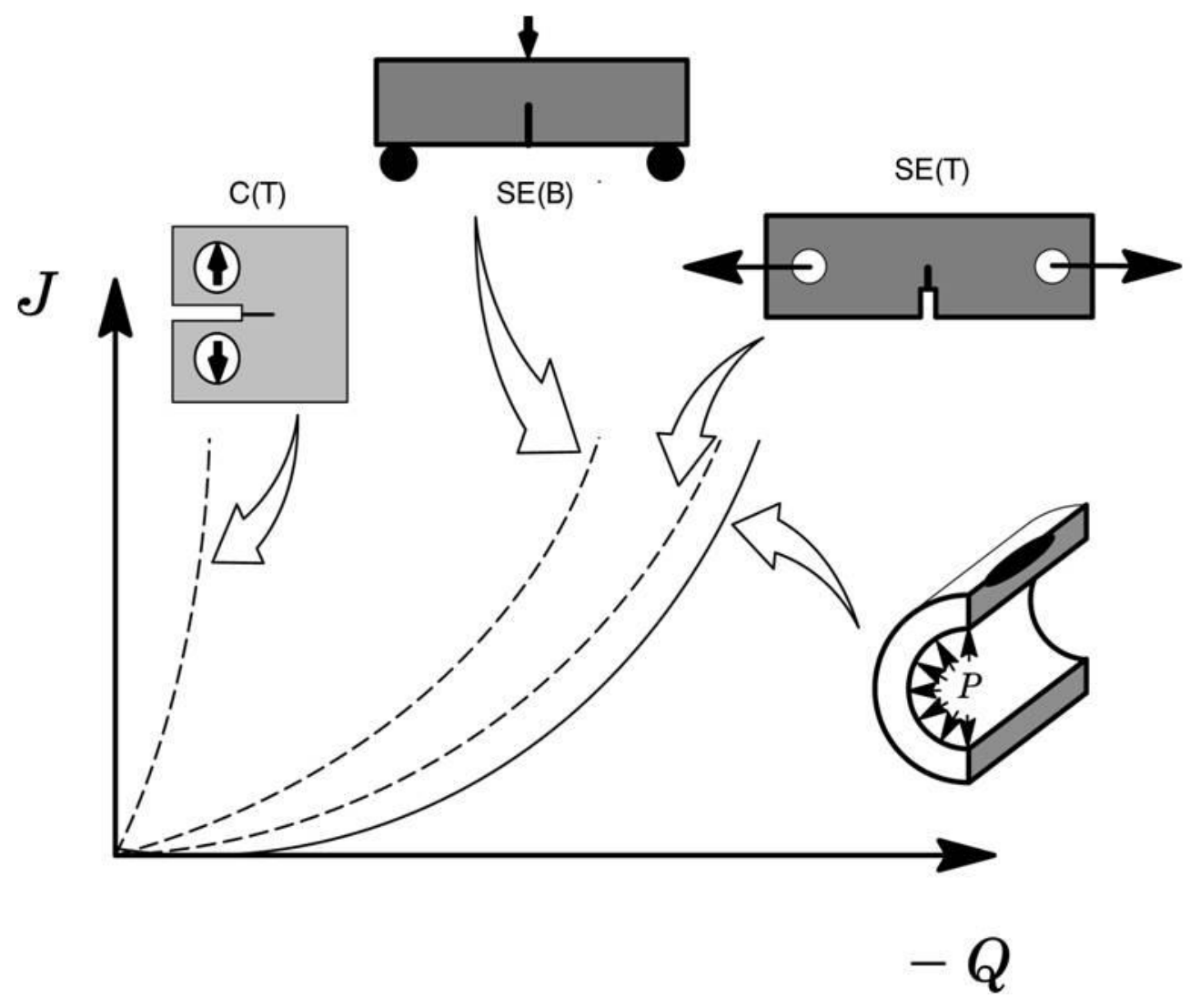

Figura 26 Influência da geometria do corpo-de-prova na trajetória $J$-Q para espécimes $C(T)$, $S E(B)$ $\mathrm{SE}(\mathrm{T})$ e duto [29].

\subsection{EXTRAÇÃO DE FATORES ETA}

A obtenção computacional de fatores $\eta$ neste trabalho segue a interpretação da integral $J$ como um parâmetro energético que mede taxa de liberação de energia de um sólido contendo uma trinca e pode ser correlacionado com a área sob a curva do gráfico de carga $v s$. deslocamento ( $\triangle$ ou CMOD).

Tal curva é gerada por uma análise de elementos finitos simulando a geometria compacta, $\mathrm{C}(\mathrm{T})$, do corpo-de-prova que sofre passos incrementais de carregamentos. Este carregamento discreto produz deslocamentos discretos da linha de carga (ou CMOD) e o gráfico de carga (P) vs. LLD (CMOD) é gerado conforme o gráfico da Figura 27. 


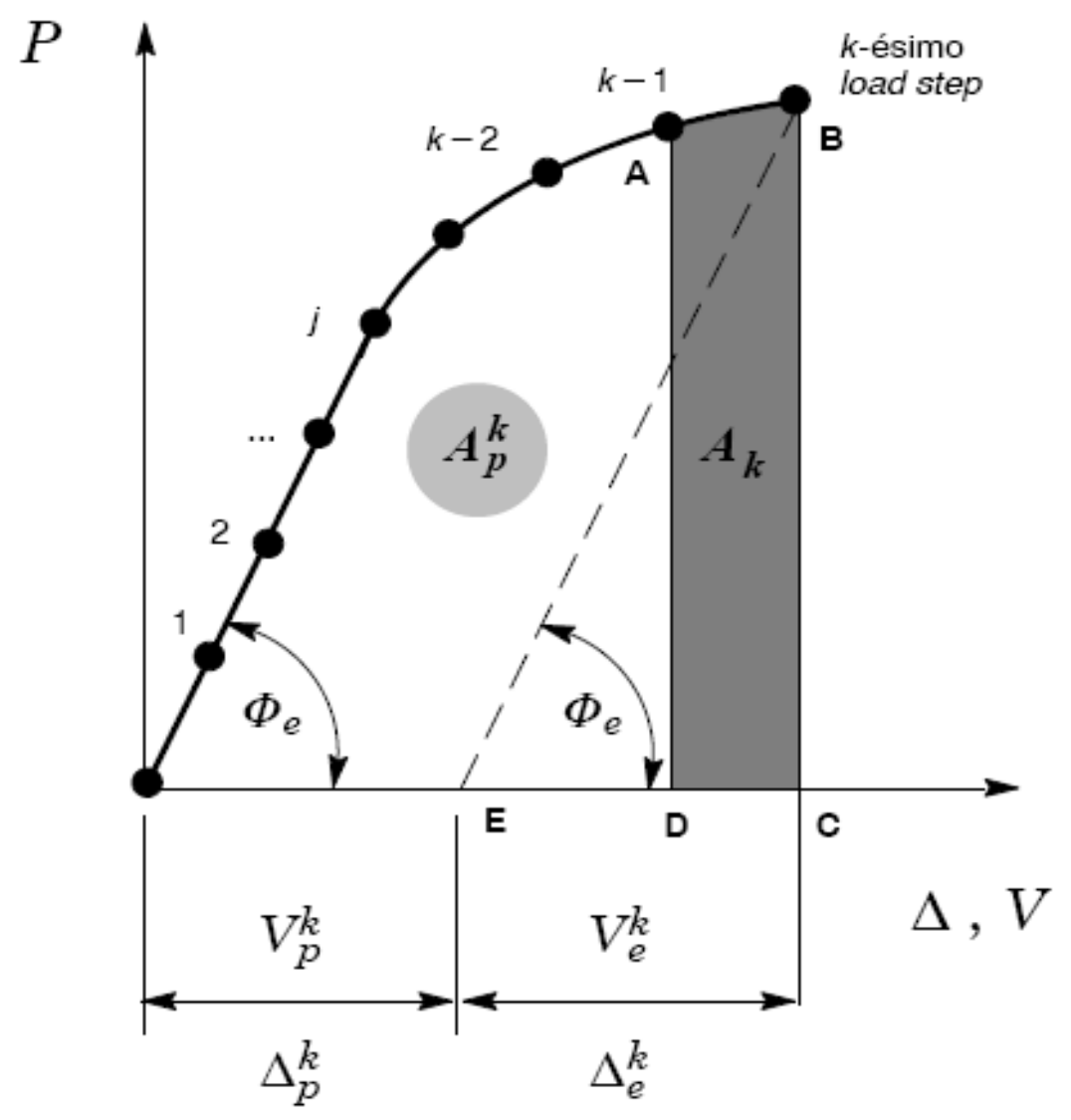

Figura 27 Representação da curva de carga vs. deslocamento (LLD, CMOD) obtida computacionalmente para incrementos discretos de carga [38].

A partir deste gráfico é possível avaliar a área total, assim como, suas componentes elástica e plástica necessárias ao cálculo de $\eta$.

Este procedimento é realizado em quatro passos descritos a seguir:

Primeiro: Determinar a parcela elástica. Esta parcela será definida da regressão linear feita ponto a ponto a partir dos resultados numéricos definindo-se a diferença do ângulo $\Phi_{\mathrm{e}}$ entre pontos seqüentes conforme a Eq.(31):

$$
\Phi_{e ; k}-\Phi_{\mathrm{e} ; \mathrm{k}-1} \leq \Delta
$$

onde $\Delta$ é o critério de parada para a definição do ângulo $\Phi_{\mathrm{e}}$, uma vez que tal diferença é atingida defini-se o triângulo ECB e calcula-se a área por ele determinada. 
Segundo: Determinação da área total. Para o cálculo da área total sob a curva é utilizada a Regra de Simpson [38] definida por

$$
A_{k}=\frac{(b-a)}{6}\left[f(a)+4 f\left(\frac{a+b}{2}\right)+f(b)\right]
$$

onde $A_{k}$ é a área definida pelo quadrilátero $\mathbf{A B C D}$ da Figura 27. Portanto a área total será o somatório de todas as parcelas de $A_{k}$.

$$
A_{T}=\Sigma A_{k}
$$

Terceiro: De posse das áreas total e elástica, faz-se a diferença entre ambas para se obter a parcela plástica da área.

Quarto: Resolução da Eq. (34) para definição do $\eta_{P l}$ para o $k$ - ésimo passo de carga.

$$
\eta_{P l}^{k}=\frac{J_{P l}^{k} B b}{A_{P l}^{k}}
$$




\section{RESULTADOS}

Este capítulo apresenta os resultados essenciais referentes à utilização de espécimes compactos $\mathrm{C}(\mathrm{T})$ em procedimentos de avaliação de tenacidade em juntas soldadas. Inicialmente, o efeito da dissimilaridade mecânica ("weld strength overmatch"), sobre o nível de restrição plástica, será descrito em termos de trajetórias $J-Q$ para os espécimes e configurações analisados. A seguir, os fatores $\eta$ serão apresentados para diferentes relações de $a / W$, níveis de dissimilaridade mecânica $\left(M_{y}\right)$ e largura de cordão de solda $(2 h)$ nas condição de estado planos de tensões (2D) e condição tridimensional. No caso tridimensional as análises contemplam as dimensões $1 \mathrm{~T}(W=25.4 \mathrm{~mm})$ e $0.5 \mathrm{~T}(W=12.7 \mathrm{~mm})$ no intuito de avaliar, também, o efeito de espessura e consequente efeito de triaxialidade sob os valores de fator $\eta$.

O fator $m$, conhecido na literatura por fator de restrição plástica, foi avaliado sob diferentes condições de dissimilaridade mecânica para todo o intervalo de comprimentos de trinca $(0.45 \leq a / W \leq 0.7)$. A precisa correlação entre $J$ e CTOD pode ser afetada por este parâmetro e é por meio dele que os valores de $J$ da norma ASTM 1290 são transformados em valores de CTOD permitindo a comparação com os valores obtidos pela norma BS 7448. A seção sobre fatores $m$ é encerrada com um comparativo entre fatores $m$ obtidos pela aplicação de diferentes formulações analíticas na estimação do limite de resistência do material. O capítulo termina com a apresentação dos comparativos entre os valores de CTOD $(\delta)$ calculados pelas normas ASTM 1290 e BS 7448 e os obtidos numericamente. 


\subsection{EFEITO DA DISSIMILARIDADE MECÂNICA NA TRAJETÓRIA $J$ - $Q$ DE ESPÉCIMES C(T)}

O parâmetro $Q$ é responsável por medir comparativamente o nível de triaxialidade de tensões na região à frente da ponta da trinca, para uma distância adimensional $r /\left(J \sigma_{0}\right)=2$. Quanto maior for o valor de $Q$ maior será o nível de restrição plástica na ponta da trinca, o que significa menor relaxamento de tensões e aumento nas chances do material falhar por clivagem.

Inicialmente, foi realizado um estudo exploratório para avaliar o desenvolvimento dos níveis de triaxialidade nos espécimes com geometria compacta tendo como comparação resultados, consolidados, obtidos para a geometria SE(B) [4]. Para um mesmo comprimento de trinca e largura de cordão de solda $(2 h=15 \mathrm{~mm})$ o espécime $\mathrm{C}(\mathrm{T})$ apresentou níveis de restrição plástica maiores aos do espécime SE(B), porém o mais importante a se destacar é que a variação desta restrição plástica com o aumento dos níveis de dissimilaridade mecânica foi similar aos dois espécimes.

Conforme representado pela Figura 28, o aumento no nível de dissimilaridade mecânica aumentou o nível de restrição plástica provocando o deslocamento das curvas para a esquerda. Esse deslocamento é semelhante para ambas as geometrias de corpo-de-prova, conferindo, portanto, um comportamento análogo entre elas. Este resultado é um forte suporte para o uso de espécimes compactos em alternativa aos espécimes $\mathrm{SE}(\mathrm{B})$ na avaliação de parâmetros de tenacidade à fratura na presença de dissimilaridade mecânica. 

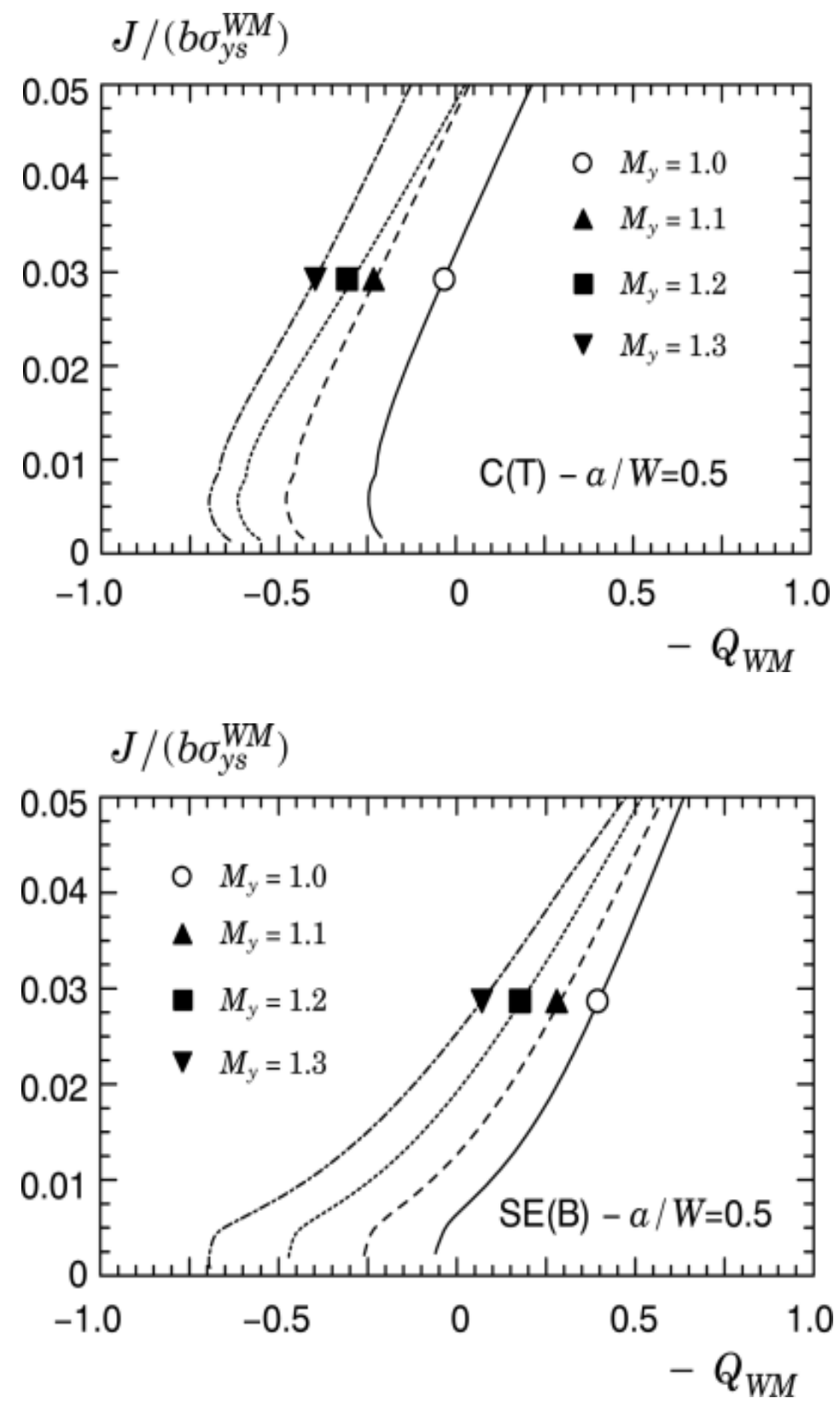

Figura 28 Influência da geometria do corpo-de-prova e da dissimilaridade mecânica do material na trajetória $J-Q$ para espécimes $\mathrm{SE}(\mathrm{B})$ e $\mathrm{C}(\mathrm{T})$ com mesmo comprimento de trinca adimensional $(a / W)$. [4] 
Os gráficos das Figuras 29 - 34 representam as trajetórias $J-Q$ para cada uma das configurações da matriz de análise da Tabela 2. Para cada comprimento de trinca e largura cordão de solda foi variado o nível de dissimilaridade mecânica entre o metal de base e o metal de solda aumentando-se gradativamente a resistência do segundo ("weld strength overmatch") tendo como referência para comparação a curva da condição homogênea $\left(M_{y}=1.0\right)$.

Os gráficos estão com o eixo ordenado adimensionalizado, $\left(J / \sigma_{0} b\right)$, onde $\sigma_{0}$ é a tensão de escoamento do metal onde se encontra a trinca, $b$ é o ligamento remanescente do espécime e o parâmetro $Q$ está plotado com o sinal invertido [- $Q$ ] de forma a manter a escala positiva. As curvas $J-Q$ são bastante sensíveis à geometria do espécime ensaiado e apresentaram um aumento significativo no nível de restrição plástica com 0 aumento do nível de dissimilaridade mecânica. A variação da largura do cordão de solda também gerou alteração nos níveis de triaxialidade principalmente para os casos de trincas mais rasas, $a / W \leq 0.5$. Entretanto, a largura de cordão tem uma influência muito menos pronunciada quando comparada ao efeito provocado pela dissimilaridade mecânica

Para valores de $a / W>0.5$ as curvas $J-Q$ não mais apresentam influências marcantes devido à variação do comprimento de trinca e largura do cordão de solda. Isto mostra que os níveis de restrição plástica desenvolvidos no corpo-de-prova compacto tendem a ser estáveis para uma faixa bastante grande de configurações da matriz de análise e confere robustez aos resultados obtidos. 


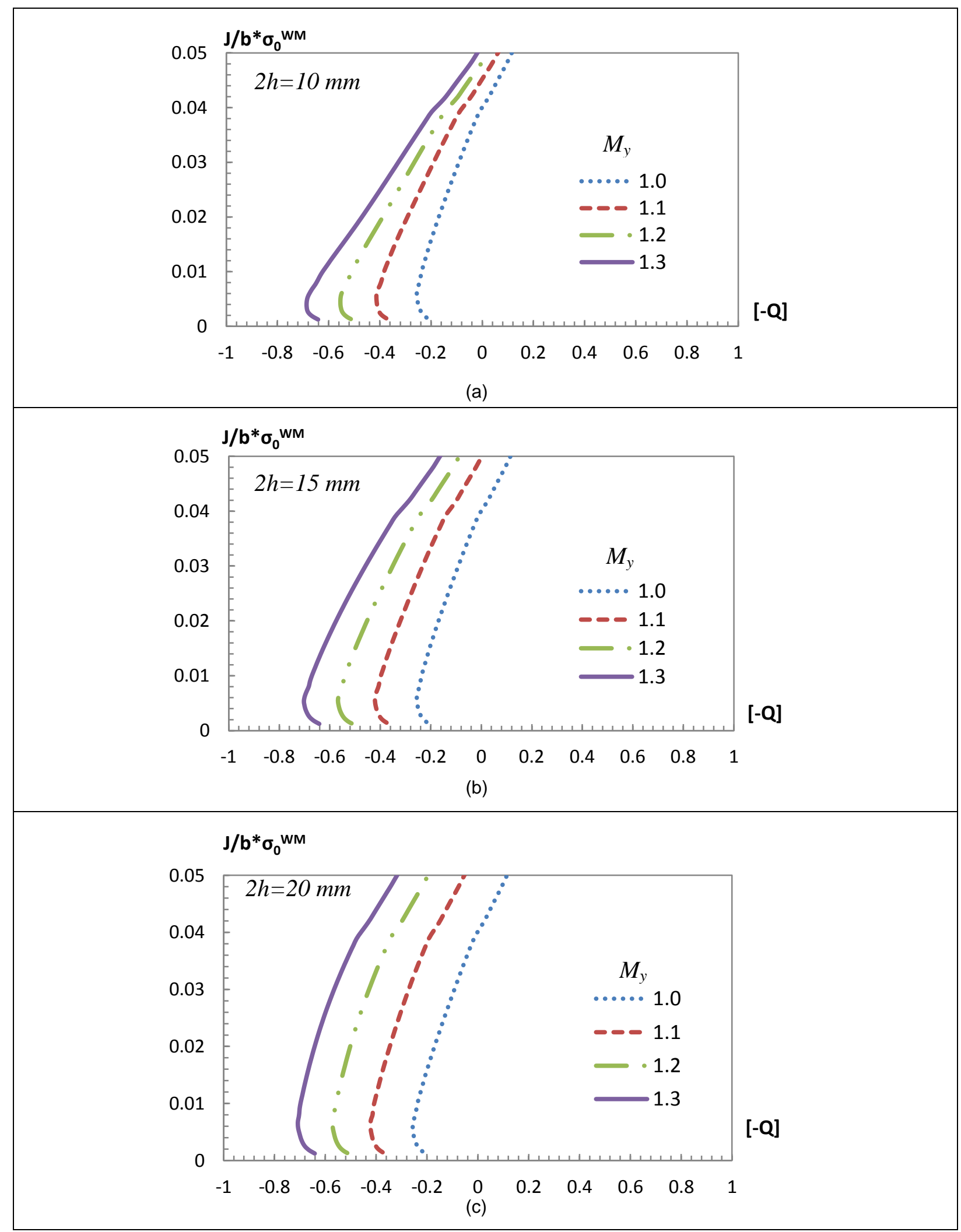

Figura 29 Trajetória $J$ - $Q$ para diferentes níveis de dissimilaridade mecânica. $\mathbf{a} / \mathbf{W}=\mathbf{0 . 4 5}$. (a) cordão de solda com largura $2 \mathrm{~h}=10 \mathrm{~mm}$; (b) cordão de solda com largura $2 \mathrm{~h}=15 \mathrm{~mm}$;(c) cordão de solda com largura $2 h=20 \mathrm{~mm}$. 


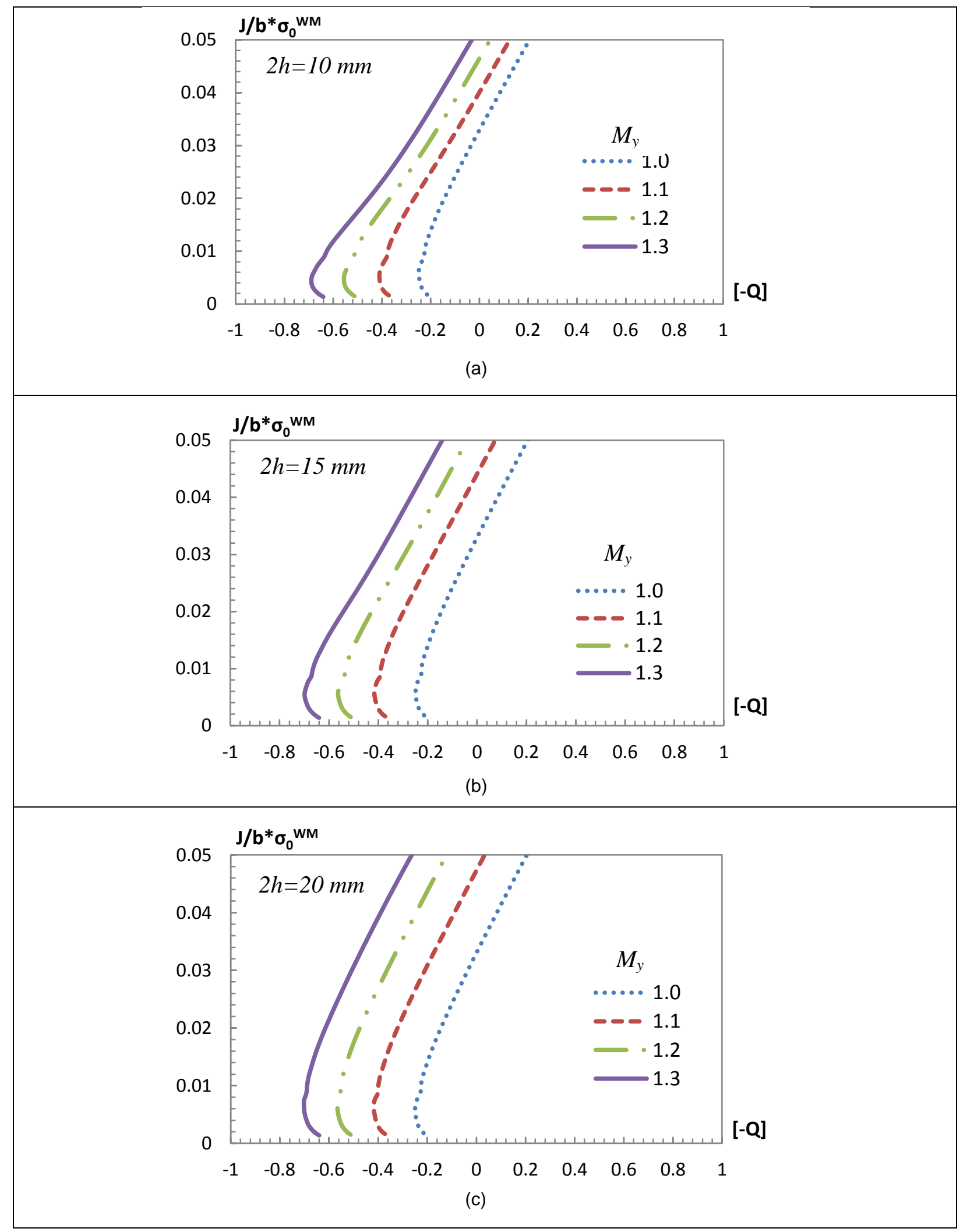

Figura 30 Trajetória $J-Q$ para diferentes níveis de dissimilaridade mecânica. $\mathbf{a} / \mathbf{W}=\mathbf{0 . 5}$. (a) cordão de solda com largura $2 h=10 \mathrm{~mm}$; (b) cordão de solda com largura $2 h=15 \mathrm{~mm}$;(c) cordão de solda com largura $2 h=20 \mathrm{~mm}$. 


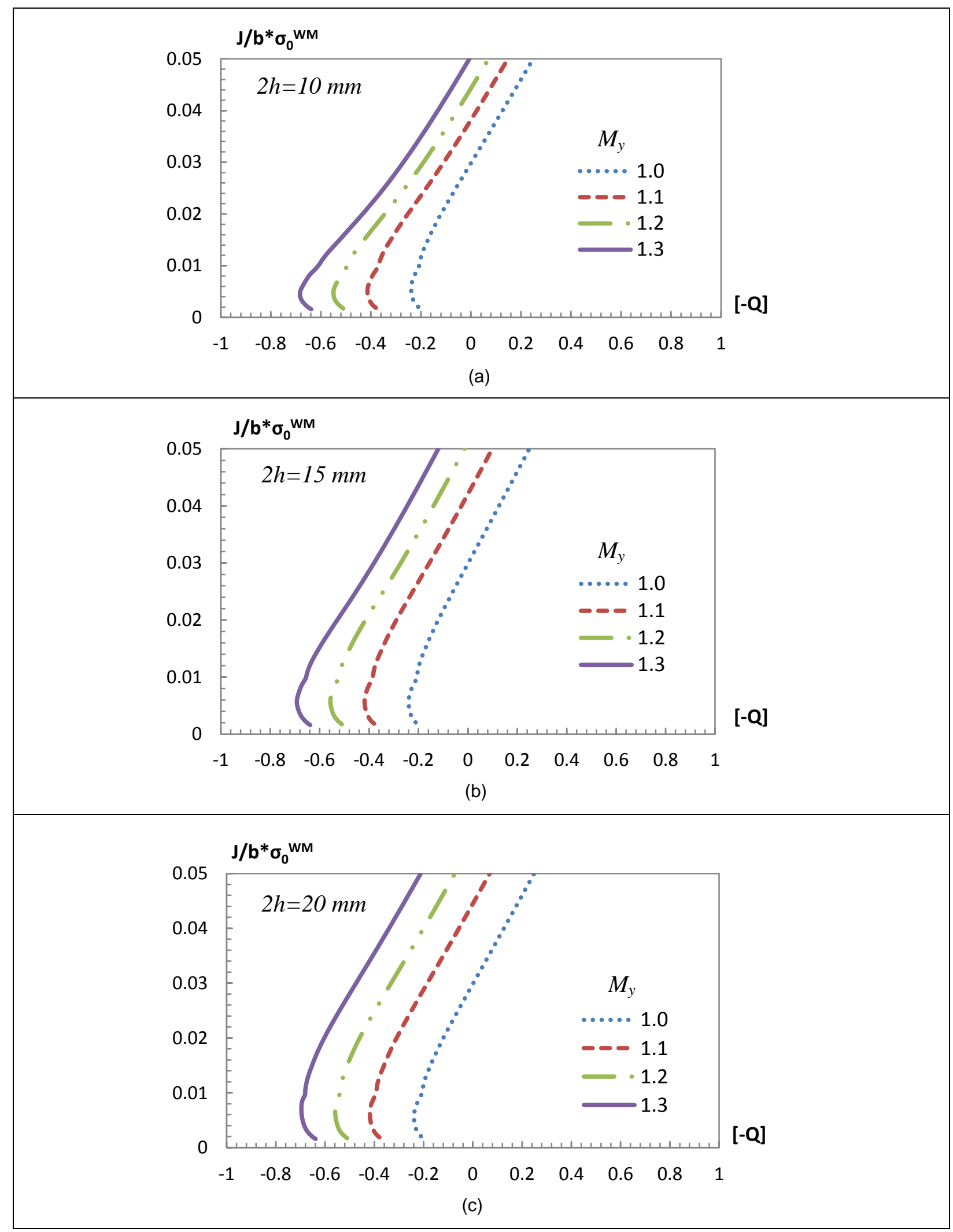

Figura 31 Trajetória $J-Q$ para diferentes níveis de dissimilaridade mecânica. a/W=0.55. (a) cordão de solda com largura $2 h=10 \mathrm{~mm}$; (b) cordão de solda com largura $2 h=15 \mathrm{~mm}$;(c) cordão de solda com largura $2 h=20 \mathrm{~mm}$. 


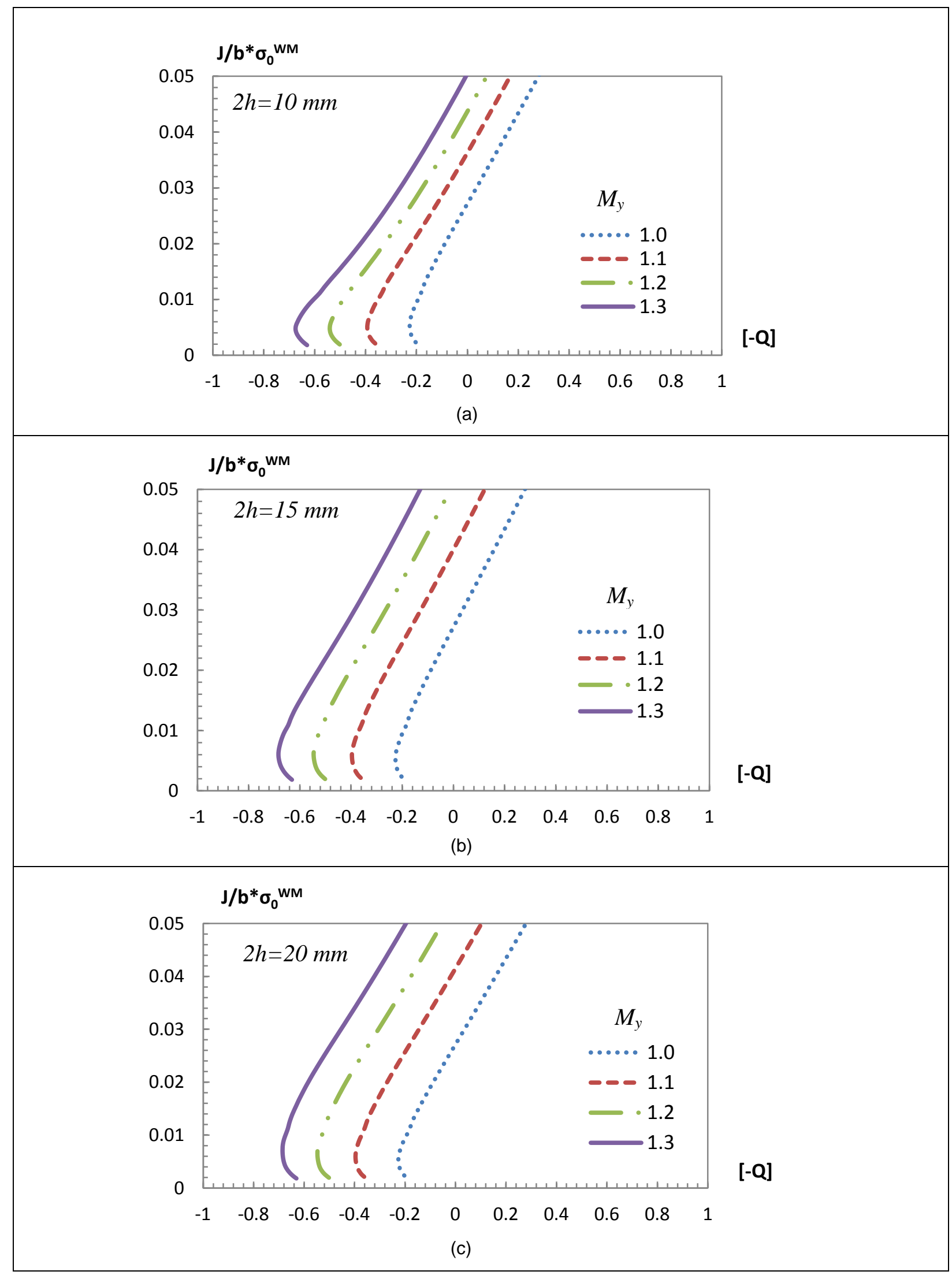

Figura 32 Trajetória $J-Q$ para diferentes níveis de dissimilaridade mecânica. a/W=0.6. (a) cordão de solda com largura $2 h=10 \mathrm{~mm}$; (b) cordão de solda com largura $2 \mathrm{~h}=15 \mathrm{~mm}$;(c) cordão de solda com largura $2 h=20 \mathrm{~mm}$. 


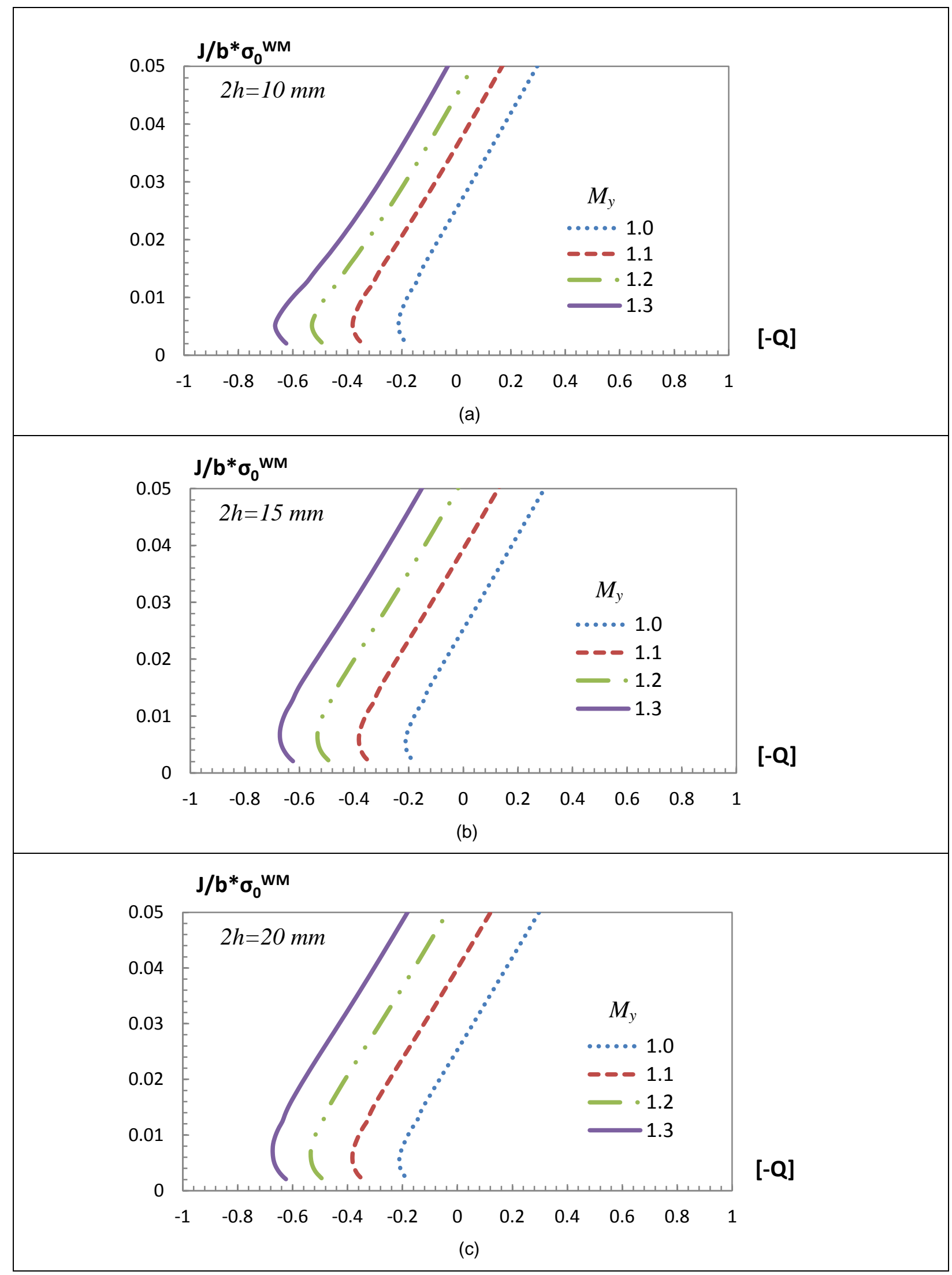

Figura 33 Trajetória $J-Q$ para diferentes níveis de dissimilaridade mecânica. $\mathbf{a} / \mathbf{W}=\mathbf{0 . 6 5}$. (a) cordão de solda com largura $2 h=10 \mathrm{~mm}$; (b) cordão de solda com largura $2 h=15 \mathrm{~mm}$;(c) cordão de solda com largura $2 h=20 \mathrm{~mm}$. 


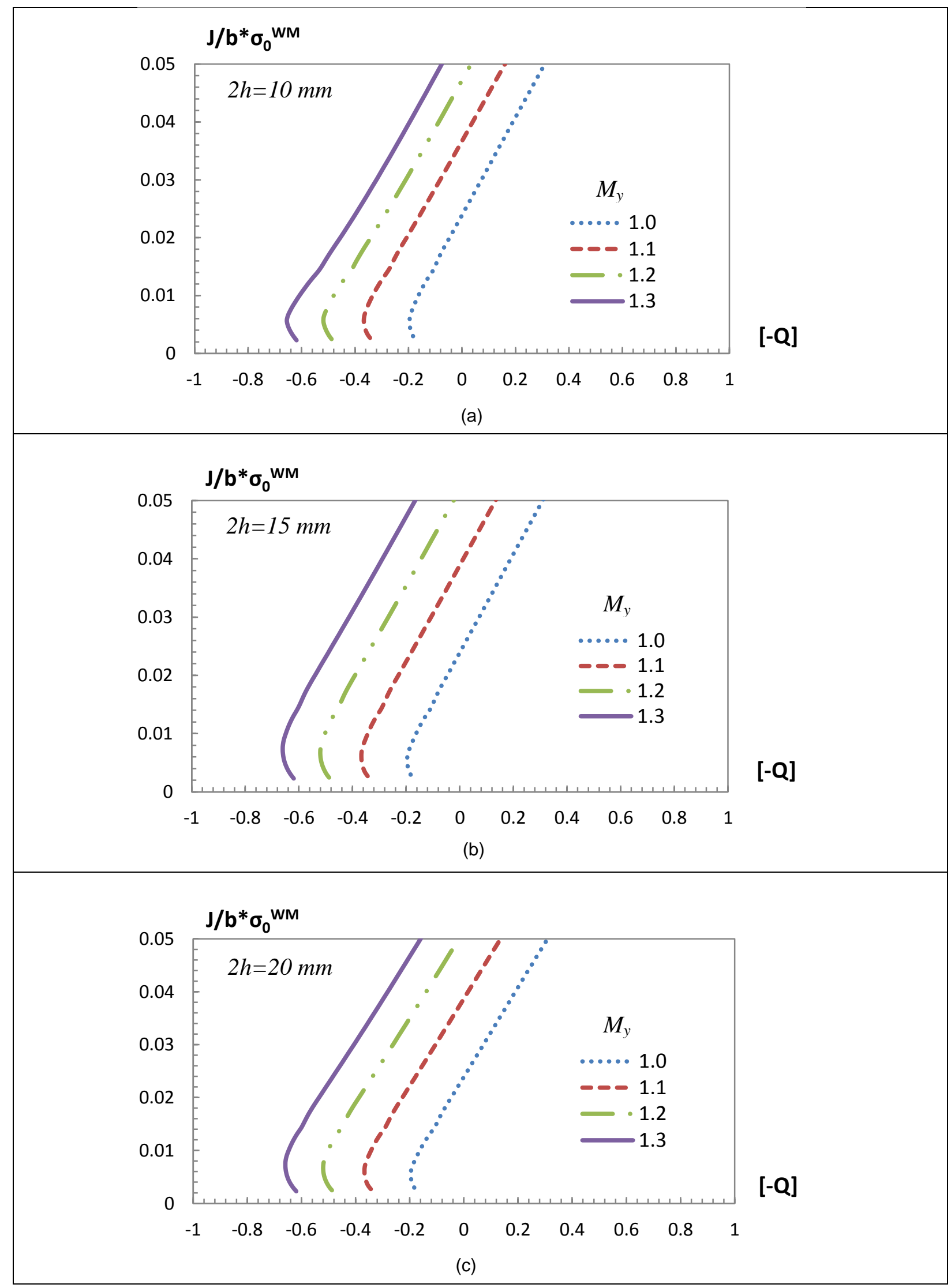

Figura 34 Trajetória $J-Q$ para diferentes níveis de dissimilaridade mecânica. a/W=0.7. (a) cordão de solda com largura $2 h=10 \mathrm{~mm}$; (b) cordão de solda com largura $2 h=15 \mathrm{~mm}$;(c) cordão de solda com largura $2 h=20 \mathrm{~mm}$. 


\subsection{FATORES $\eta$ PLÁSTICOS}

Nesta seção serão apresentados os resultados obtidos para o parâmetro adimensional, $\eta$, que correlaciona a área plástica sob a curva de carga $v s$. deslocamento com energia de deformação, $J$, para um corpo-de-prova com trinca passante. As subseções conterão resultados para diversas configurações de análise proporcionando um vasto compêndio deste fator.

Inicialmente serão apresentados os valores para a condição homogênea em estado plano de deformação e a comparação com os valores de $\eta$ obtidos por meio de normas (ASTM 1290 e ASTM 1820). Na sequência, serão analisadas as influências da dissimilaridade mecânica e da largura do cordão de solda sobre os fatores $\eta$. Finalmente, a seção se encerra com a apresentação dos fatores $\eta$ para a condição tridimensional, explorando os efeitos de largura e dimensional com as geometrias $1 \mathrm{~T}$ e $0.5 \mathrm{~T}$.

\subsubsection{ESPÉCIMES HOMOGÊNEOS}

No processo de extração dos fatores $\eta$ a curva de carga vs. deslocamento é requerida e a medição do deslocamento pode ser feita em dois pontos, no CMOD $(V)$ ou no LLD $(\Delta)$, conforme representado pela Figura 35. As normas de ensaio da ASTM que fazem uso de metodologia $\eta$ para a obtenção de parâmetros de tenacidade à fratura contemplam estes mesmos pontos para a medição do deslocamento. Especificamente para o espécime $\mathrm{C}(\mathrm{T})$, as normas colocam os dois pontos como coincidentes e localizados no ponto de deslocamento da linha de carga. 

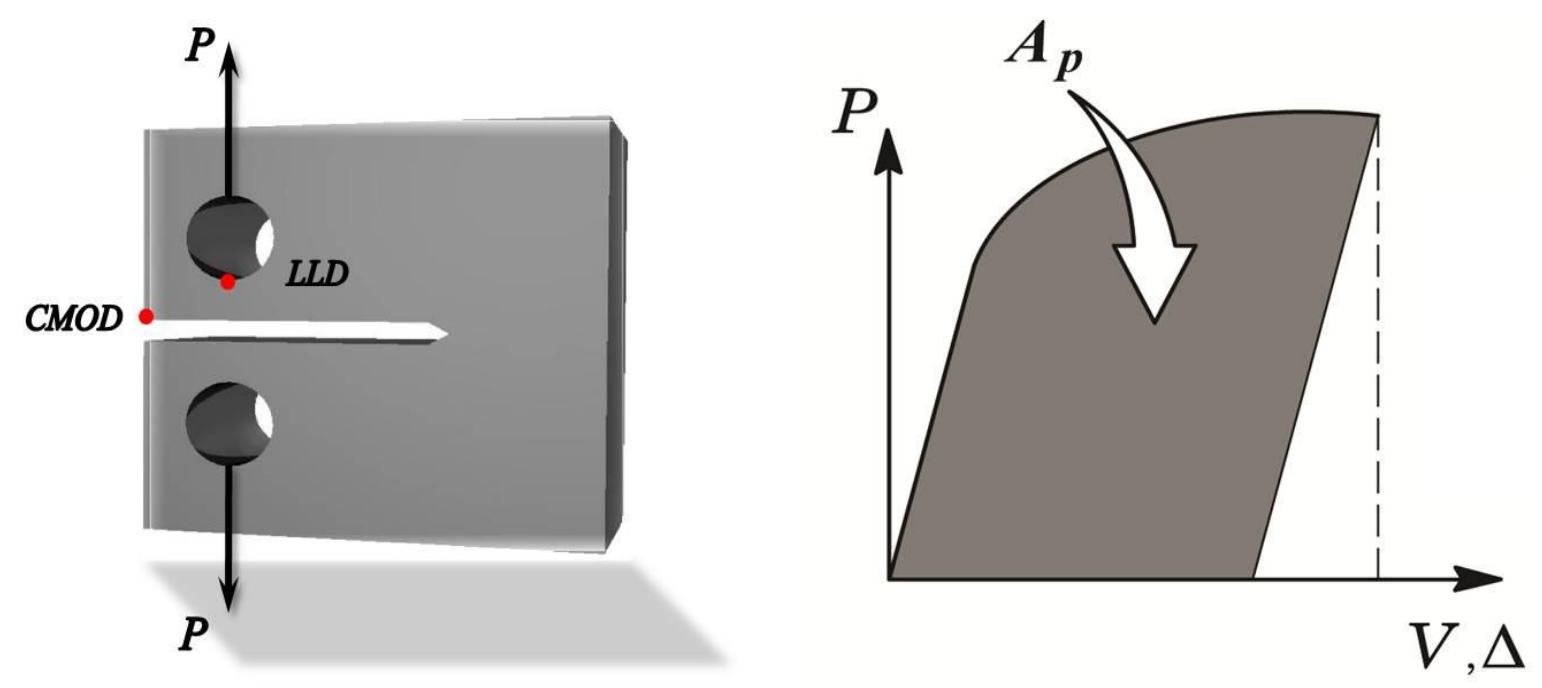

Figura $35 \mathrm{O}$ gráfico de carga $(\mathrm{P}) v s$. deslocamento pode ser contruído em relação aos dois pontos em destaque, $\operatorname{LLD}(\Delta)$ e CMOD $(V)$.

As normas também oferecem basicamente três configurações distintas para 0 espécime $\mathrm{C}(\mathrm{T})$, conforme mostra a Figura 36 . Análises preliminares foram realizadas no intuito de identificar uma possível influência destas geometrias nos valores de eta; os resultado não serão mostrados aqui por motivos de brevidade. Porém não foi identificada qualquer alteração comprometedora dos valores de $\eta$ extraídos das análises e a configuração escolhida foi a mais simples, Figura 36 (c).

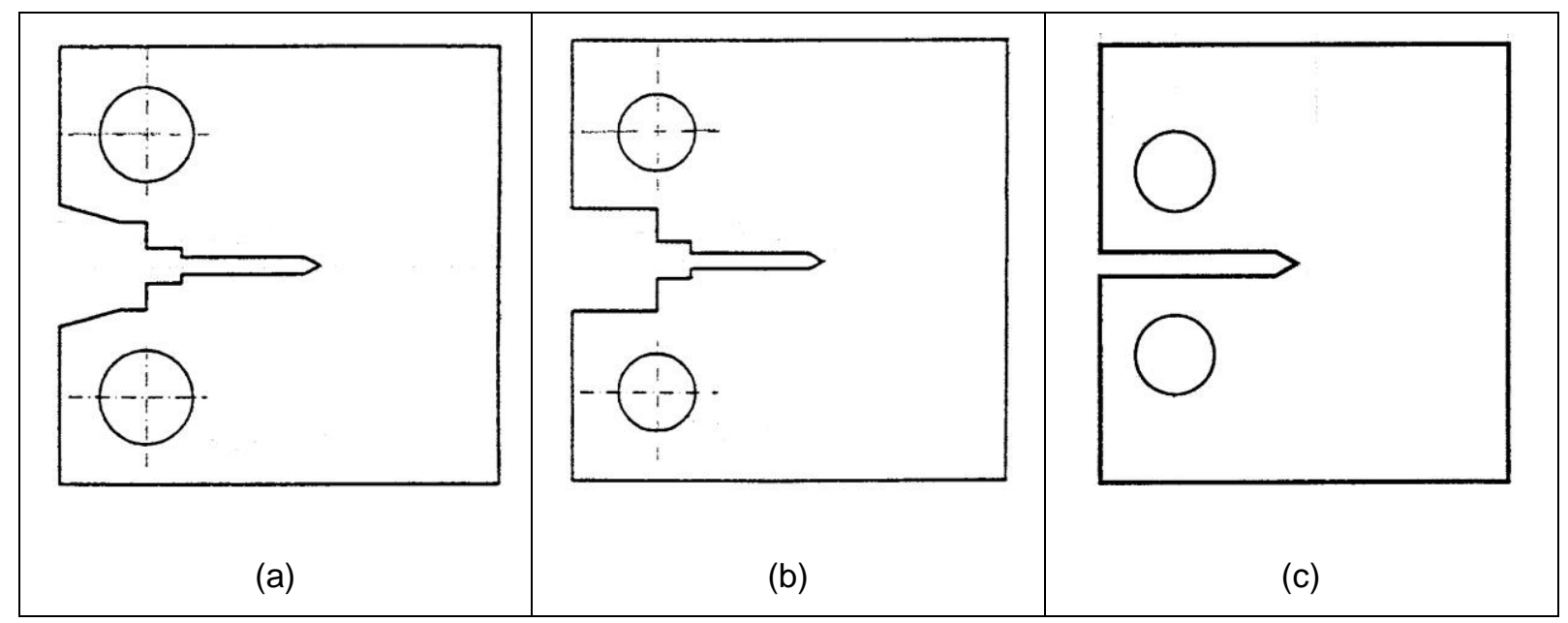

Figura 36 Representação das três geometrias apresentadas pelas normas da ASTM para o espécime $\mathrm{C}(\mathrm{T})$.

O gráfico da Figura 37 representa os valores de $\eta$ medidos a partir do deslocamento da linha de carga para a condição homogênea e permite a avaliação 
para diferentes comprimentos de trinca, comparando os valores obtidos pelas normas ASTM E 1290 e ASTM E 1820 com os valores obtidos pela simulação numérica e extraídos utilizando o código FRACTUS 2D. As duas normas citadas têm expressões validas para o cálculo de $\eta_{J}^{L L D}$ no intervalo de $0.45 \leq a / W \leq 0.7$.

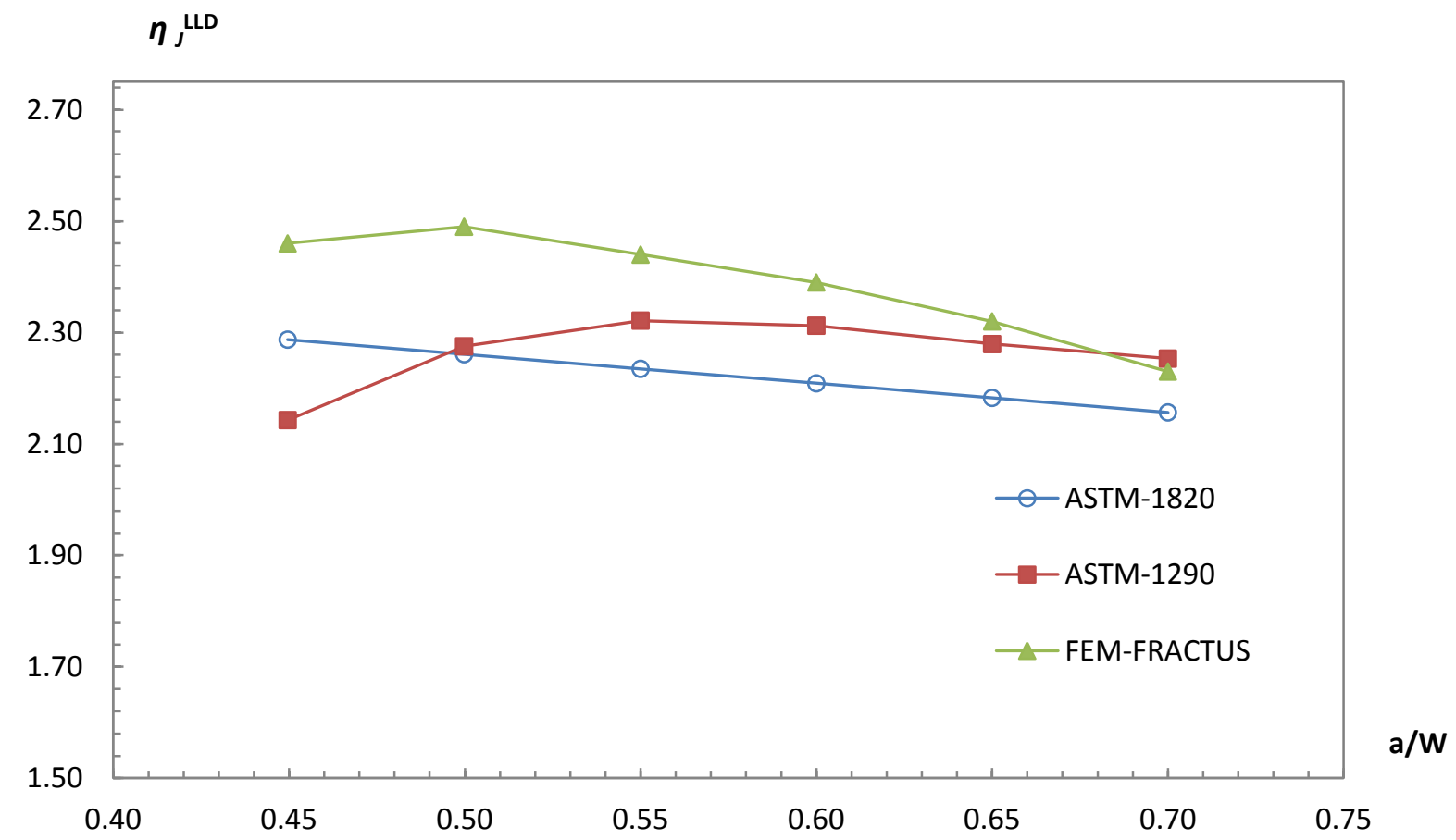

Figura 37 Comparação dos fatores $\eta_{J}^{L D}$ obtidos por norma e por simulação numérica para corposde-prova homogêneos.

$\mathrm{Na}$ Tabela 4 segue o comparativo com as diferenças percentuais entre os resultados calculados do gráfico da Figura 37 utilizando corpos-de-prova homogêneos aplicando as formulações das normas ASTM e o método de elementos finitos. Os resultados numéricos apresentaram diferenças percentuais aceitáveis para $a / W>0.5$, principalmente em comparação aos resultados apresentados pela ASTM 1290. A metodologia de extração de fatores $\eta$ utilizada para a determinação das expressões analíticas encontradas na norma ASTM 1290 é semelhante à adotada neste trabalho, maiores detalhes ver [52]. Já as 
formulações da ASTM 1820 derivam de uma abordagem distinta, carga limite ${ }^{2}$, e isso explica a maior diferença percentual para quase toda a faixa de valores apresentada.

Tabela 4 Diferença percentual entre os valores de $\eta_{J}^{L L D}$ calculados pelas normas ASTM e a simulação computacional por elementos finitos.

\begin{tabular}{ccc}
\hline $\boldsymbol{a} / \boldsymbol{W}$ & FEM-FRACTUS x ASTM-1820 & FEM-FRACTUS x ASTM-1290 \\
\hline 0.45 & $8 \%$ & $15 \%$ \\
0.5 & $10 \%$ & $9 \%$ \\
0.55 & $9 \%$ & $5 \%$ \\
0.6 & $8 \%$ & $3 \%$ \\
0.65 & $6 \%$ & $2 \%$ \\
0.7 & $3 \%$ & $-1 \%$ \\
\hline
\end{tabular}

\subsubsection{ESPÉCIMES COM DISSIMILARIDADE MECÂNICA: ANÁLISES 2D}

A partir dos modelos computacionais sob estado plano de deformações foram obtidos os fatores $\eta_{J}^{\mathrm{CMOD}}, \eta_{J}^{\mathrm{LLD}}$ e $\eta_{\delta}^{\mathrm{CMOD}}$ variando $\mathrm{o}$ comprimento de trinca adimensional $(a / W)$ para diferentes valores de dissimilaridade mecânica e largura do cordão de solda conforme mostram as Figuras 38 - 40 para a geometria 1T.

Para os fatores $\eta_{J}^{\mathrm{CMOD}}$ e $\eta_{J}^{\mathrm{LLD}}$, as tendências observadas são as mesmas diferindo entre si apenas pelo valor absoluto dos fatores adimensionais, o que de certa forma era esperado visto que a única diferença é um pequeno distanciamento entre os pontos de medição do deslocamento. Ambos os fatores apresentaram sensibilidade devido às variações no comprimento de trinca, dissimilaridade mecânica e largura

\footnotetext{
${ }^{2}$ A obtenção de fatores $\eta$ utilizando a formulação de carga limite consiste em derivar da carga limite, $\mathrm{P}_{0}$, em função do comprimento de trinca $a / W$. Não é foco deste trabalho entrar em detalhes desta formulação, portanto para maiores informações consultar [17] e [53].
} 
do corão de solda, porém estes fatores afetam os valores de $\eta$ com intensidades diferentes.

A variação do comprimento de trinca promove uma variação com formato "parabólico" nos valores de eta para a condição $M_{y}=1.0$. Inicialmente, os valores são crescentes, atingem um valor máximo em $a / W=0.55$ e decaem suavemente com o aumento do comprimento de trinca. Com o aumento da dissimilaridade mecânica os valores de eta são transladados igualmente para baixo em todo o intervalo de comprimentos de trinca; esta tendência fica clara para o cordão com largura $2 h=10 \mathrm{~mm}$. A variação na largura do cordão de solda altera os valores de eta provocando uma maior dispersão para trincas rasas ( $a / W \leq 0.45)$, dispersão esta que tende a diminuir até praticamente 0 total desaparecimento para trincas profundas $(a / W=0.7)$ onde os valores de eta tendem a colapsar em um ponto único para $2 h=20 \mathrm{~mm}$.

Aparentemente existe um efeito acoplado entre o nível de dissimilaridade mecânica e a largura do cordão de solda. A maior largura de cordão (i.e. $2 h=20 \mathrm{~mm}$ ) potencializa o efeito provocado pela dissimilaridade mecânica em trincas rasas, $a / W<0.55$, diminuindo os valores de $\eta$ com o incremento de $M_{y}$. A maior diferença observada se dá para a configuração $2 h=20 \mathrm{~mm}$ e $a / W=0.45$ entre $M_{y}=1.0$ e 1.3 que é de aproximadamente $23 \%$ para ambos os fatores eta $\left(\eta_{J}^{\mathrm{CMOD}}\right.$ e $\left.\eta_{J}^{\mathrm{LLD}}\right)$. Na próxima subseção o efeito da largura de cordão de solda será explorado em maior profundidade. 


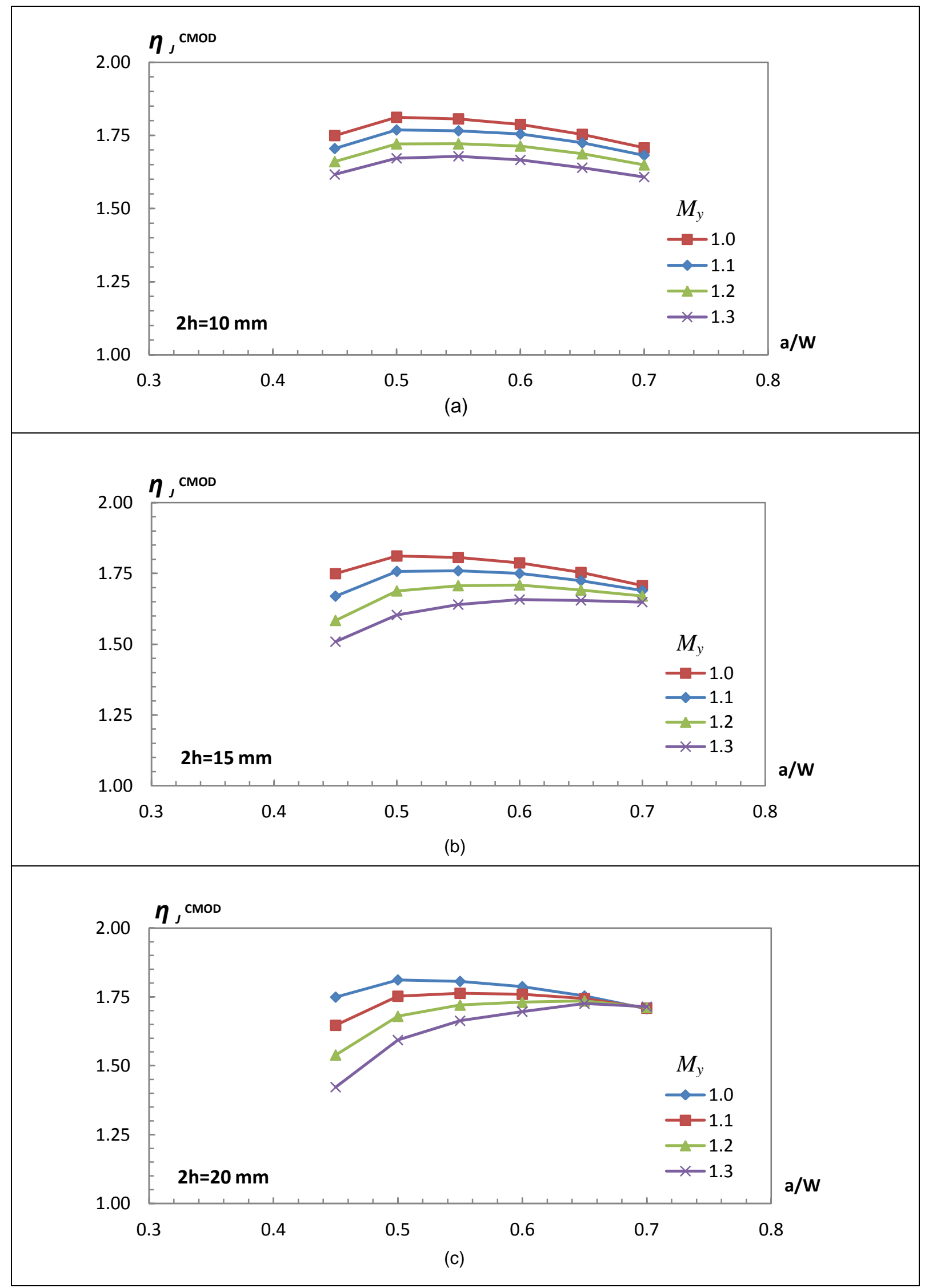

Figura 38 Fatores $\eta_{J}^{\text {CMOD }}$ para corpos-de-prova com diferentes níveis de dissimilaridade mecânica. (a) cordão de solda com largura $2 h=10 \mathrm{~mm}$; (b) cordão de solda com largura $2 h=15 \mathrm{~mm}$; (c) cordão de solda com largura $2 h=20 \mathrm{~mm}$. 


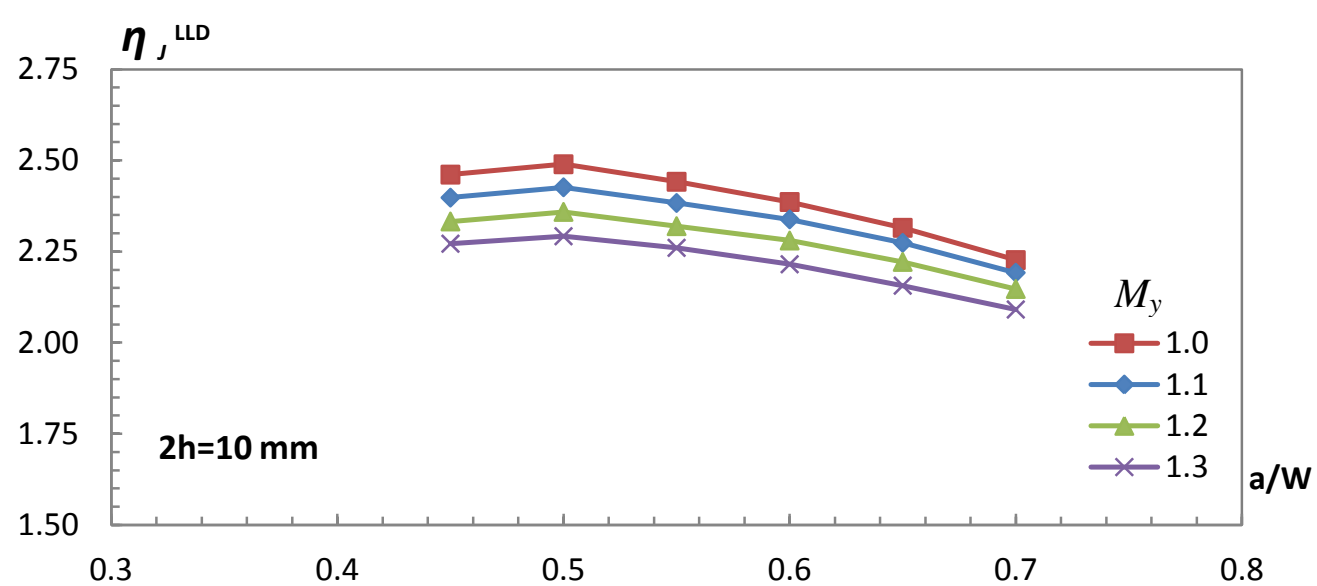

(a)

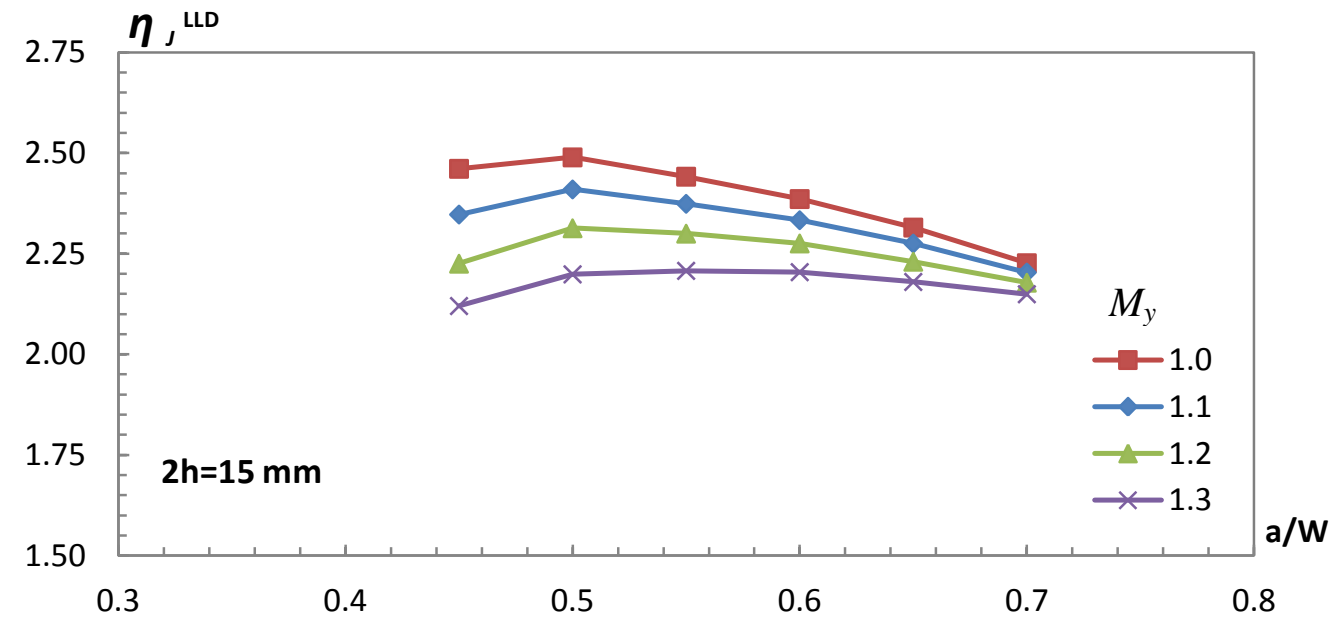

(b)

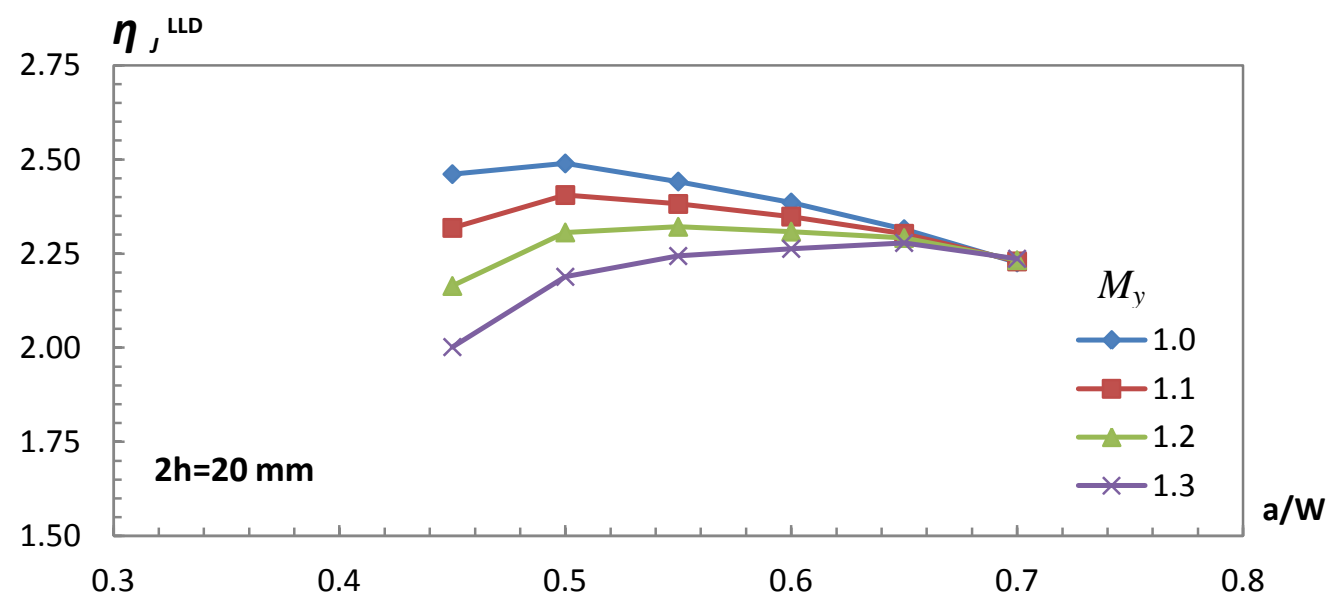

(c)

Figura 39 Fatores $\eta_{J}^{\text {LLD }}$ para corpos-de-prova com diferentes níveis de dissimilaridade mecânica. (a) cordão de solda com largura $2 h=10 \mathrm{~mm}$; (b) cordão de solda com largura $2 h=15 \mathrm{~mm}$; (c) cordão de solda com largura $2 h=20 \mathrm{~mm}$. 
Uma análise separada deve ser feita para os fatores $\eta_{\delta}^{\mathrm{CMOD}}$, uma vez que este apresenta tendências distintas às observadas para os fatores $\eta_{J}^{\mathrm{CMOD}}, \eta_{J}^{\mathrm{LLD}}$. Os fatores $\eta_{\delta}^{\mathrm{CMOD}}$ se mostraram praticamente insensíveis ao comprimento de trinca e largura do cordão de solda proporcionando valores praticamente constantes de eta em todo o intervalo simulado. Quando aumentado o nível de dissimilaridade mecânica, observou-se o aumento nos valores de eta, conforme mostram os gráficos da Figura 40. A maior diferença observada se dá para a configuração $2 h=10 \mathrm{~mm}$ e $a / W=0.65$ entre $M_{y}=1.0$ e 1.3 que é de aproximadamente $26 \%$. Aparentemente o aumento da largura do cordão de solda causa uma pequena diminuição da sensibilidade de $\eta$ para as diferentes condições de dissimilaridade mecânica, um indicativo de que as variações nos níveis de triaxialidade na ponta da trinca não afetam significativamente o parâmetro adimensional $\eta_{\delta}^{\mathrm{CMOD}}$. 


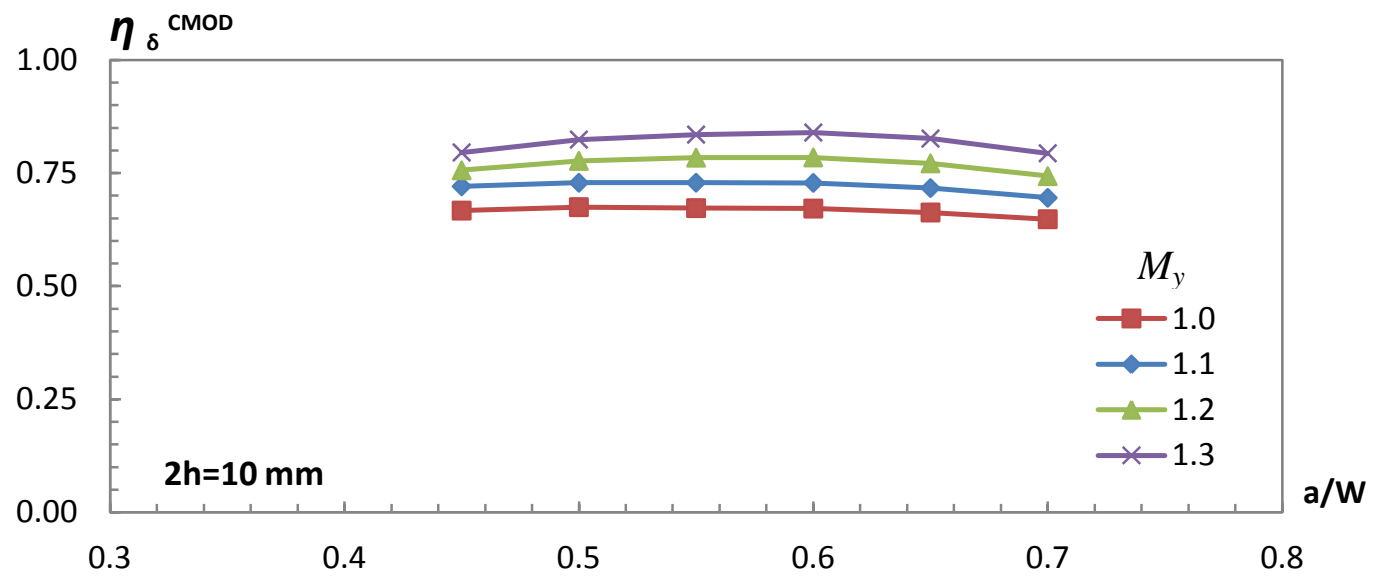

(a)

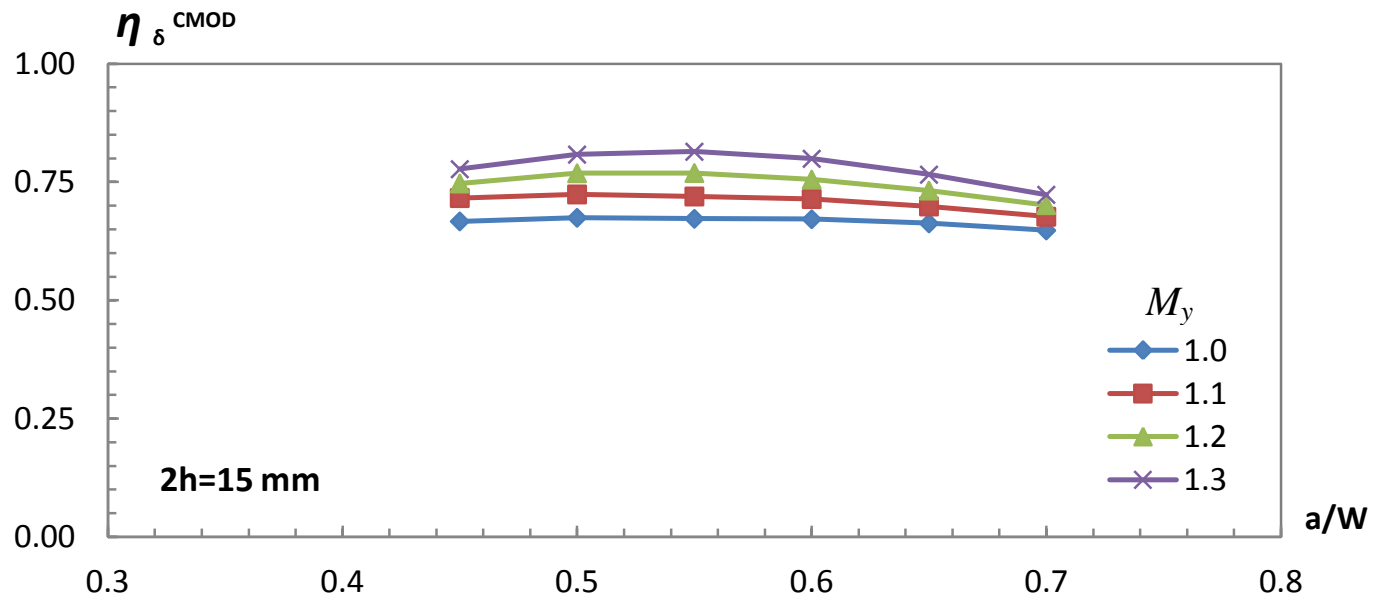

(b)

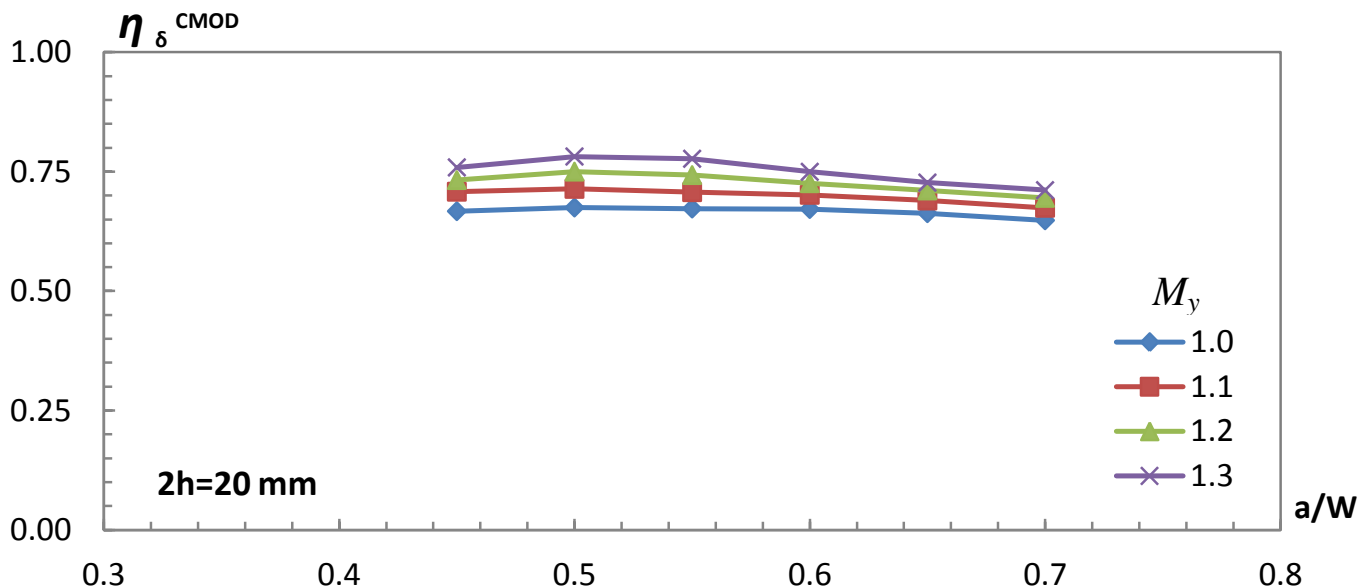

(c)

Figura 40 Fatores $\boldsymbol{\eta}_{\boldsymbol{\delta}}^{\text {CMOD }}$ para corpos-de-prova com diferentes níveis de dissimilaridade mecânica. (a) cordão de solda com largura $2 h=10 \mathrm{~mm}$; (b) cordão de solda com largura $2 h=15 \mathrm{~mm}$; (c) cordão de solda com largura $2 h=20 \mathrm{~mm}$. 


\subsection{INFLUÊNCIA DA LARGURA DO CORDÃO DE SOLDA SOBRE OS FATORES $\eta$ EM ESTADO PLANO DE DEFORMAÇÃO}

$\mathrm{Na}$ seção anterior foi observado um efeito acoplado provocado pela variação da dissimilaridade mecânica e a largura do cordão de solda que se faz mais intenso para trincas mais rasas. Isso motivou um estudo mais detalhado deste efeito combinado visando avaliar melhor sua influência sobre os fatores $\eta$.

Nos gráficos das Figuras 41 - 43, $\eta$ foi plotado em função de $M_{y}$ para o intervalo de largura de cordão de solda de $10 \mathrm{~mm} \leq 2 h \leq 20 \mathrm{~mm}$ e três diferentes comprimentos de trinca, aqui tratados por trinca rasa $(a / W=0.45)$, trinca moderada $(a / W=0.6)$ e trinca profunda $(a / W=0.7)$. A curva para condição "All Weld Metal" $(\mathrm{AWM})^{3}$ foi incluída como referência. $O$ decaimento dos valores de eta em relação a curva AWM sugere que a plasticidade desenvolvida na ponta da trinca extrapolou os limites de largura do cordão de solda, invadindo o material base. Quanto maior a queda, p.ex. como a observada para $2 h=20 \mathrm{~mm}$, maior é a parcela de deformação transferida para o metal de base evidenciando o efeito desejado da condição overmatch (metal de solda com maior resistência do que o metal de solda) de proteção da junta soldada.

Novamente, as tendências observadas para $\eta_{J}^{\mathrm{CMOD}}$ e $\eta_{J}^{\mathrm{LLD}}$ são semelhantes possuindo apenas valores absolutos de $\eta$ diferentes entre si. Para trincas rasas notou-se uma variação maior nos valores de $\eta$, mas que rapidamente desapareceu para $a / W \geq 0.6$. Para a trinca $a / W=0.45$ a maior diferença, $14.1 \%$, se deu em $M_{y}=1.3$, entre $2 h=10 \mathrm{~mm}$ e $2 h=20 \mathrm{~mm}$.

\footnotetext{
${ }^{3}$ Condição onde o corpo-de-prova é homogêneo e possui propriedades do material variando de 110 a $130 \%$ em relação à condição base original $\left(\sigma_{y s}=412 \mathrm{MPa}\right.$ e $\left.n=10\right)$.
} 


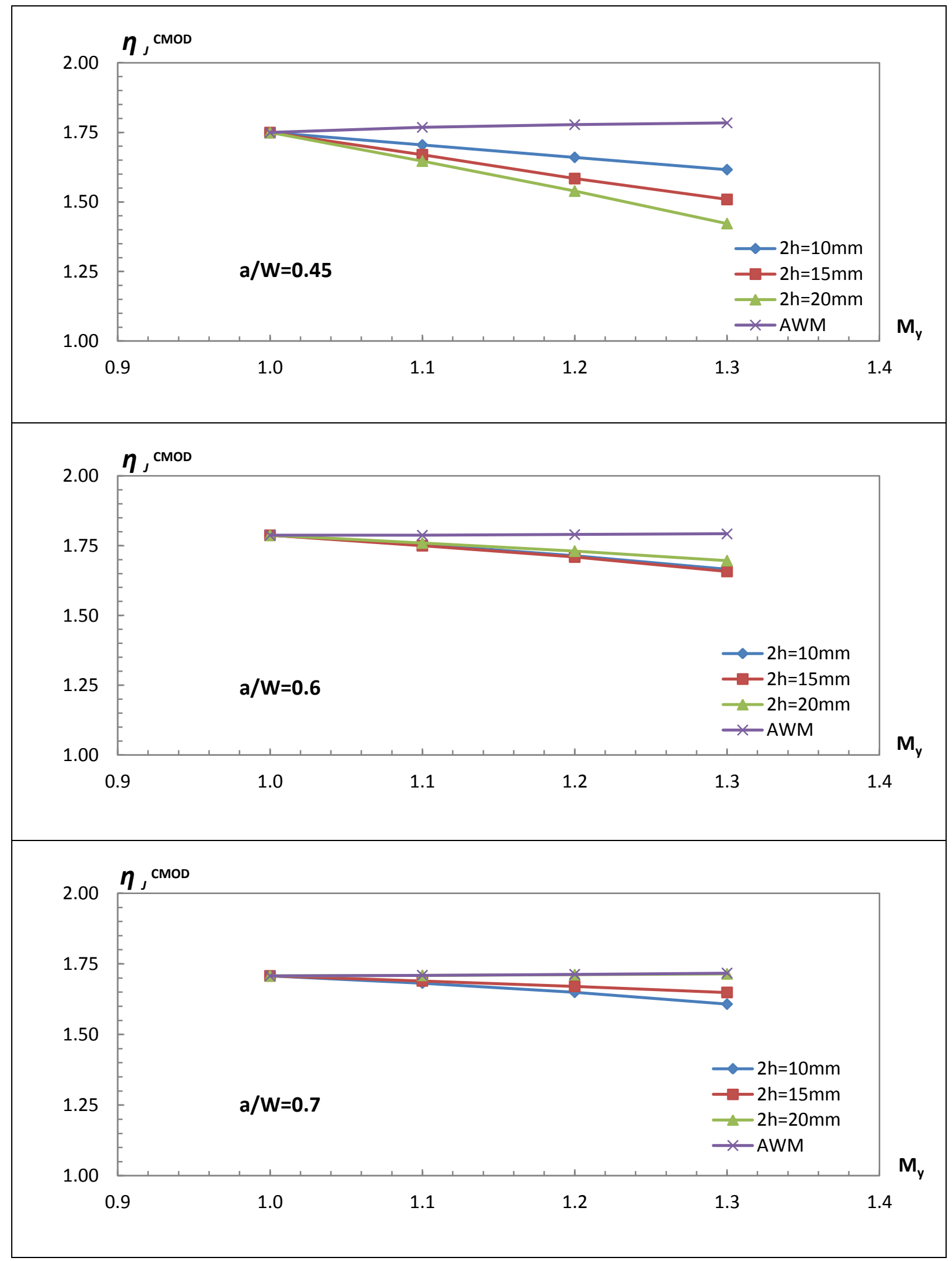

Figura 41 Influência da largura do cordão de solda sobre os fatores $\eta_{J}^{\text {CMOD }}$ para diferentes comprimentos de trinca adimensional, de raso a profundo. $0.45 \leq a / W \leq 0.7$. 


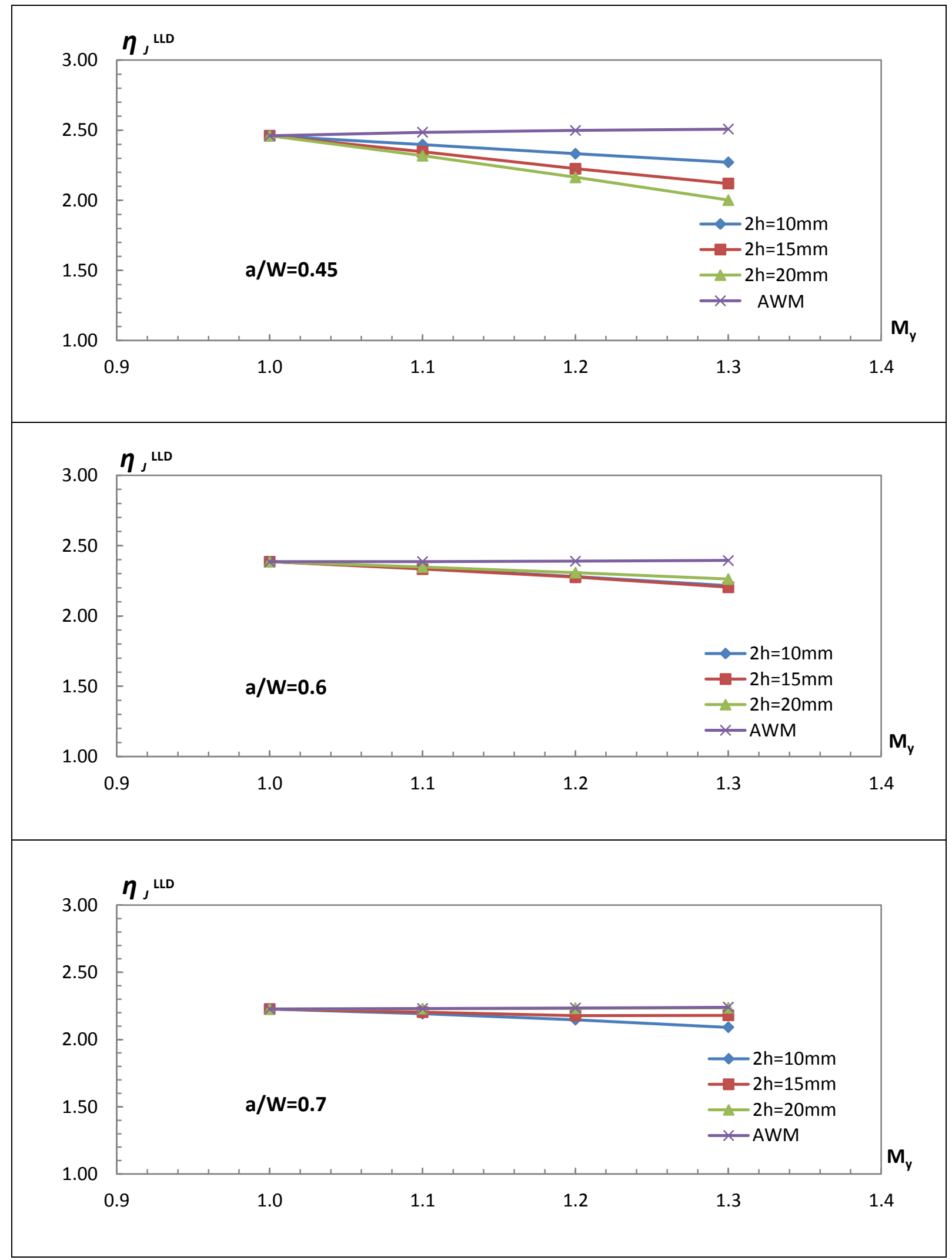

Figura 42 Influência da largura do cordão de solda sobre os fatores $\eta_{J}^{\mathrm{LLD}}$ para diferentes comprimentos de trinca adimensional, de raso a profundo. $0.45 \leq a / W \leq 0.7$.

Para $\eta_{\delta}^{\mathrm{CMOD}}$ o mesmo esquema gráfico foi utilizado, Figura 43. Fica claro, pela a análise da figura que a largura do cordão de solda não influencia significativamente 
os valores de $\eta$ em toda a faixa de comprimentos de trinca, como já havia sido observado anteriormente.

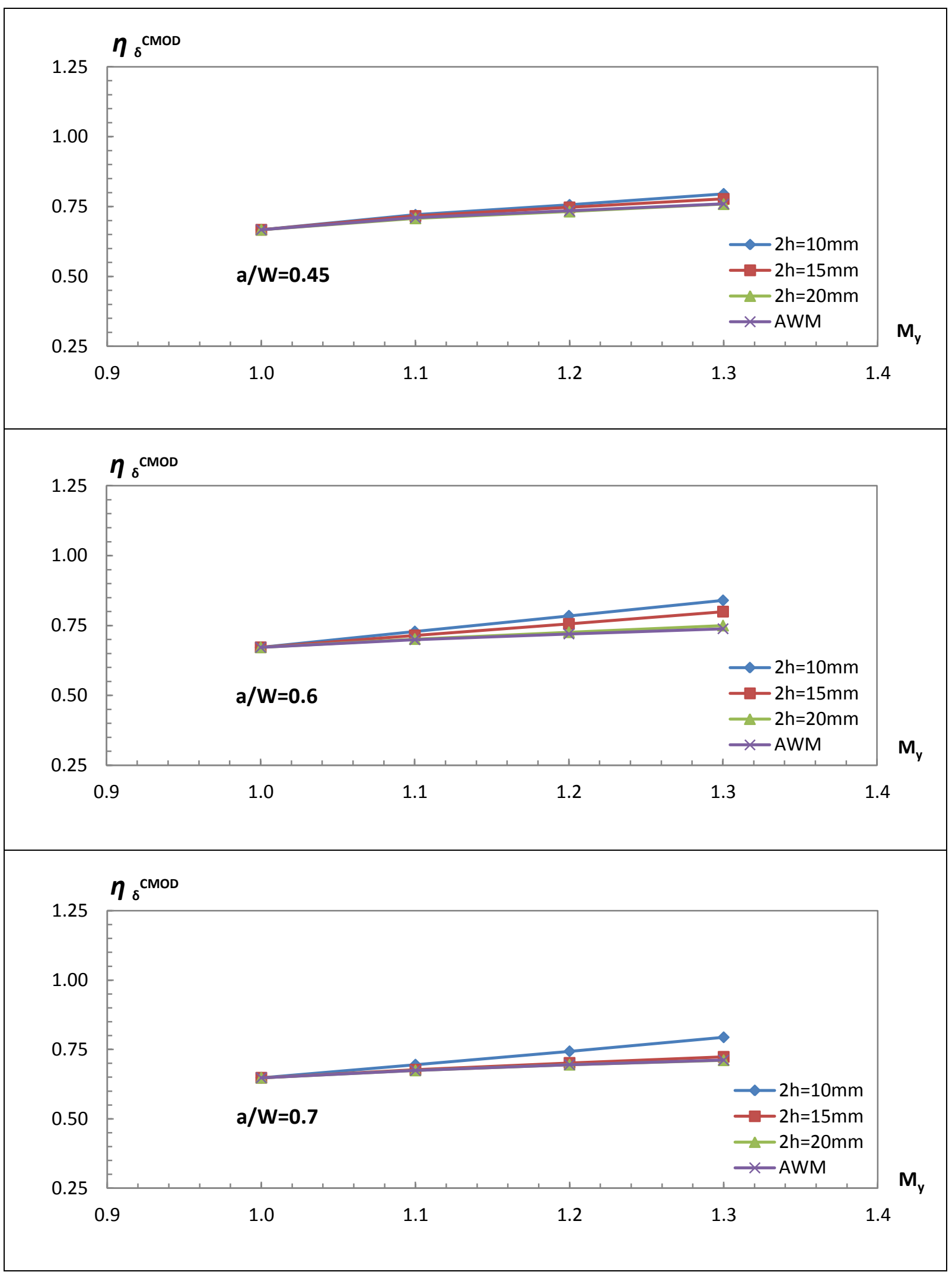

Figura 43 Influência da largura do cordão de solda sobre os fatores $\eta_{\delta}^{\text {CMOD }}$ para diferentes comprimentos de trinca adimensional, de moderado a profundo. $0.45 \leq a / W \leq 0.7$ 
A partir das análises mostradas acima foram, realizadas regressões polinomiais, aplicando o método de mínimos quadrados [54]. Estas regressões permitiram a descrição dos fatores $\eta$ uma função do comprimento de trinca adimensional e do nível de dissimilaridade mecânica.

Estas regressões foram geradas a partir dos dados obtidos para um cordão de solda $2 h=15 \mathrm{~mm}$ no intuito de excluir a largura de cordão das regressões polinomiais sem comprometer a precisão dos resultados. O suporte a esta decisão está na pequena diferença observada, de aproximadamente $7 \%$, entre o maior e 0 menor valor de fatores $\eta_{J}^{\mathrm{CMOD}}$ e $\eta_{J}^{\mathrm{LLD}}$ observados no gráfico ( $a / W=0.45$ e $\left.M_{y}=1.3\right)$ em relação ao valor intermediário encontrado tendo como referência o cordão de solda $2 h=15 \mathrm{~mm}$ e para o fato deste mesmo parâmetro não ter influência sobre $\eta_{\delta}^{\mathrm{CMOD}}$.

Os polinômios para o cálculo de eta são escritos na seguinte forma

$$
\begin{gathered}
\eta=f\left(\frac{a}{W} ; M_{y}\right) \\
\eta(a / W)=C_{0}+C_{1}\left(\frac{a}{W}\right)+C_{2}\left(\frac{a}{W}\right)^{2}+C_{3}\left(\frac{a}{W}\right)^{3} \\
C_{k}=f\left(M_{y}\right)
\end{gathered}
$$

e nas Tabelas 5 - 7 encontram-se os respectivos coeficientes das regressões polinomiais para o cálculo de $\eta_{J}^{C M O D}, \eta_{J}^{\mathrm{LLD}}$ e $\eta_{\delta}^{\mathrm{CMOD}}$. 
Tabela 5 Coeficientes para aplicação no polinômio de regressão múltipla para o cálculo de $\eta_{J}^{C M O D}$.

\begin{tabular}{|c|c|c|c|}
\hline & $K_{0}$ & $K_{1}$ & $K_{2}$ \\
\hline $\mathbf{C}_{0}$ & 110.83 & -200.08 & 86.02 \\
\hline $\mathbf{C}_{1}$ & -557.81 & 1027.30 & -444.90 \\
\hline $\mathbf{C}_{2}$ & 941.21 & -1732.30 & 752.17 \\
\hline $\mathbf{C}_{3}$ & -524.31 & 961.95 & -417.77 \\
\hline
\end{tabular}

Tabela 6 Coeficientes para aplicação no polinômio de regressão múltipla para o cálculo de $\eta_{J}^{\mathrm{LLD}}$.

\begin{tabular}{|c|c|c|c|}
\hline & $K_{0}$ & $K_{1}$ & $K_{2}$ \\
\hline $\mathbf{C}_{0}$ & 135.35 & -239.71 & 102.23 \\
\hline $\mathbf{C}_{1}$ & -672.47 & 1221.3 & 525.27 \\
\hline $\mathbf{C}_{2}$ & 1125.2 & -2046 & 882.45 \\
\hline $\mathbf{C}_{3}$ & -623.07 & 1129.7 & -487.2 \\
\hline
\end{tabular}


Tabela 7 Coeficientes para aplicação no polinômio de regressão múltipla para o cálculo de $\eta_{\delta}^{\mathrm{CMOD}}$.

\begin{tabular}{|c|c|c|c|}
\hline & $K_{0}$ & $K_{1}$ & $K_{2}$ \\
\hline $\mathbf{C}_{0}$ & -7.0224 & 14.964 & -7.54 \\
\hline $\mathbf{C}_{1}$ & 23.075 & -46.992 & 24.938 \\
\hline $\mathbf{C}_{2}$ & 18.275 & 37.926 & -20.605 \\
\hline
\end{tabular}

Estas regressões polinomiais são estritamente válidas para o seguinte intervalo

$$
0.45 \leq \frac{a}{W} \leq 0.7 \quad e \quad 1.0 \leq M_{y} \leq 1.3
$$




\subsection{ESPÉCIMES COM DISSIMILARIDADE MECÂNICA: ANÁLISES 3D}

Nesta seção são apresentados os fatores $\eta_{J}^{\text {CMOD }}, \eta_{J}^{\text {LLD }}$ e $\eta_{\delta}^{\text {CMOD }}$ obtidos dos modelos tridimensionais para diferentes níveis de dissimilaridades mecânicas entre o metal de base e o metal de solda. A partir das análises realizadas para avaliação da influência da largura do cordão de solda sobre os fatores $\eta$ foi decidido que apenas os modelos com largura de cordão intermediária, $2 h=15 \mathrm{~mm}$, seriam simulados. Inicialmente, são mostrados nas Figuras 44 - 46 os gráficos com as curvas para cada um dos fatores $\eta$ DD variando-se a dissimilaridade mecânica e na sequência são apresentados os comparativos entre os fatores adimensionais obtidos nas análises em estado plano de deformação e 3D, conforme o gráfico da Figura 47, e para a variação dimensional 1T e 0.5T (condição 3D), conforme o gráfico da Figura 48.

Por apresentarem tendências similares, primeiramente e conjuntamente serão analisados os fatores $\eta_{J}^{\mathrm{CMOD}}$ e $\eta_{J}^{\mathrm{LLD}}$, Figuras 45 - 46. Os valores de eta são inicialmente crescentes para as trincas $a / W=0.45$ e 0.5 , ficam praticamente estáveis até $a / W=0.6$ e tornam a crescer até o final do intervalo $(a / W=0.7)$, portanto são sensíveis à variação do comprimento de trinca.

Os fatores eta também se mantiveram sensíveis à dissimilaridade mecânica. Para um mesmo comprimento de trinca o aumento nos níveis de dissimilaridade translada para baixo a curva de valores do fator adimensional, a diminuição nos valores é praticamente constante em todo o intervalo $a / W$, havendo exclusivamente para a configuração $a / W=0.7$, uma tendência de colapso entre os valores de eta.

Existe um efeito acoplado entre o nível de dissimilaridade mecânica e o comprimento de trinca $a / W$. Observa-se que as diferenças entre os valores de eta, identificados para as configurações com $a / W=0.45$ e 0.7 , aumenta com o aumento da de dissimilaridade mecânica. Para estes comprimentos de trinca e nas condições $M_{y}=1.0$ e 1.5, há uma diferença percentual para valores de $\eta_{J}^{\mathrm{CMOD}}$ igual a $7.2 \%$ e $16.9 \%$, respectivamente. 


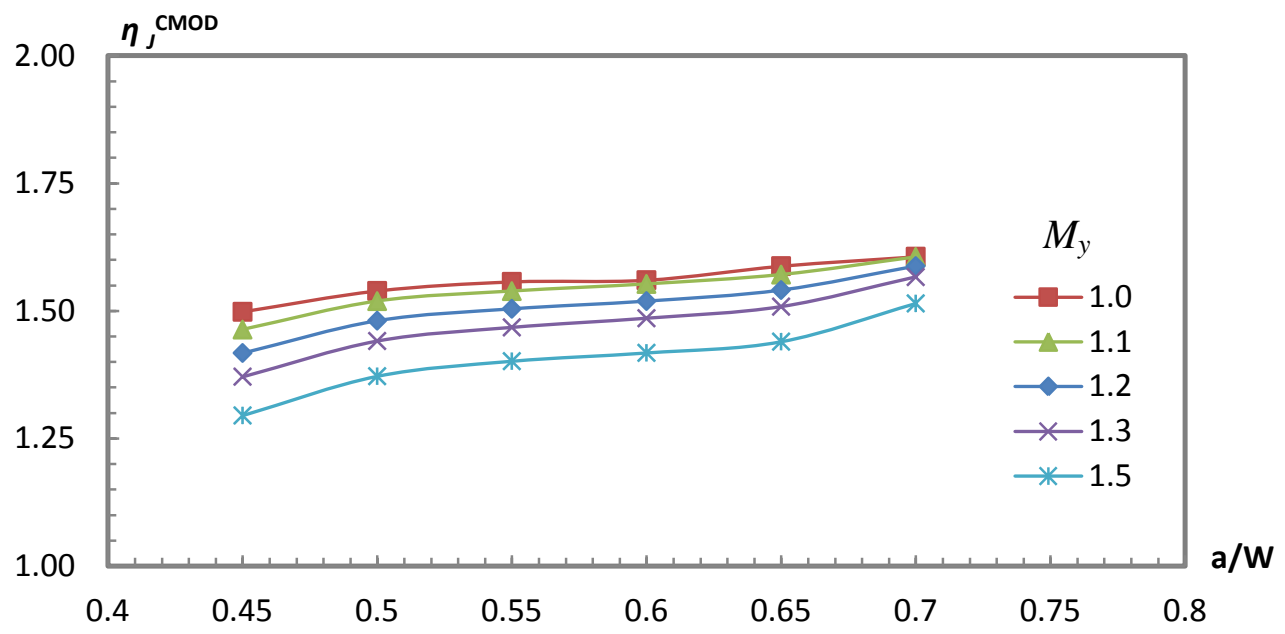

Figura 44 Fatores $\eta_{J}^{\text {CMOD }} 3 \mathrm{D}$ 1T para corpos-de-prova com diferentes níveis de dissimilaridade mecânica e cordão de solda com largura $2 h=15 \mathrm{~mm}$.

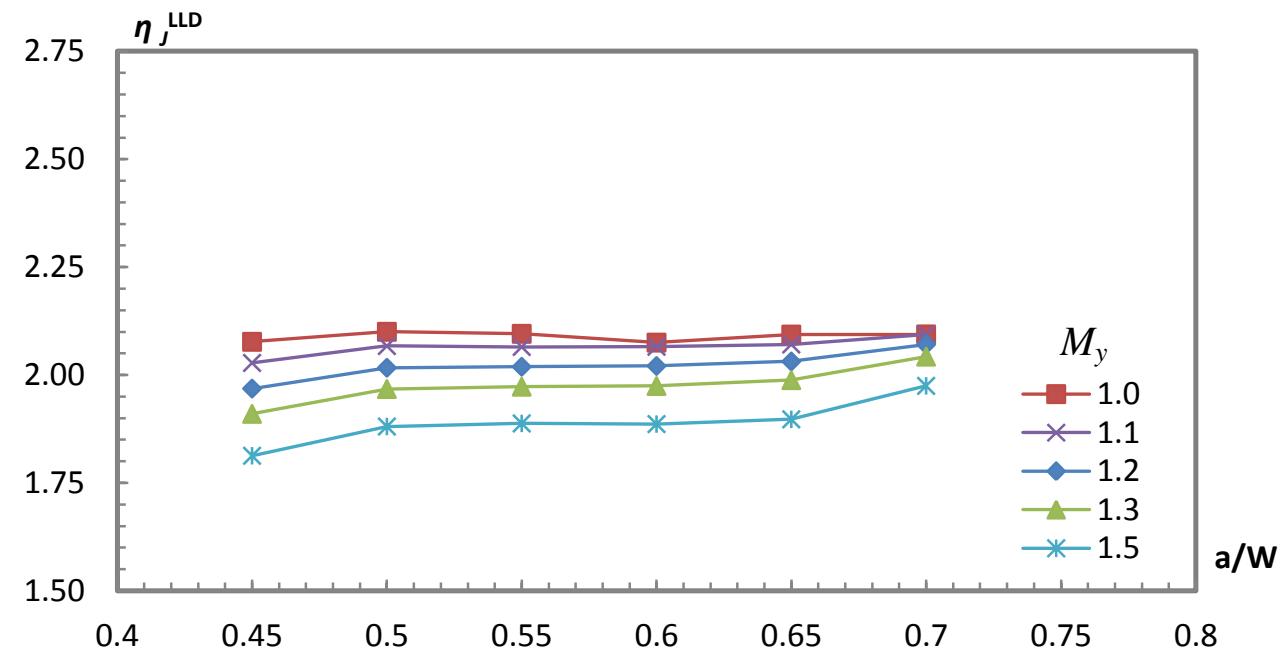

Figura 45 Fatores $\eta_{J}^{\mathrm{LL}}$ 3D $1 \mathrm{~T}$ para corpos-de-prova com diferentes níveis de dissimilaridade mecânica e cordão de solda com largura $2 h=15 \mathrm{~mm}$.

Os valores de $\eta_{\delta}^{\mathrm{CMOD}}$, ilustrados pelo gráfico da Figura 46, mostraram-se sensíveis à variação do comprimento de trinca e aos níveis de dissimilaridade mecânica. Para as trincas mais rasas, $a / W=0.45$, a sensibilidade à dissimilaridade mecânica é menor (diferença de $9.4 \%$ entre $M_{y}=1.0$ e 1.5 ) quando comparada às trincas mais profundas, $a / W>0.6$, (diferença de $20 \%$ entre $M_{y}=1.0$ e 1.5 para $a / W=0.7$ ). $O$ valor de $M y=1.5$ foi avaliado para a condição 3D no intuito de identificar possíveis alterações de tendência, porém as curvas mantiveram-se constantes 
acompanhando as tendências observadas para os demais níveis de dissimilaridade mecânica.

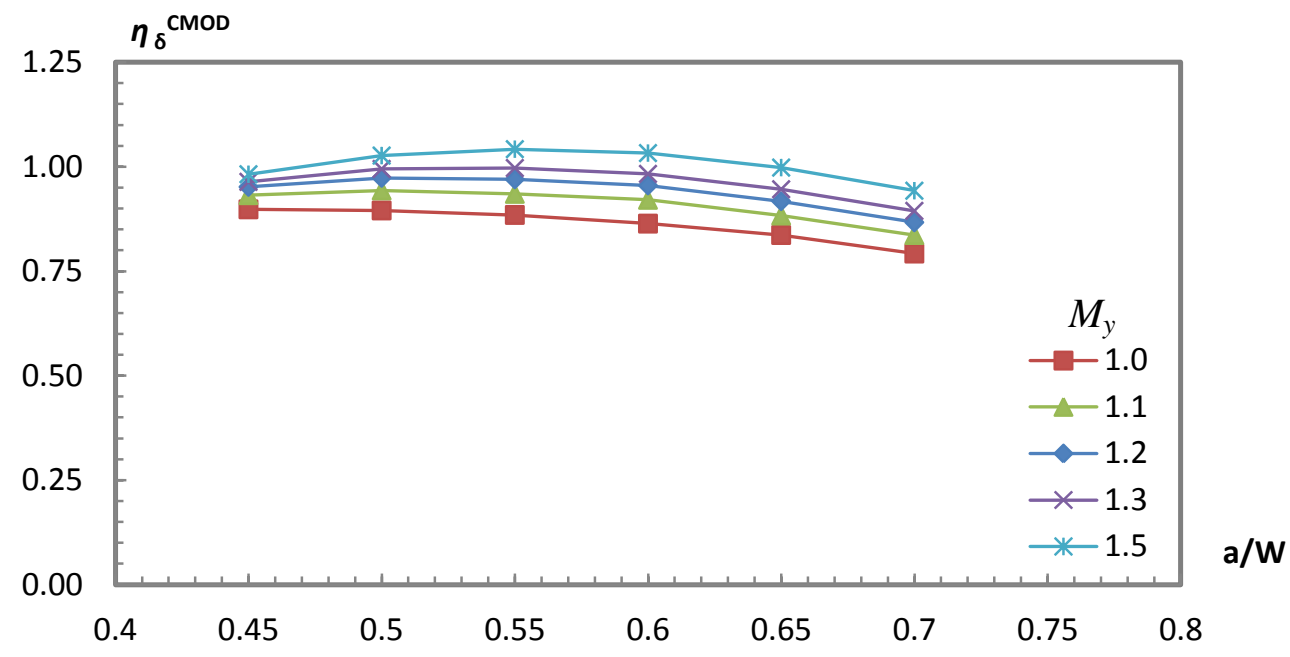

Figura 46 Fatores $\eta_{\delta}^{\mathrm{CMOD}}$ 3D 1T para corpos-de-prova com diferentes níveis de dissimilaridade mecânica e cordão de solda com largura $2 h=15 \mathrm{~mm}$.

Nos gráficos da Figura 47 encontram-se os comparativos dos valores de $\eta$ para as condições de simulação em estado plano de deformação (linhas pontilhadas) e tridimensional (linhas cheias). Para facilitar a visualização das tendências e efeitos devido à variação da espessura, as curvas foram geradas apenas para as condições $M_{y}=1.0$ e 1.3 .

O efeito da espessura nos fatores $\eta_{J}^{\mathrm{CMOD}}$ e $\eta_{J}^{\mathrm{LD}}$ transladou os valores das curvas para baixo e atenuou os efeitos de dissimilaridade mecânica e comprimento de trinca, proporcionado uma tendência mais constante para os fatores $\eta$ tridimensionais comparados aos fatores $\eta$ em estado plano de deformação.

Para $\eta_{\delta}^{\text {CMOD }}$, o efeito da espessura e o nível de dissimilaridade mecânica transladaram as curvas de eta para cima. Observou-se também que o comprimento de trinca tem maior influência na condição tridimensional homogênea. 


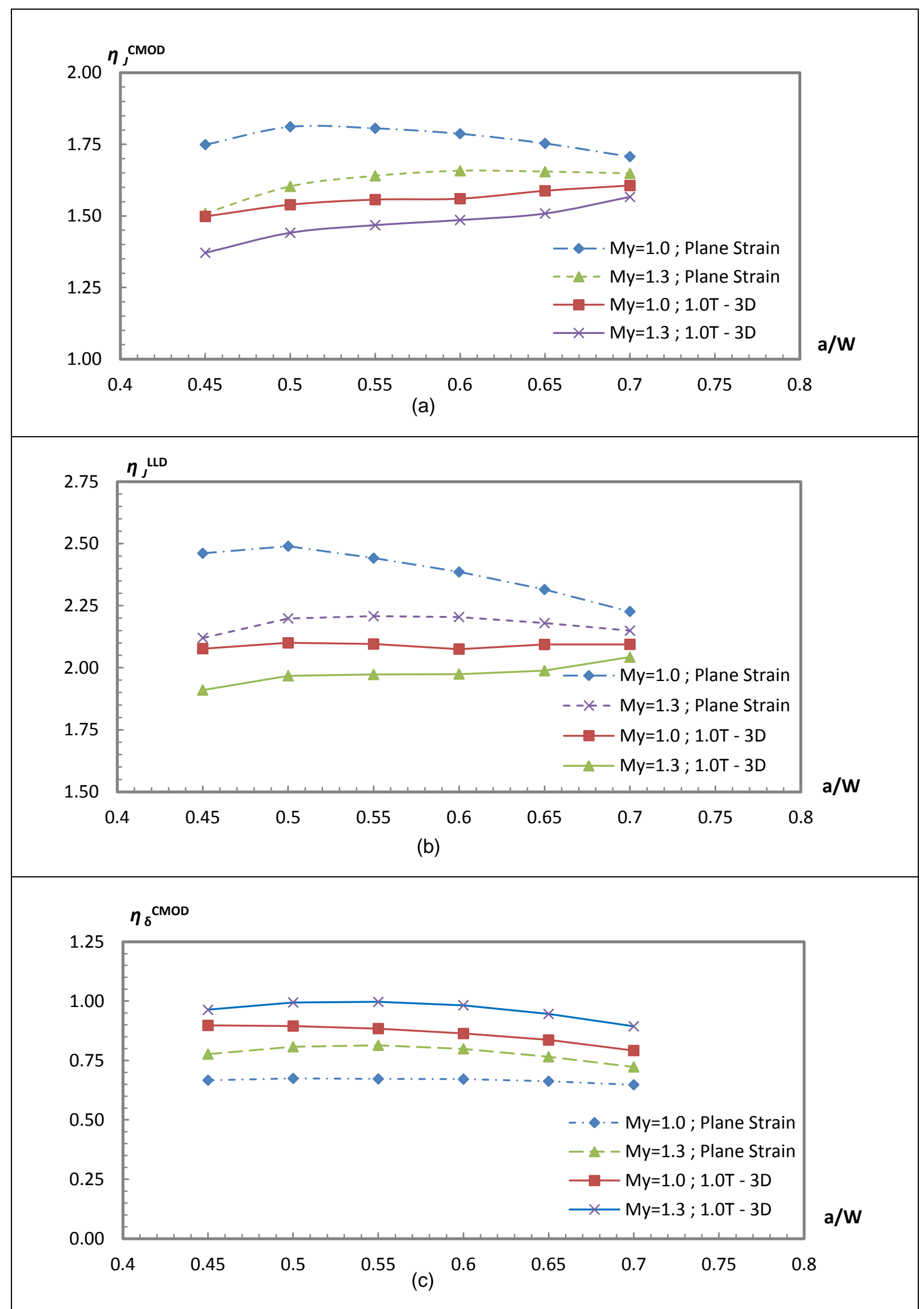

Figura 47 Gráficos comparativos entre fatores $\eta$ obtidos para os modelos tridimensionais e modelos sob a condição de estado plano de deformação. (a) $\eta_{J}^{\mathrm{CMOD}}$; (b) $\eta_{J}^{\mathrm{LLD}}$; (c) $\eta_{\delta}^{\mathrm{CMOD}}$ 
$\mathrm{Na}$ Figura 48, encontram-se os comparativos dos modelos tridimensionais com dimensões $1 \mathrm{~T}$ e $0.5 \mathrm{~T}$ com largura adimensional de cordão de solda de $h / W=0.15$. A diminuição nas dimensões do corpo-de-prova elevou os valores de $\eta_{J}^{C M O D}, \eta_{J}^{\mathrm{LLD}} \mathrm{e}$ $\eta_{\delta}^{\text {CMOD }}$ tanto para a condição homogênea como para a condição com dissimilaridade mecânica de $130 \%$, porém as diferença encontradas não são significativas do ponto de vista da prática experimental.

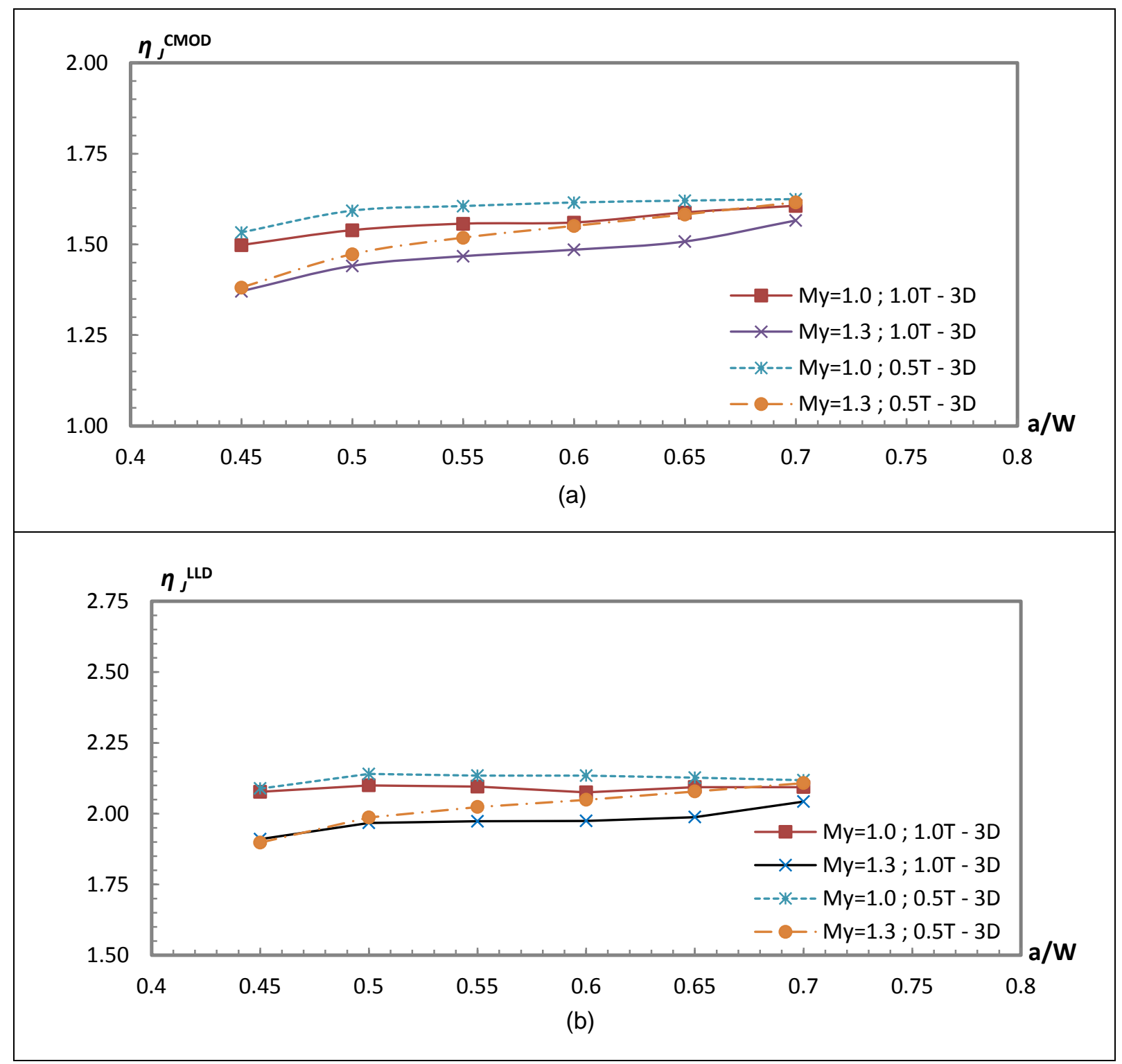




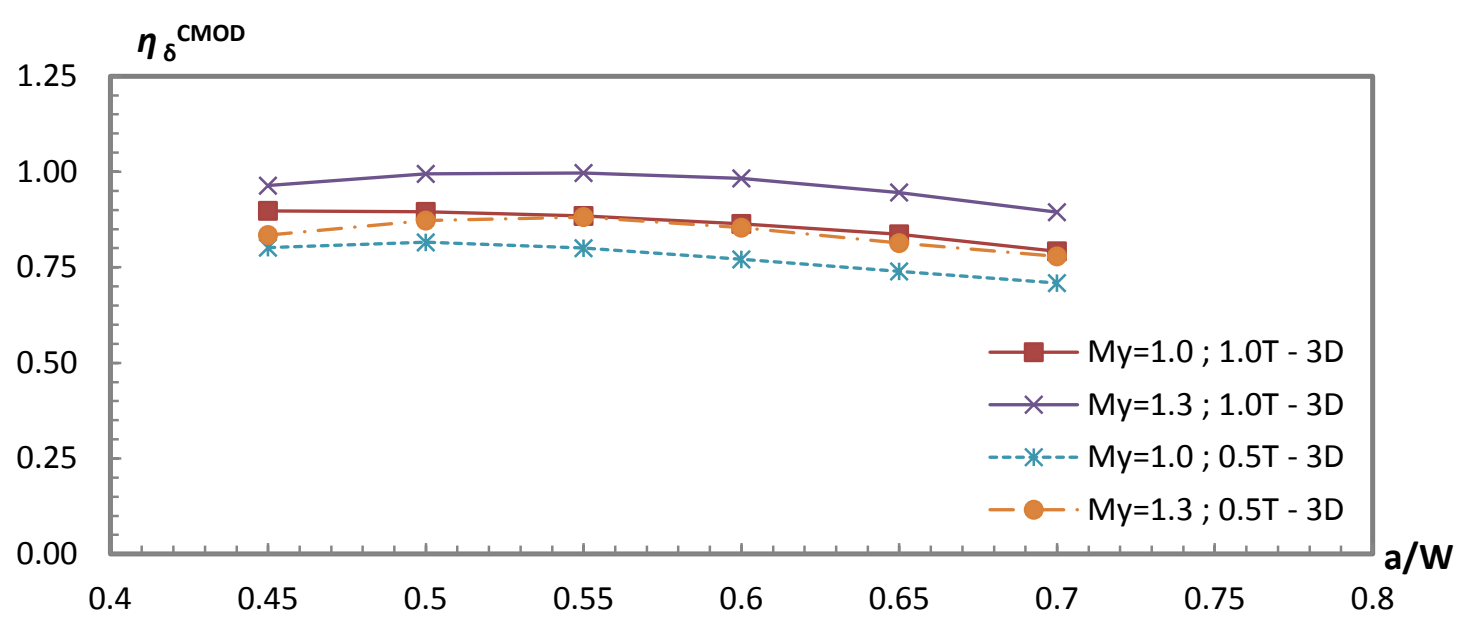

(c)

Figura 48 Gráficos comparativos entre fatores $\eta$ obtidos para os modelos tridimensionais com geometria $1 \mathrm{~T}$ e $0.5 \mathrm{~T}$. (a) $\eta_{J}^{\mathrm{CMOD}}$; (b) $\eta_{J}^{L L D}$; (c) $\eta_{\delta}^{\mathrm{CMOD}}$

\subsection{CORRELAÇÃO ENTRE $J$ E CTOD}

Conforme apresentado em seções anteriores, os estudos pioneiros realizados por Shih demonstraram que o parâmetro adimensional $d_{n}$, descrito pela Eq. (38), é fortemente influenciado pelo nível de encruamento do material. Panontin [52] em seu estudo, direcionado a corpos-de-prova com geometria compacta e homogêneos, mostrou que há uma influência praticamente desprezível do comprimento de trinca sobre o fator de restrição plástica, para $a / W>0.45$ (caso semelhante ao deste trabalho), porém este fator continua sendo fortemente influenciado pelo encruamento do material.

$$
d_{n}=\frac{1}{m}
$$

Utilizando a abordagem proposta por Kirk [40], os fatores $m$ podem ser obtidos do coeficiente angular da reta de $J$ vs. CTOD, ilustrado nas Figura 49 e Figura 50. Esta inclinação é igual a $m \sigma_{0}$,onde $\sigma_{0}$ é uma tensão de referência expressa neste trabalho como 


$$
\sigma_{0}=\sigma_{y s}^{M S}
$$

Nas Figuras 49 e 50 são plotados os valores de $J$ vs. CTOD para avaliar a influência do comprimento de trinca e nível de dissimilaridade mecânica sobre os fatores $m$. Para a condição homogênea os resultados obtidos para os fatores $m$ se mostraram semelhantes aos observados no trabalho de Panontin [52], as variações são mínimas ( 2\%) entre os valores extremos e podem ser consideradas desprezíveis.

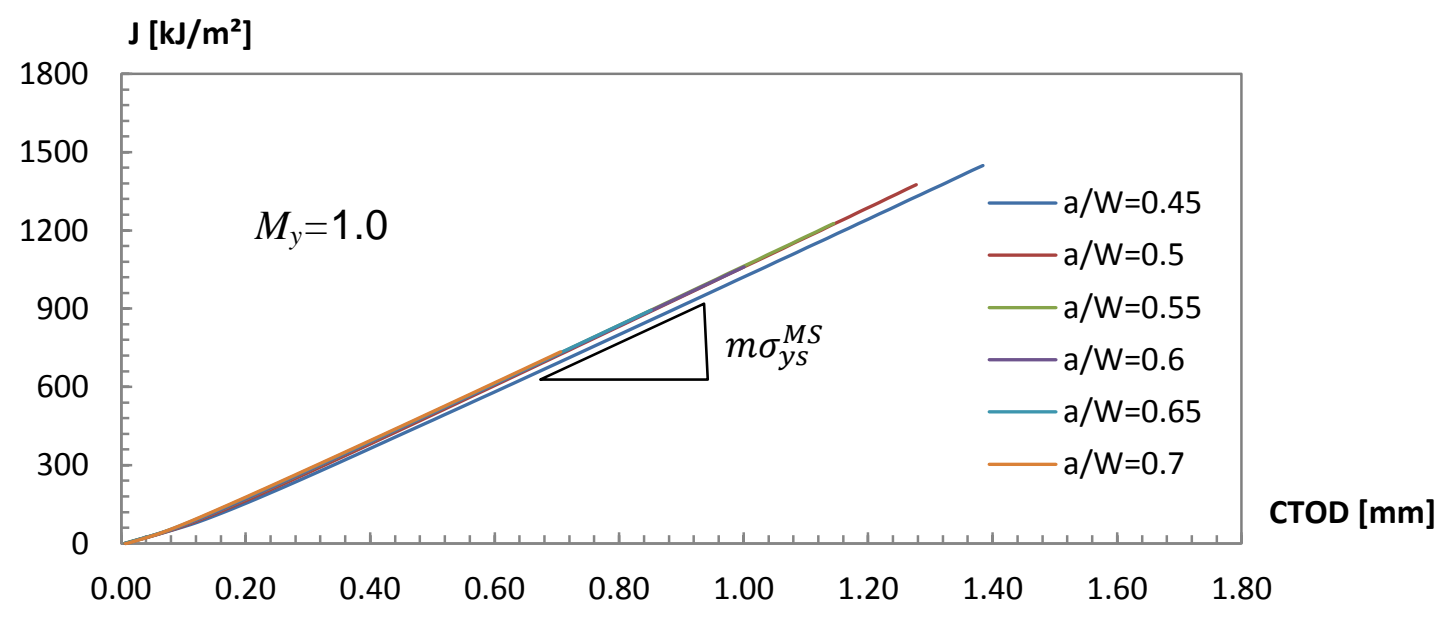

Figura 49 Relação entre $J$ vs. CTOD para a condição homogênea, $M_{y}=1.0$, com para diversos comprimentos de trinca.

Porém diferentemente ao observado nos trabalhos mencionados anteriormente 0 conjunto de gráficos da Figura 50 demonstra haver um efeito acoplado entre o nível de dissimilaridade mecânica e o comprimento de trinca adimensional $(a / W)$ afetando o fator $m$. 


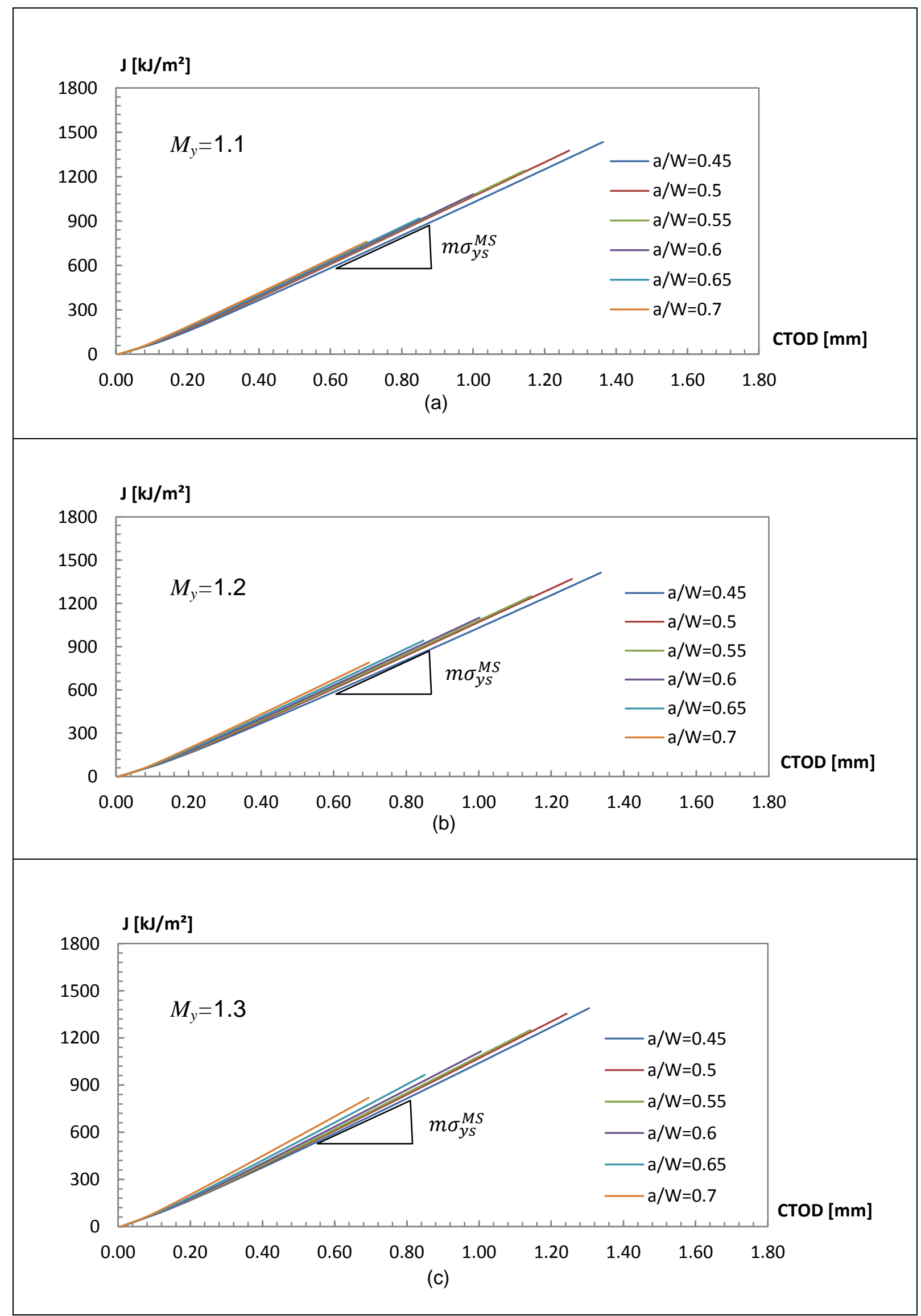

Figura 50 Relação entre $J$ vs. CTOD sob efeito de dissimilaridade mecânica para diversos comprimentos de trinca. (a) $M_{y}=1.1$; (b) $M_{y}=1.2$; (c) $M_{y}=1.3$. 
No gráfico da Figura 51 fica mais claro como se dá a influência do nível de dissimilaridade mecânica e do comprimento de trinca sobre o fator $m$. Do gráfico é possível inferir que o aumento no nível de dissimilaridade mecânica provoca a diminuição do fator de restrição plástico para todo o intervalo de comprimento de trinca e o comportamento dos valores do fator $m$ devido à variação do comprimento de trinca não é uniforme apresentando tendências sutilmente crescentes para trinca mais profundas e valores de $M_{y} \geq 1$.2. A título de ilustração, para uma trinca $a / W=0.45$ e $M_{y}=1.0$ obtém-se $m=2.59$, mantendo $a / W=0.45$ e variando $M y$ para 1.3, $m$ será igual a 2 , dando uma diferença percentual de aproximadamente $30 \%$ enquanto que para as mesmas condições citadas de dissimilaridade mecânica, mas para uma trinca a/W=0.7 a diferença é de $15.1 \%$.

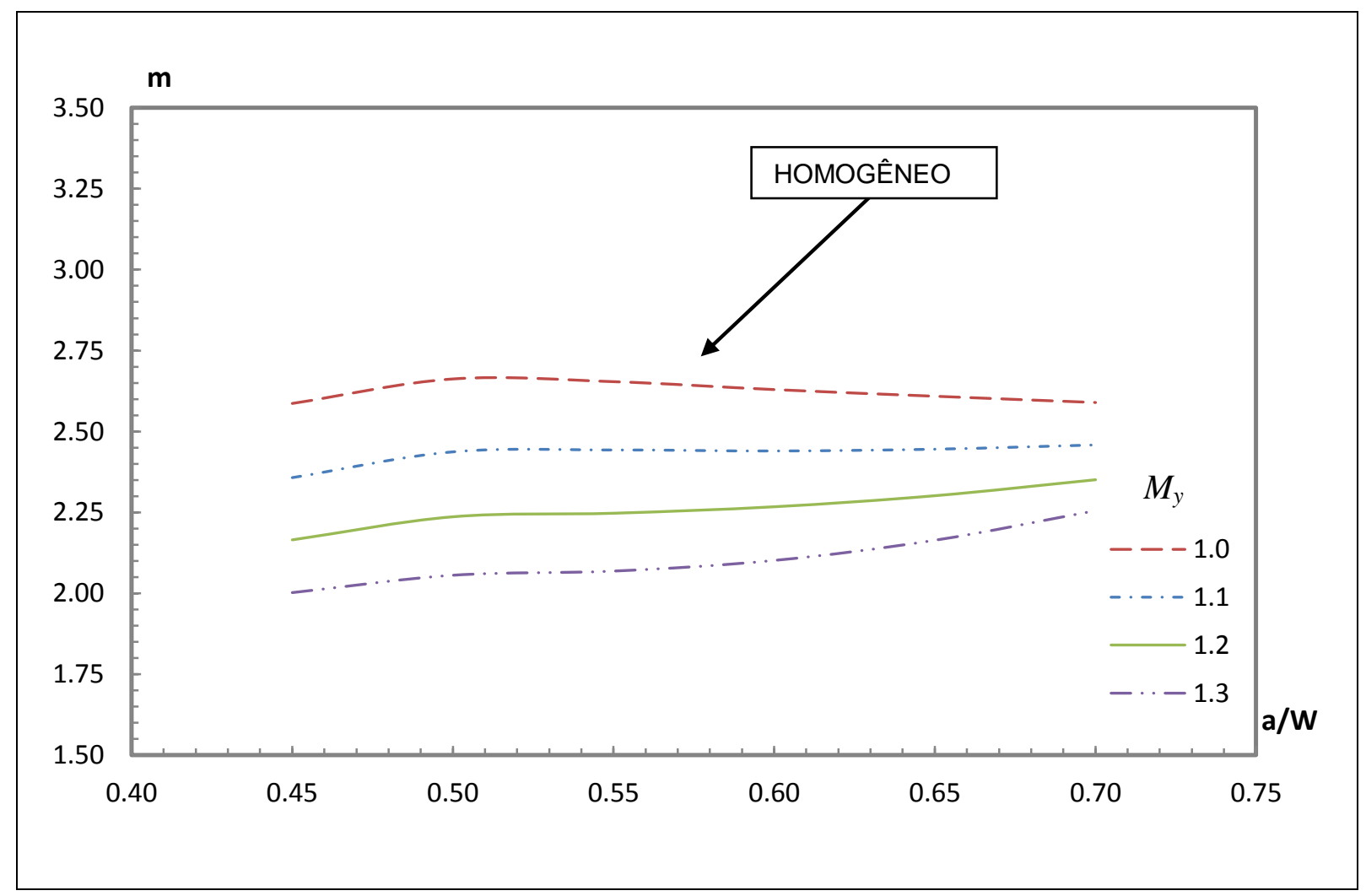

Figura 51 Influência do nível de dissimilaridade e comprimento de trinca adimensional $(a / W)$ sobre o fator $m$.

Foram realizadas regressões polinomiais aplicando o método dos mínimos quadrados [54] permitindo obter o fator $m$ em função do comprimento de trinca $(a / W)$ e do nível de dissimilaridade mecânica $\left(M_{y}\right)$, conforme mostram as Eqs. (4043). Os coeficientes desta regressão encontram-se na Tabela 8. 


$$
\begin{gathered}
m=f\left(\frac{a}{W} ; M_{y}\right) \\
m(a / W)=C_{0}+C_{1}\left(\frac{a}{W}\right)+C_{2}\left(\frac{a}{W}\right)^{2}+C_{3}\left(\frac{a}{W}\right)^{3}+C_{4}\left(\frac{a}{W}\right)^{4} \\
C_{k}=f\left(M_{y}\right) \\
C_{k}=K_{0}+K_{1}\left(M_{y}\right)+K_{2}\left(M_{y}\right)^{2}+K_{3}\left(M_{y}\right)^{3}
\end{gathered}
$$

Tabela 8 Coeficientes para a regressão polinomial da Eq.43 para cálculo do fator $m$.

\begin{tabular}{|c|c|c|c|c|}
\hline & $K_{0}$ & $K_{1}$ & $K_{2}$ & $K_{3}$ \\
\hline $\mathrm{C}_{0}$ & -1379.928 & 3558.640 & -3119.950 & 911.500 \\
\hline $\mathrm{C}_{1}$ & 10413.201 & -26840.768 & 23487.000 & -6844.167 \\
\hline $\mathrm{C}_{2}$ & -28918.334 & 74747.675 & -65395.200 & 19033.500 \\
\hline $\mathrm{C}_{3}$ & 35220.988 & -91290.972 & 79896.200 & -23244.833 \\
\hline $\mathrm{C}_{4}$ & -15874.425 & 41245.687 & -36118.150 & 10509.833 \\
\hline
\end{tabular}

Esta regressão polinomial multivariável é estritamente válida para o seguinte intervalo:

$$
0.45 \leq \frac{a}{W} \leq 0.7 \quad \text { e } \quad 1.0 \leq M_{y} \leq 1.3
$$


Algumas normas de ensaio de tenacidade à fratura empregam para a correlação entre $J$ e CTOD a tensão de referência definida por $\sigma_{0}=\sigma_{F L O W}$ onde $\sigma_{F L O W}=$ $\left(\sigma_{y s}+\sigma_{U T S}\right) / 2$. Frequentemente, os valores das propriedades mecânicas do material não estão disponíveis, mas alguns procedimentos de avaliação de integridade estrutural como API 579 e DNV F-101 fornecem expressões analíticas para a determinação do limite de resistência do material, Eqs (44 - 45) respectivamente. Porém os valores obtidos com estas expressões podem afetar o fator $m$.

$$
\begin{gathered}
\sigma_{U T S}=\sigma_{y S}\left[\frac{(500 N)^{N}}{\exp (N)}\right] \quad \text { onde } \quad N=1 / n \\
N=1.724-6.098\left(\frac{\sigma_{y s}}{\sigma_{U T S}}\right)+8.326\left(\frac{\sigma_{y s}}{\sigma_{U T S}}\right)^{2}-3.965\left(\frac{\sigma_{y s}}{\sigma_{U T S}}\right)^{3} \quad \text { onde } \quad N=\frac{1}{n}
\end{gathered}
$$

$\mathrm{Na}$ Figura 52 (a) e (b) são apresentas as curvas para o fator $m$ quando $\sigma_{F L O W}$ é empregada como tensão de referência e o limite o de resistência do material é calculado pela formulação da API 579 e pela formulação da DNV F-101, respectivamente.

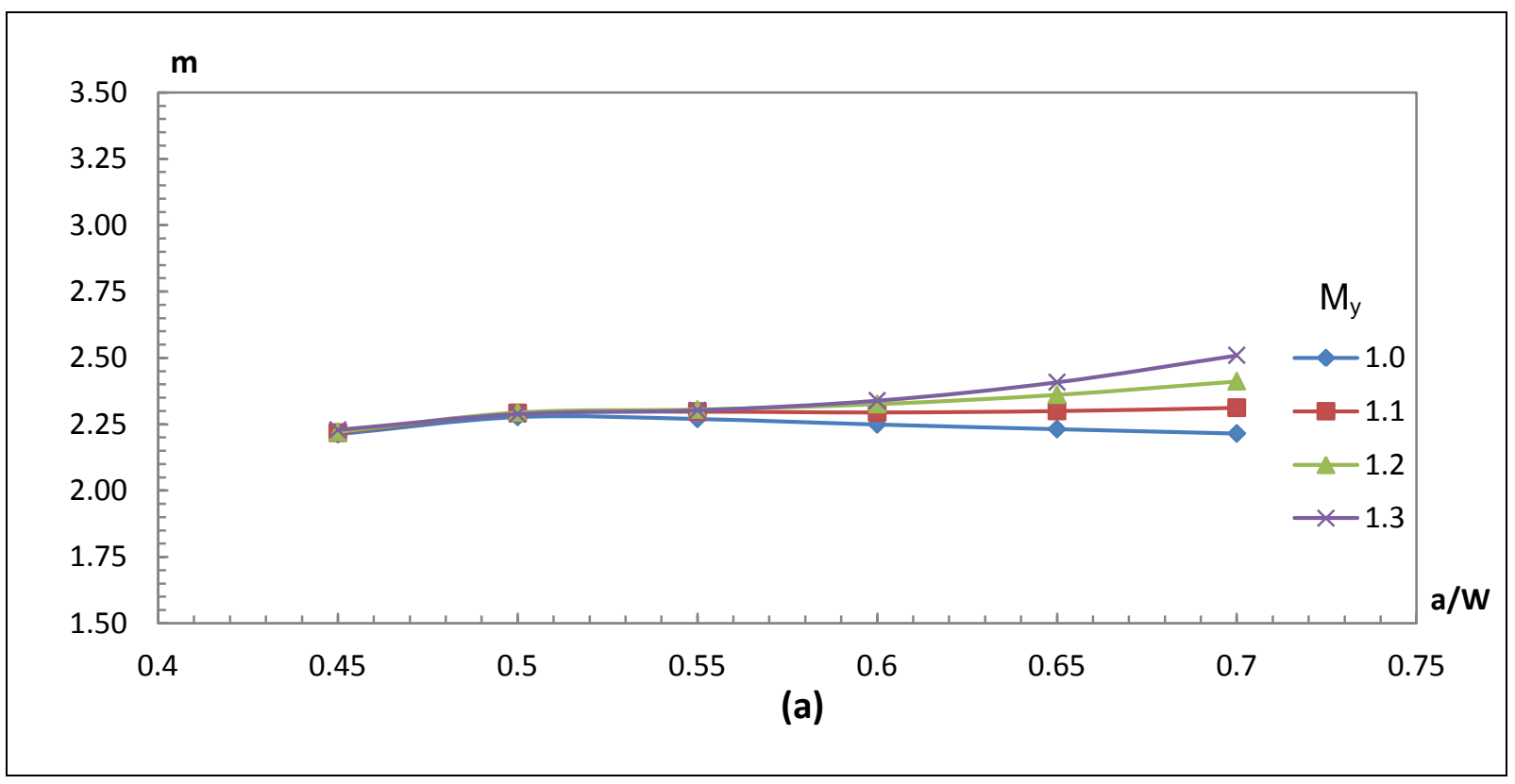




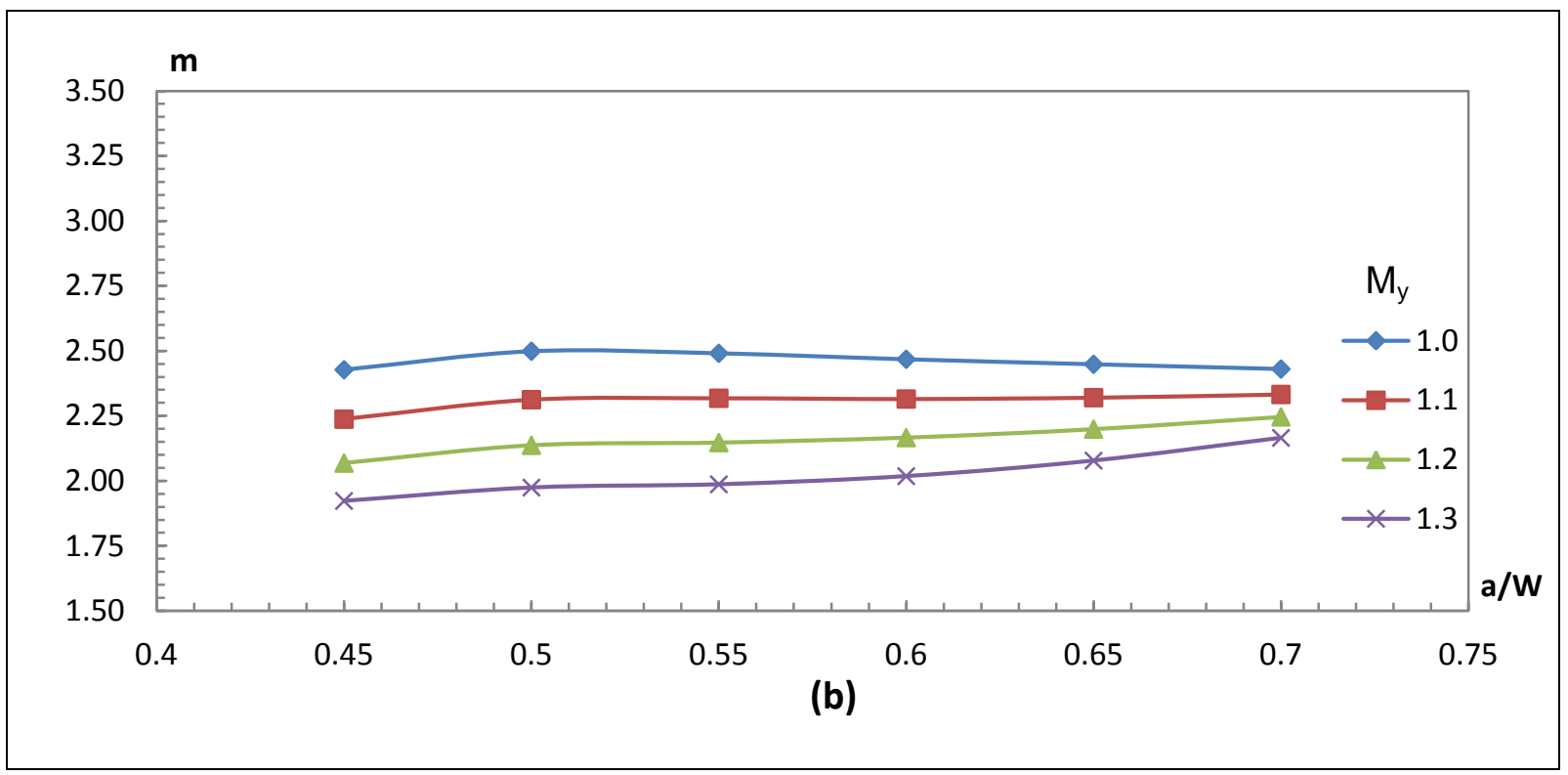

Figura 52 Gráficos para os valores de fator $m$ utilizando $\sigma_{F L O W}$ como tensão de referência. (a) Utilizando a expressão analítica da API 579 para o cálculo do limite de resistência do material. (b) Utilizando a expressão analítica da DVN F-101 para o cálculo do limite de resistência do material.

As três abordagens mostradas neste trabalho apresentam resultados diferentes entre si. A utilização da formulação encontrada no procedimento da DNV, para o cálculo do limite de resistência do material, gera valores e tendências mais próximos dos obtidos das análises realizadas neste trabalho. Com a utilização da formulação proposta pela API o fator $m$ apresentou uma baixa sensibilidade ao nível dissimilaridade mecânica para $a / W \leq 0.6$. 


\subsection{COMPARAÇÃo ENTRE OS VALORES DE CTOD NUMÉRICO E CALCULADOS POR NORMAS}

Esta seção apresenta a comparação dos valores de CTOD, $\delta$, calculados pelas normas experimentais de teste, BS 7448 (1991) e ASTM 1290 (2008), e os obtidos por meio de simulações numéricas sob a condição de estado plano de deformação. Para o cálculo analítico do CTOD os valores de área plástica, CMOD plástico e carregamento foram obtidos das simulações numéricas propostas na matriz de análise. Inicialmente são apresentados os resultados comparativos entre o CTOD numérico, $\delta_{90^{\circ}}$, e o CTOD obtido pela formulação da norma britânica, $\delta_{\mathrm{BS}}$, a seguir serão apresentados os valores comparativos $\delta_{90^{\circ}} v s . \delta_{\mathrm{ASTM}} \mathrm{e}$, finalmente, o comparativo entre $\delta_{\mathrm{BS}} v s$. $\delta_{\mathrm{ASTM}}$.

Nas Figuras 53 - 55, encontram-se os gráficos comparativos de $\delta_{90^{\circ}} v s$. $\delta_{\mathrm{BS}}$ para diversos comprimentos de trinca e níveis de dissimilaridade mecânica. Vale notar que o intervalo de comprimento de trinca permitido pela norma britânica é mais restrito $(0.45 \leq a / W \leq 0.55)$ do que o intervalo da norma da ASTM. Porém, para efeito de estudo, os gráficos da figura abaixo abrangem os comprimentos de trinca permitidos pela norma da ASTM, $0.45 \leq a / W \leq 0.7$.

Observou-se uma boa aderência entre os CTOD's para a condição homogênea, inclusive para os valores de trinca que excedem o comprimento $a / W=0.55$, a maior diferença encontrada foi de $11 \%$, para $a / W=0.45$. Porém, na presença de dissimilaridade mecânica, há discrepância entre os valores e tal discrepância aumenta constantemente com o tamanho adimensional da trinca até um máximo de $55 \%$, para $a / W=0.7$. Se considerado o valor máximo de $a / W$ recomendado pela norma britânica essa diferença é de $25.5 \%$. 


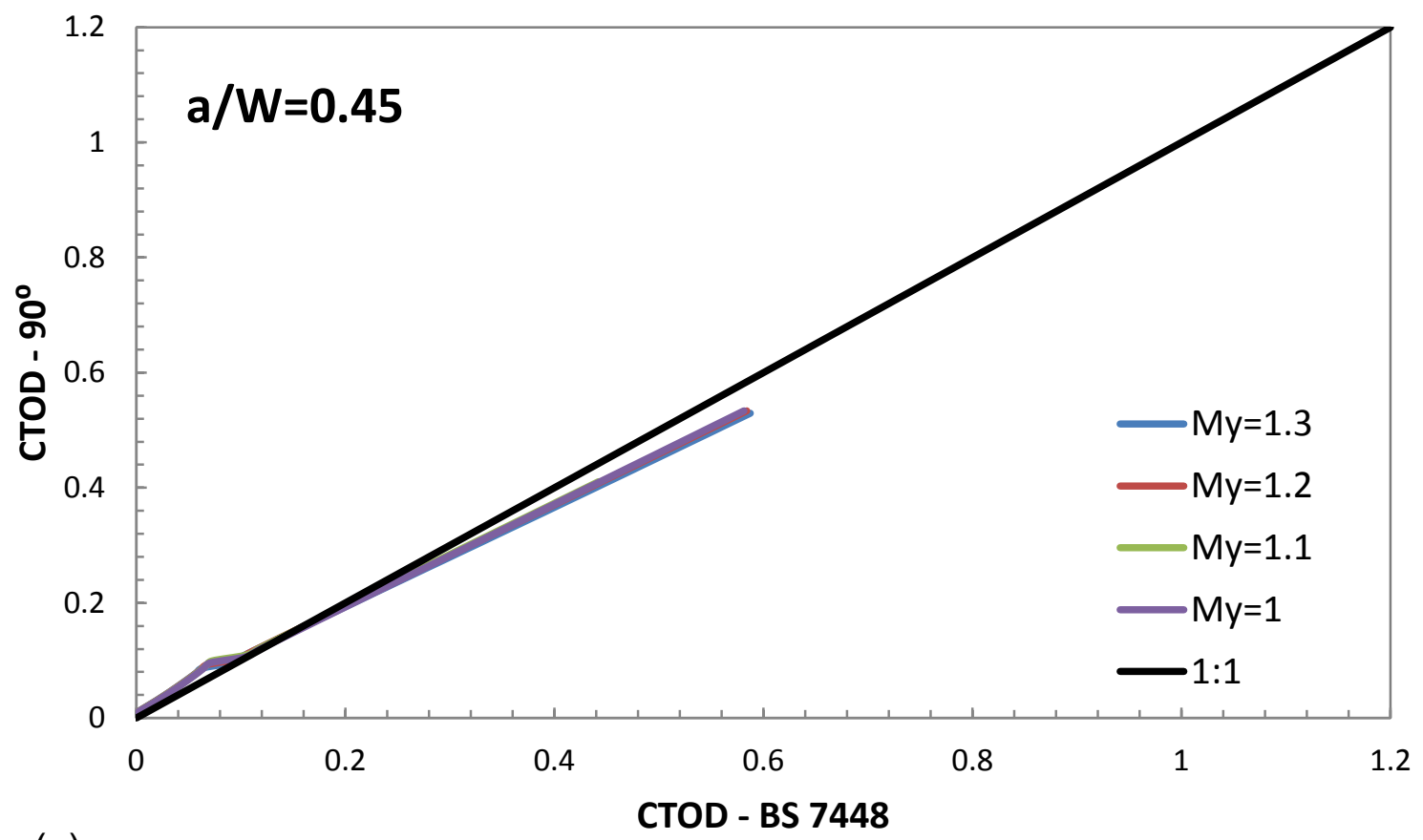

(a)

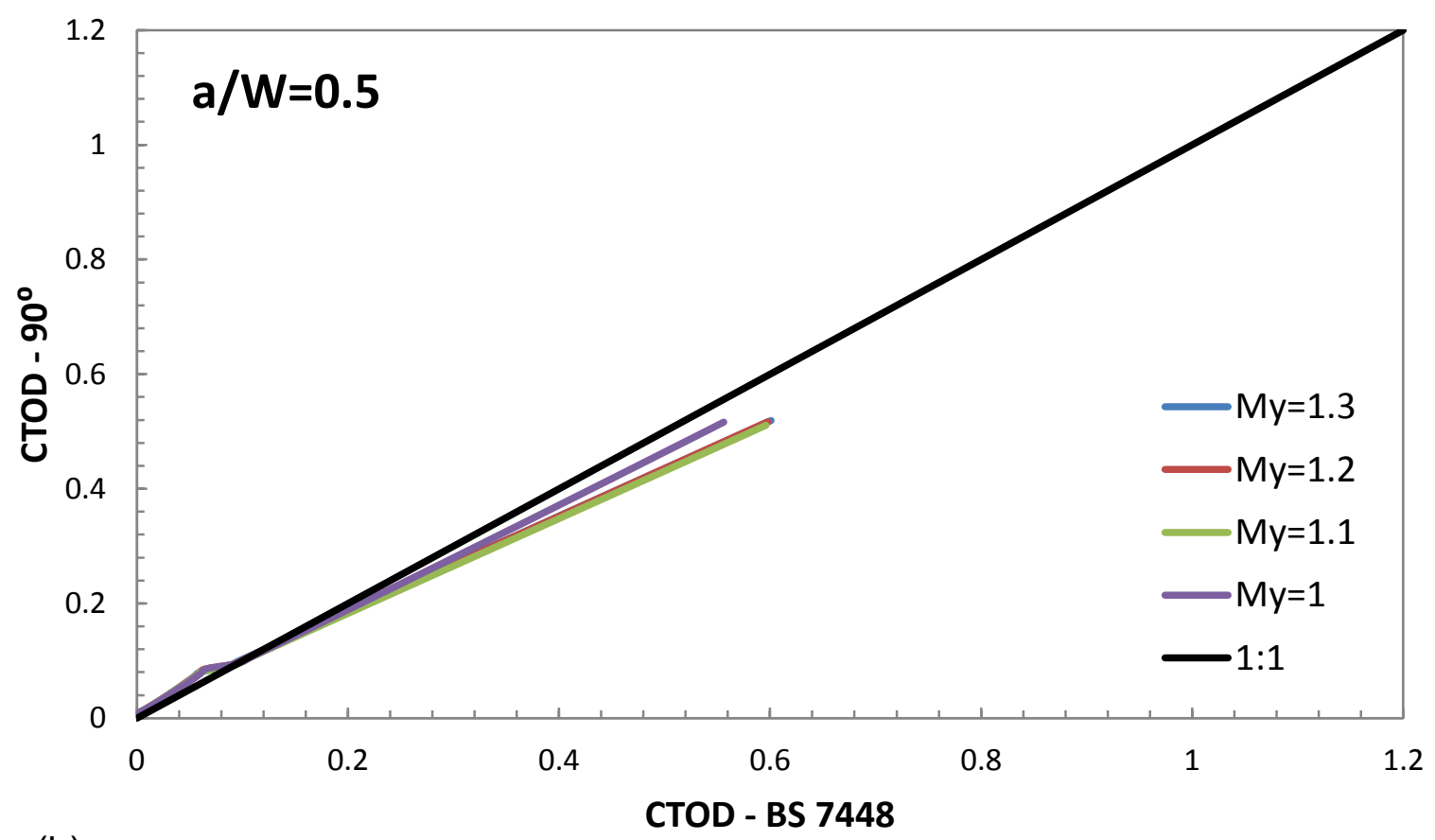

(b)

Figura 53 Comparativo entre os valores de CTOD obtidos das análises numérica (CTOD 90) e os valores de CTOD obtidos pelas formulações da norma BS 7448 [18]; (a) $a / W=0.45$; (b) $a / W=0.5$. 


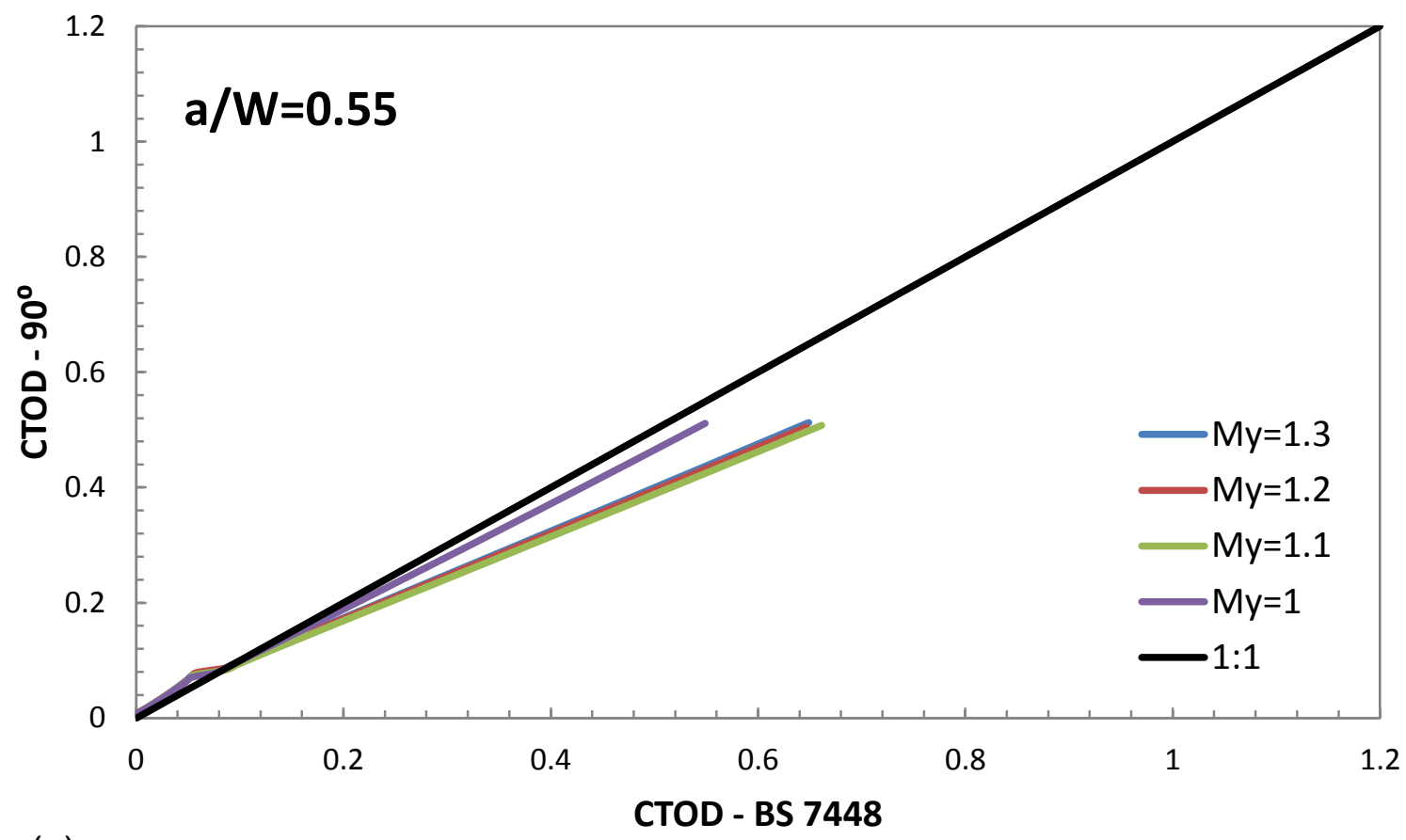

(a)

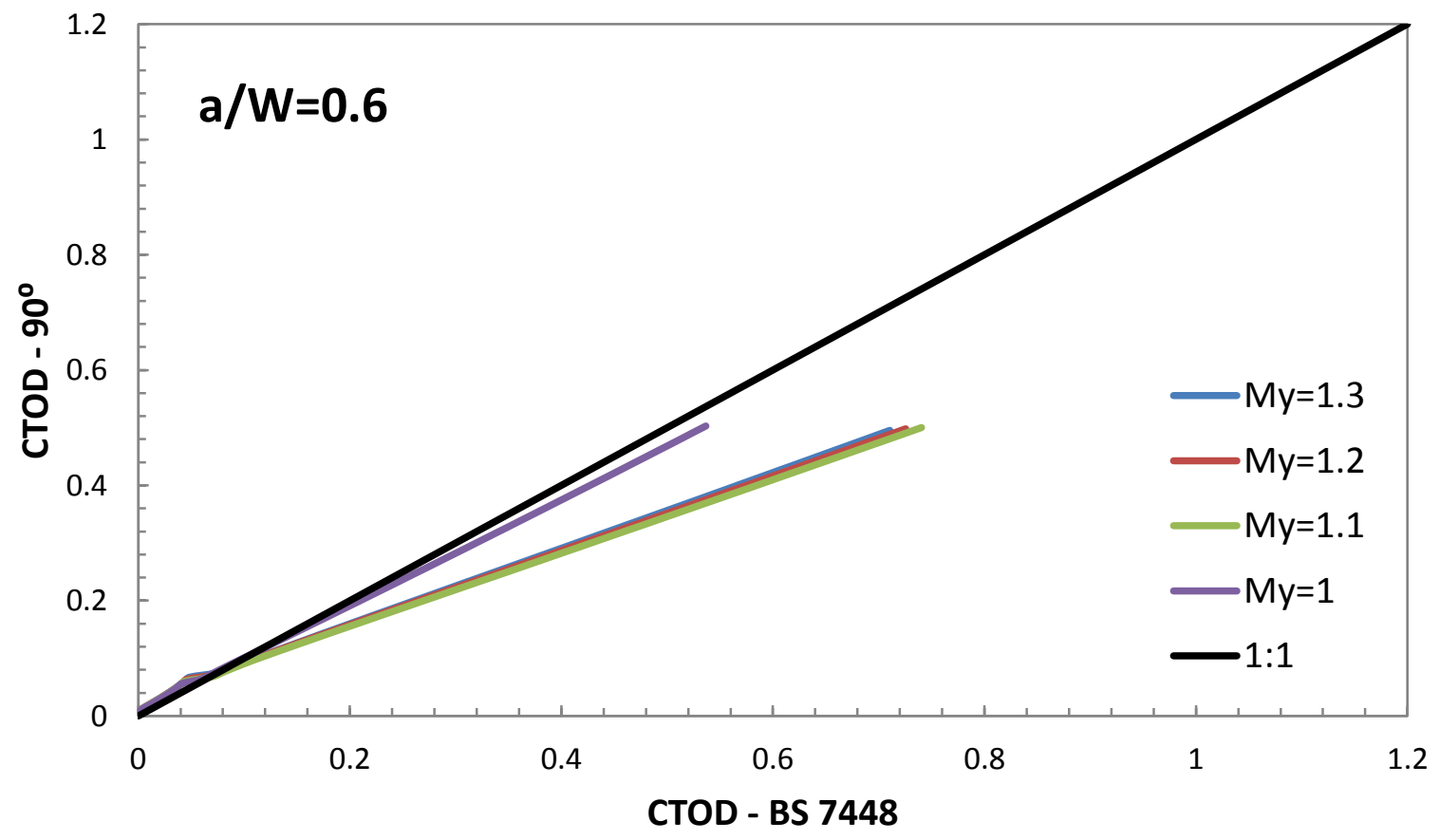

(b)

Figura 54 Comparativo entre os valores de CTOD obtidos das análises numérica (CTOD 90) e os valores de CTOD obtidos pelas formulações da norma BS 7448 [18]; (a) $a / W=0.55$; (b) $a / W=0.6$. 

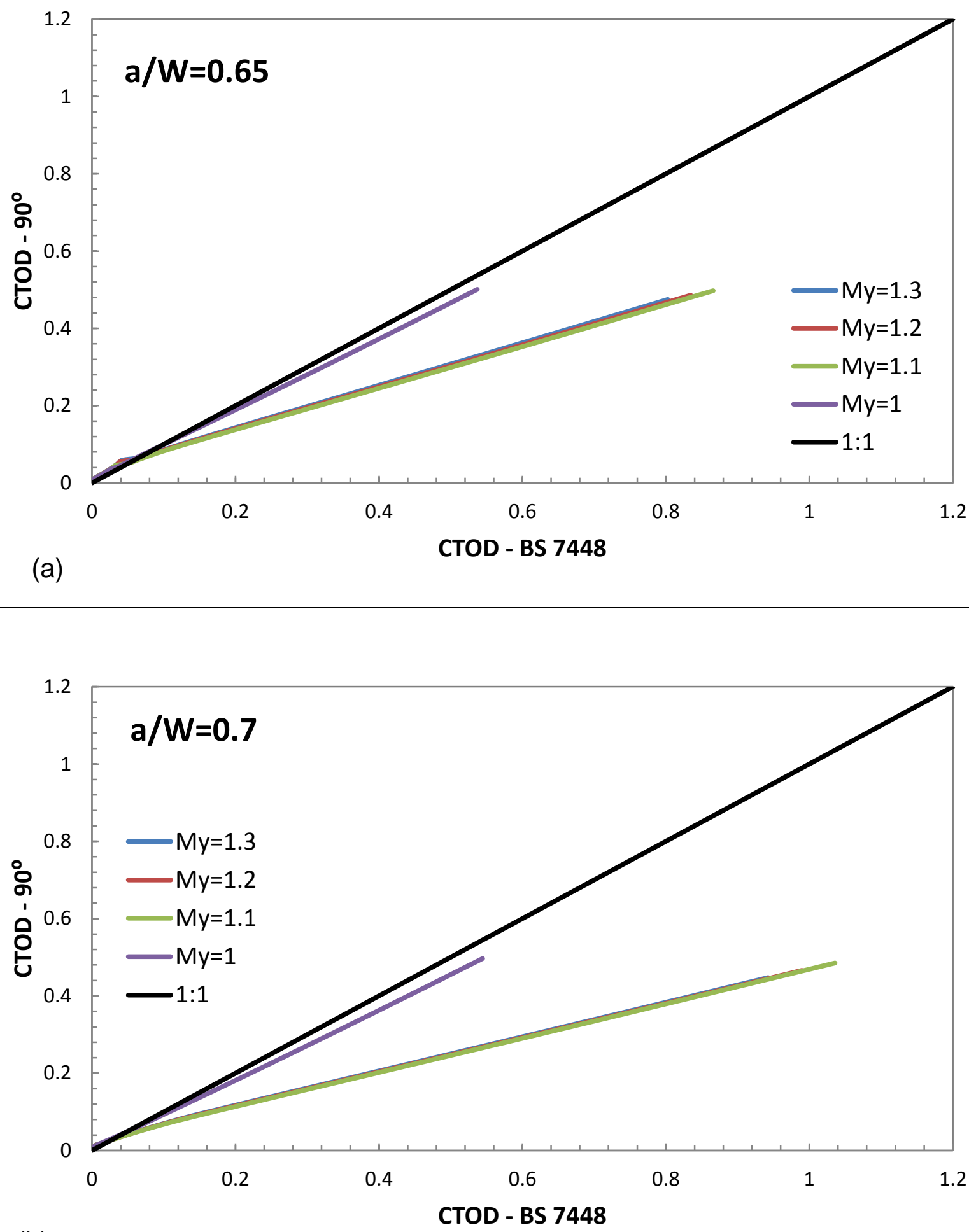

(b)

Figura 55 Comparativo entre os valores de CTOD obtidos das análises numérica (CTOD 90) e os valores de CTOD obtidos pelas formulações da norma BS 7448 [18]; (a) $a / W=0.65$; (b) $a / W=0.7$.

Abaixo seguem as expressões recomendadas pela BS 7448 para o cálculo do CTOD utilizando a geometria compacta da Figura 36 (C). 


$$
\begin{gathered}
\delta_{\text {Total }}=\delta_{E l}+\delta_{P l} \\
\delta_{E l}=\left(\frac{K^{2}}{2 E^{\prime} \sigma_{y s}}\right) \\
\delta_{P l}=\frac{r_{p}(W-a) V_{P l}}{r_{p}+0.54 a+(C-W)+z}
\end{gathered}
$$

$\mathrm{Na}$ expressão acima $z$ é distância entre a face da faca utilizada para afixação do medidor de deslocamento e a face frontal do corpo-de-prova. No caso deste trabalho $z=0 . r_{p}$ é o fator adimensional do modelo da rótula plástica, usualmente recomendado com o valor de 0.46 para a geometria $\mathrm{C}(\mathrm{T}), V_{P l}$ é o valor da componente plástica da abertura da boca da trinca.

Note que na parcela elástica do CTOD o fator de restrição plástica, neste caso $m_{\text {ssy }}$, pois deriva do modelo da faixa de escoamento, é mantido com o valor fixo de 2 e a tensão de referência, no denominador, é a tesão de escoamento do material. Para a parcela plástica nota-se que $r_{p}$ é fixo para todas as configurações de comprimento de trinca.

Nas Figuras 56 - 58 encontram-se os gráficos comparativos de $\delta_{90^{\circ}} v s$. $\delta_{\mathrm{ASTM}}$ para diversos comprimentos de trinca e níveis de dissimilaridade mecânica. Observa-se que os valores numéricos e obtidos por norma são bastante próximos tanto para a condição homogênea quanto para os casos com dissimilaridade mecânica em todo intervalo de comprimentos de trinca. $\mathrm{Na}$ condição homogênea a maior diferença observada foi de $12.4 \%$, diferença semelhante à encontrada para o caso com dissimilaridade mecânica. 


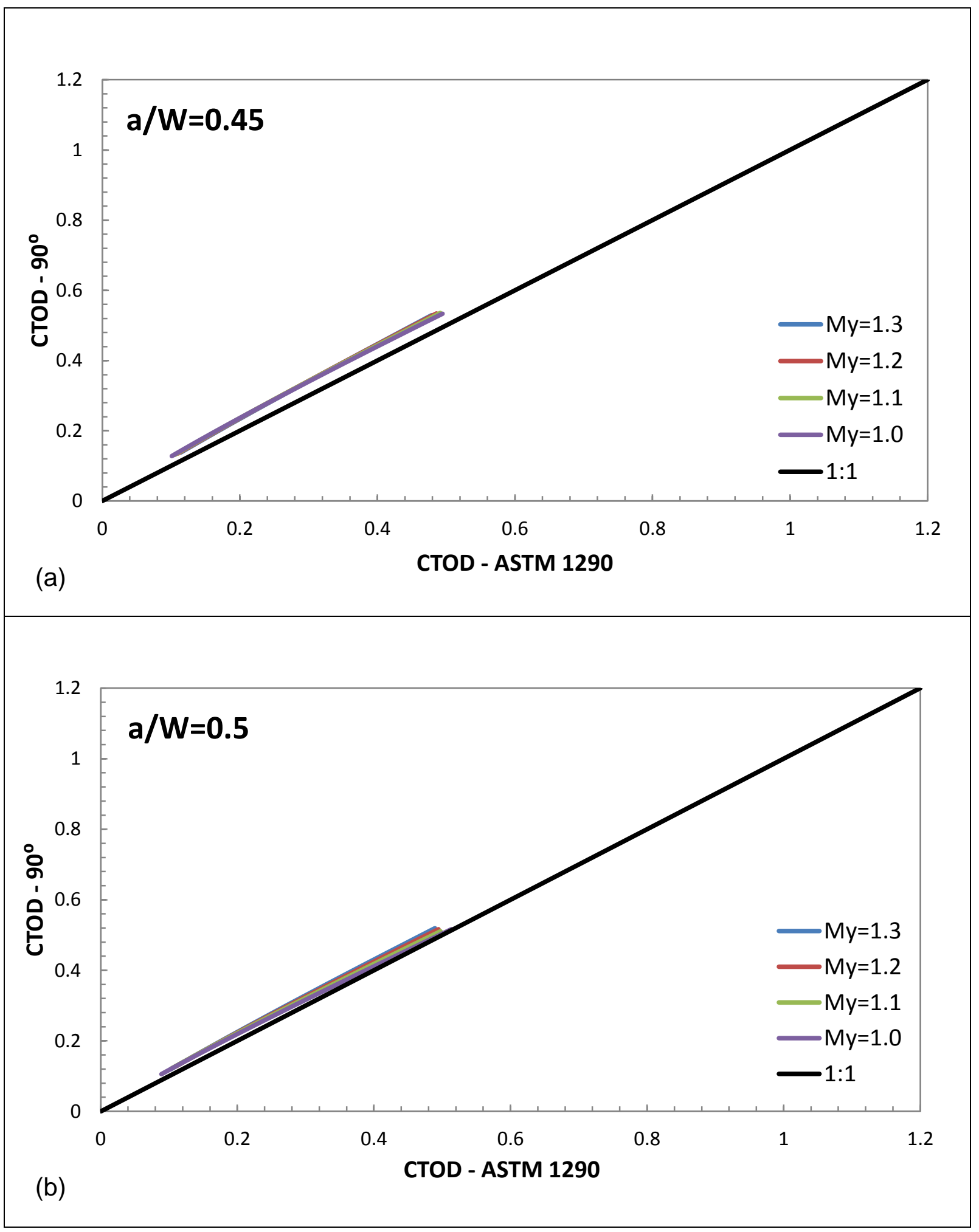

Figura 56 Comparativo entre os valores de CTOD obtidos as análises numérica (CTOD $\left.90^{\circ}\right)$ e os valores de CTOD obtidos pelas formulações da norma ASTM 1290 [19]; (a); $a / W=0.45$; (b) $a / W=0.5$. 

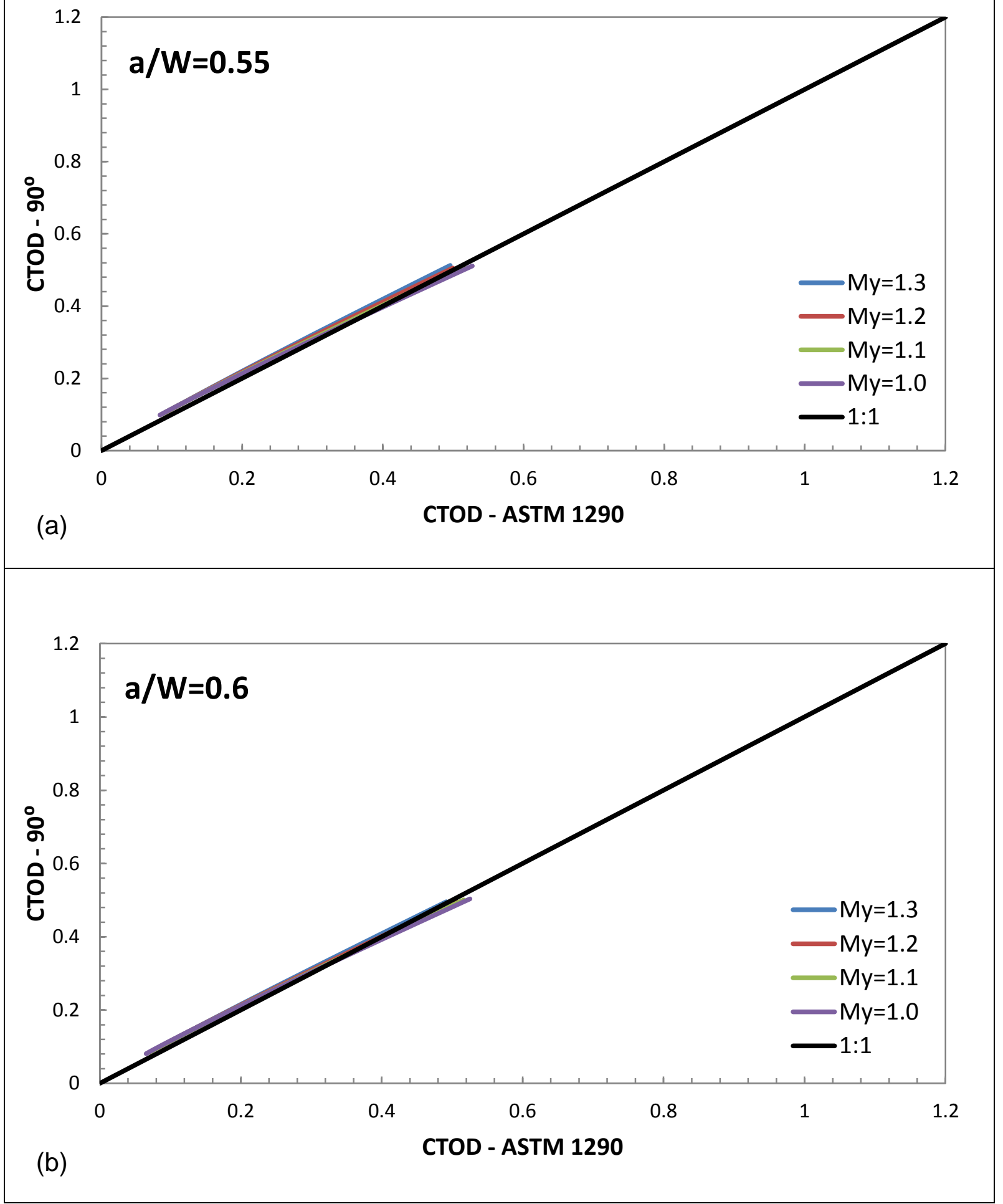

Figura 57 Comparativo entre os valores de CTOD obtidos as análises numérica (CTOD 90) e os valores de CTOD obtidos pelas formulações da norma ASTM 1290 [19]; (a); $a / W=0.55$; (b) $a / W=0.6$. 


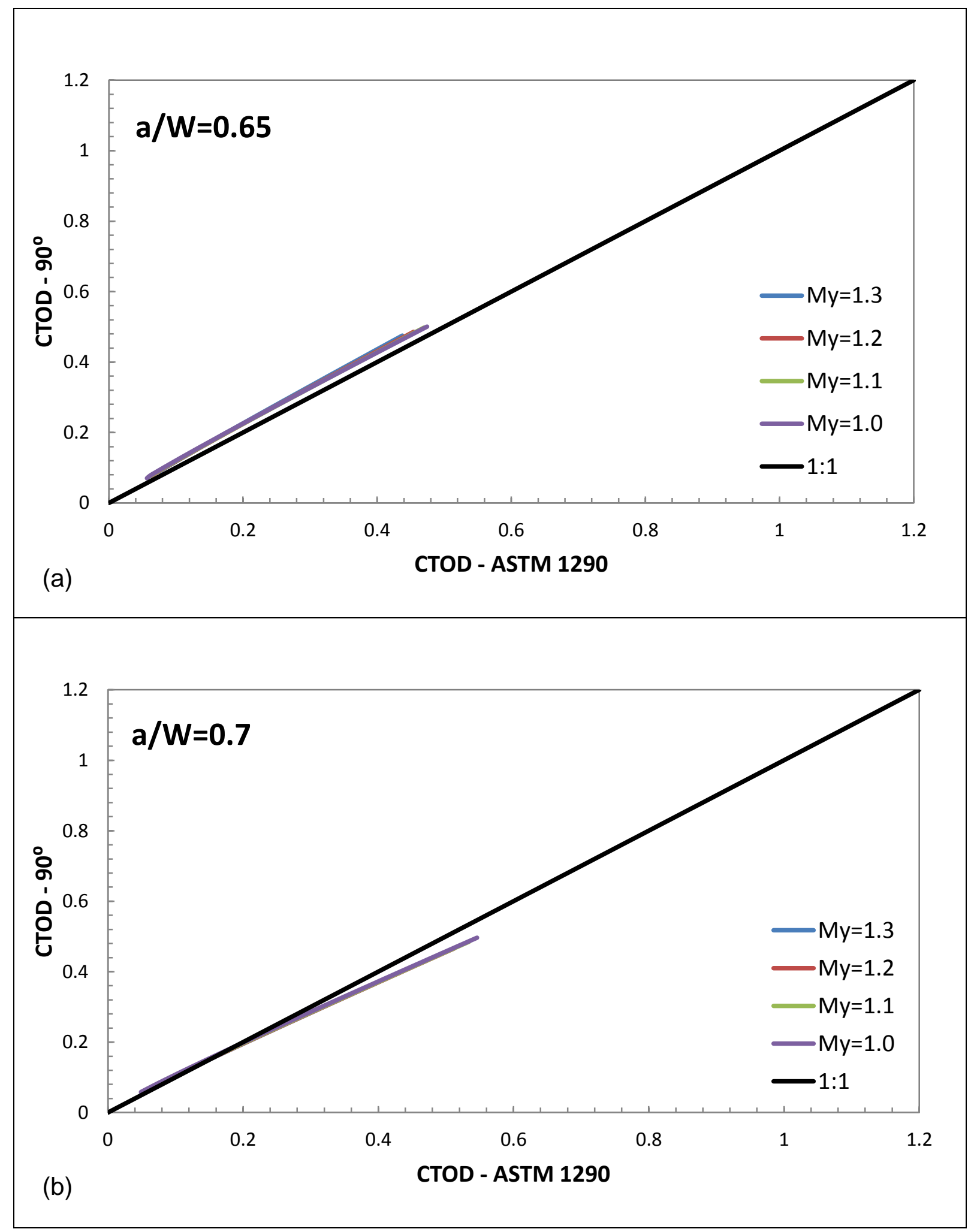

Figura 58 Comparativo entre os valores de CTOD obtidos as análises numérica (CTOD 90) e os valores de CTOD obtidos pelas formulações da norma ASTM 1290 [19]; (a); $a / W=0.65 ;$ (b) $a / W=0.7$.

Abaixo segue a formulação da norma ASTM 1290 para o cálculo de CTOD utilizando a geometria compacta, semelhante à Figura $36(\mathrm{C})$. 


$$
\delta_{\text {Total }}=\frac{1}{m \sigma_{\text {Flow }}}\left(J_{E l}+J_{P l}\right)
$$

Para a conversão de valores de $J$ em CTOD o fator de restrição plástica, ver Eq. (50), é apresentado como uma função da relação entre a tensão de escoamento do material e o limite de resistência do material. E a tensão de referência, encontrada no denominador, $\sigma_{F l o w}$, é dada pela média entre tensão de escoamento e o limite de resistência do material.

$$
\begin{gathered}
m=3.62-4.21\left(\frac{\sigma_{y s}}{\sigma_{T S}}\right)+4.33\left(\frac{\sigma_{y s}}{\sigma_{T S}}\right)^{2}-2\left(\frac{\sigma_{y s}}{\sigma_{T S}}\right)^{3} \\
\delta_{E l}=\frac{1}{m \sigma_{F l o w}}\left(\frac{K^{2}}{E^{\prime}}\right)
\end{gathered}
$$

Na parcela plástica, Eq 52, o fator $\eta$ é uma função do comprimento de trinca, conforme a Eq. 53, z é a distância entre a face da faca onde o medidor de deslocamento é fixado e a face frontal do corpo-de-prova e $\alpha$ é um fator que varia dependendo do ponto onde o deslocamento é avaliado, no caso deste trabalho $\alpha=0.25 \mathrm{~W}$, pois o ponto de avaliação do deslocamento está localizado na face frontal do espécime.

$$
\begin{gathered}
\delta_{P l}=\frac{1}{m \sigma_{F l o w}}\left[\frac{\eta A_{P l}}{B(W-a)\{1+(\alpha+z) /(0.8 a+0.2 W)\}}\right] \\
\eta=-7.999+49.737\left(\frac{a}{w}\right)-78.988\left(\frac{a}{w}\right)^{2}+41.226\left(\frac{a}{w}\right)^{3}
\end{gathered}
$$


Para a avaliação do CTOD é necessário o valor do limite de resistência do material. Este valor foi obtido utilizando a Eq. 45, fornecida pelo procedimento de análise de integridade estrutural API 579.

Os gráficos das Figuras 59 - 61 fazem o comparativo entre os valores de CTOD obtidos por norma, $\delta_{\mathrm{ASTM}} v s$. $\delta_{\mathrm{BS}}$. Conforme citado anteriormente os limites recomendados pela norma BS 7448 para comprimento de trinca foram extrapolados para fins de pesquisa. Valores de $\delta$ para trincas acima de $a / W=0.55$ foram plotados e observou-se para a condição homogênea uma boa concordância entre os valores da BS 7448, ASTM 1290 (diferença percentual máxima de 10.4\%). Porém na presença de dissimilaridade mecânica as diferenças entre as normas foram significativas (diferença máxima de $49.3 \%$ para $a / W=0.7$ e respeitando o limite de $a / W=0.55$ da BS 7448 a diferença foi $22.3 \%$ ). 


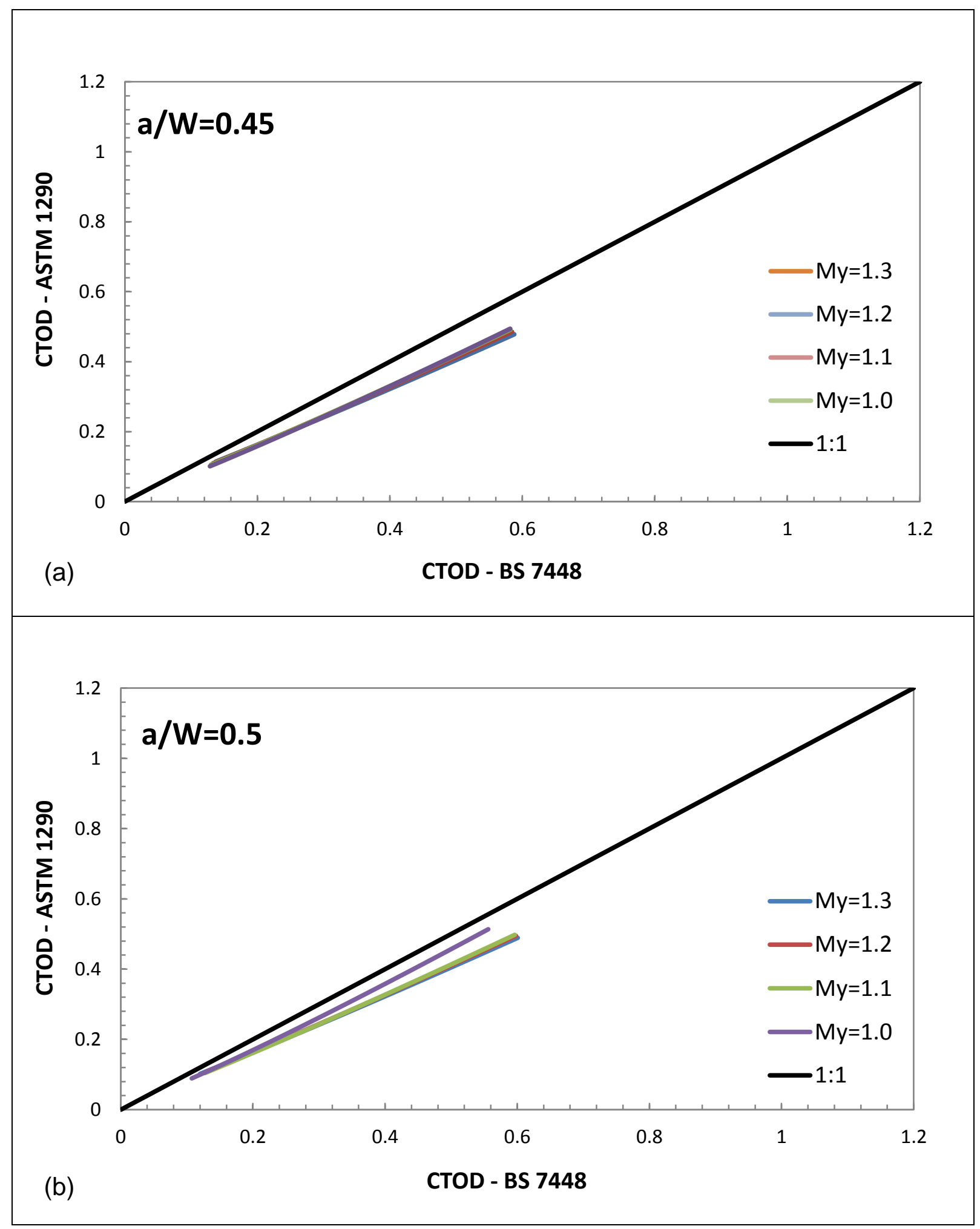

Figura 59 Comparativo entre os valores de CTOD obtidos pelas formulações da norma BS 7448 [18] e os valores de CTOD obtidos pelas formulações da norma ASTM 1290 [19]; (a); $a / W=0.45$; (b) $a / W=0.5$. 


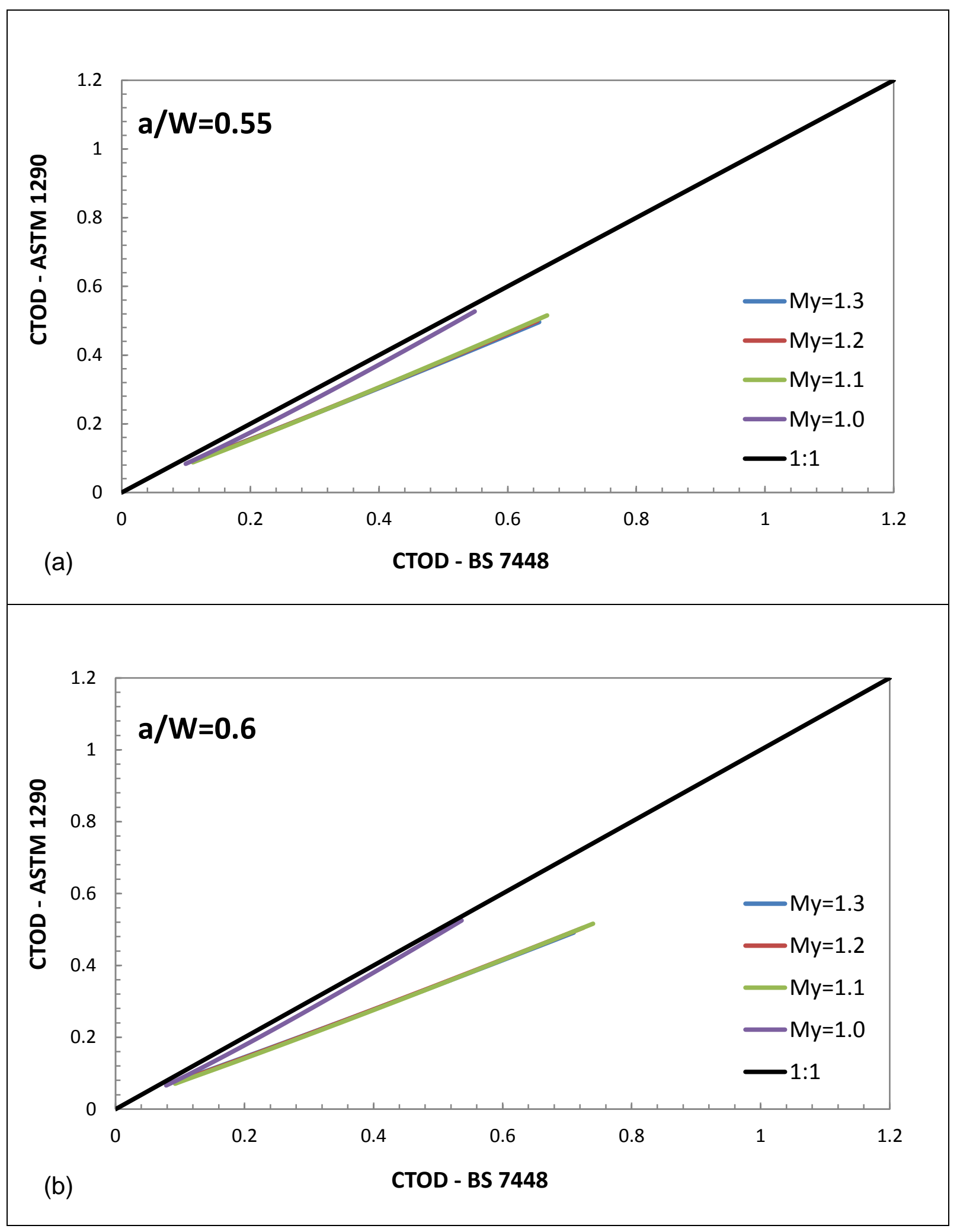

Figura 60 Comparativo entre os valores de CTOD obtidos pelas formulações da norma BS 7448 [18] e os valores de CTOD obtidos pelas formulações da norma ASTM 1290 [19]; (a); $a / W=0.55$; (b) $a / W=0.6$. 


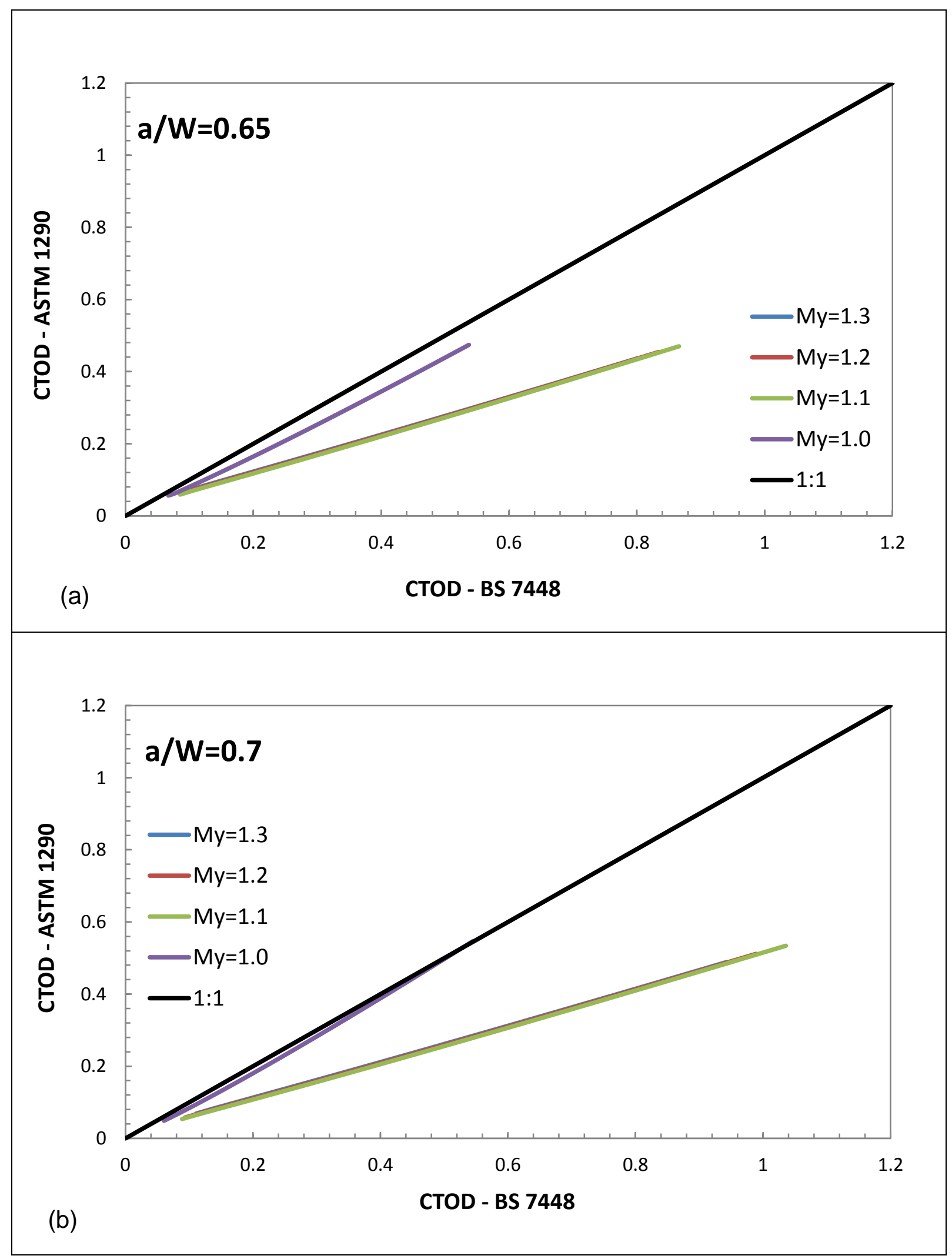

Figura 61 Comparativo entre os valores de CTOD obtidos pelas formulações da norma BS 7448 [18] e os valores de CTOD obtidos pelas formulações da norma ASTM 1290 [19]; (a); $a / W=0.65$; (b) $a / W=0.7$.

Para a caracterização de tenacidade à fratura de materiais homogêneos as normas, assim como os resultados obtidos numericamente, são coerentes entre si 
e qualquer uma das abordagens é recomendada. Entretanto existem "simplificações" na norma britânica que podem comprometer os resultados de tenacidade à fratura de juntas soldas.

Podem ser apontadas como simplificações o valor fixo para o parâmetro adimensional, $r_{p}=0.46$, e o valor fixo de 2 para o fator de restrição plástica. Como mostrado por Donato [33], em sua vasta matriz de análise, o parâmetro $r_{p}$ é influenciado tanto pelo comprimento de trinca quanto pelo nível de dissimilaridade mecânica e o fator de restrição plástica foi mostrado em seções anteriores ser também função do nível de dissimilaridade mecânica e do comprimento de trinca, em menor escala. 


\section{CONCLUSÃO}

Os resultados e análises deste trabalho vão ao encontro de inúmeros trabalhos apresentados por outros autores e disponíveis na literatura específica a respeito do forte efeito da dissimilaridade mecânica na relação entre os carregamentos globais sofridos por um componente trincado e as forças locais desenvolvidas na ponta deste defeito.

As alterações provocadas nos campos de tensões e deformações pela presença de dissimilaridades mecânicas decorrentes do processo de soldagem comprometem o uso das normas propostas pela ASTM e BS. Os resultados mostraram que mesmo dentro do limite superior aceitável de dissimilaridade mecânica, os valores obtidos por norma comparativamente aos obtidos numericamente apresentaram em alguns casos discrepâncias consideráveis deixando evidente a necessidade de dados mais precisos para a estimação de parâmetros de tenacidade à fratura de forma confiável. E neste sentido o presente trabalho corroborou para o aumento desta base de dados de fatores $\eta$ para um corpo de prova, $\mathrm{C}(\mathrm{T})$, que apresenta uma série de vantagens, mas que por vezes fica esquecido devido à inexistência de tais dados.

No que se refere à geometria compacta, alguns resultados encontrados no decorrer deste trabalho foram diferentes dos resultados apresentados no passado por outros pesquisadores que identificaram diferenças da ordem de $30 \%$ entre as duas normas. Se respeitado o intervalo de comprimento de trinca recomendado pela norma britânica $(0.45 \leq a / W \leq 0.55)$, os resultados gerados a partir das normas ASTM 1290 e BS 7448 possuem uma diferença percentual máxima de 13\% para a condição homogênea, onde não há cordão de solda.

Porém sob efeito da dissimilaridade mecânica combinado com o aumento do comprimento da trinca, a relação entre os CTOD's calculados por norma é alterada. Para o valor de trinca mais raso permitido pelas normas $(a / W=0.45)$, na presença de dissimilaridade mecânica, não houve alteração significativa dos valores de CTOD e os resultados encontrados são muito próximos dos resultados obtidos para a condição homogênea. Entretanto, para os comprimentos de trinca mais profundos. $a / W=0.5$ e 0.55 , na presença de dissimilaridade mecânica, as 
diferenças percentuais foram crescentes até o máximo de $22.3 \%$, ainda menor do que os $30 \%$ proposto por alguns autores.

Não é possível afirmar com precisão, mas as diferenças encontradas por outros autores podem ser decorrentes da utilização de versões, destas duas normas, ou considerações diferentes das utilizadas neste trabalho. Outro ponto importante de ser ressaltado é a respeito do uso de valores analíticos, obtidos por fórmulas, para o limite de resistência do material. Como apresentado anteriormente há nos procedimentos $E C A$ formulações para tal, mas o autor não pode afirmar que estas relações recuperam fidedignamente os valores obtidos por testes experimentais de tração, por exemplo, e isto pode introduzir desvios principalmente na conversão de valores de $J$ em CTOD.

Portanto, para a condição sem cordão de solda, neste trabalho tratada como condição homogênea, o uso dos valores numéricos ou dos valores calculados por norma para a determinação do CTOD são muito próximos e ambos os métodos são recomendados. Porém na presença de dissimilaridades mecânicas introduzidas pela presença de um cordão de solda, os valores de CTOD calculados por normas e obtidos numericamente mostraram discrepâncias consideráveis principalmente quando utilizadas para tal cálculo as formulações da norma BS 7448 e por isso fazse ressalva quanto ao uso desta norma para a avaliação da tenacidade à fratura de juntas soldadas. Os valores de CTOD obtidos a partir das formulações da norma ASTM 1290 apresentaram diferenças percentuais pequenas em relação aos valores numéricos e, portanto aceitáveis sendo recomendado o seu uso para a avaliação da tenacidade à fratura em juntas soldadas utilizando corpos de prova com geometria compacta. 


\section{SUGESTÃO PARA TRABALHOS FUTUROS}

- Avaliação do efeito da dissimilaridade mecânica em juntas soldadas sobre os parâmetros $J$ e CTOD, fixando-se as propriedades do metal de solda e variando as propriedades do metal de base.

- Avaliação de fatores $\eta$ em corpos-de-prova com geometria $C(T)$ e trinca na interface entre o metal de base e o metal de solda.

- Avaliação do efeito de dissimilaridade mecânica sobre o fator adimensional $r_{p}$ para uso do Modelo da Rótula Plástica em corpos-de-prova com geometria $\mathrm{C}(\mathrm{T})$. 


\section{REFERÊNCIAS BIBLIOGRAFIA}

[1]. Cravero, S., "Desenvolvimento de Procedimento para Avaliação de Curvas $J-R$ em Espécimes à Fratura $S E(T)$ Utilizando Método da Flexibilidade", Tese de Doutorado, Escola Politécnica da Universidade De São Paulo, 2007.

[2]. Leis B. N., Elber R. J., Fracture Propagation Control in Onshore Transmission Pipelines, in Onshore Pipeline Technology Conference Invited Paper, p.2.1 - 2.35, 1998, Anais.

[3]. Hippert Jr., E., "Investigação Experimental do Comportamento Dúctil de Aços Api-X70 e Aplicação de Curvas de Resistência $J$-R Para Previsão de Colapso Em Dutos.", Tese de Doutorado, Escola Politécnica da Usp, 2004.

[4]. Savioli, R. G., Ruggieri C., "Improved $J$ And CTOD Estimation Formulas for C(T) Fracture Specimens Including Overmatched Weldments", Proceedings of the Asme 2011 Pressure Vessels \& Piping Division Conference, Maryland, 2011.

[5]. British Standard Institution., "Guide on Methods for Assessing The Acceptability of Flaws In Metallic Structures", BS7910,1999.

[6]. American Petroleum Institute. "Recommend Practice for Fitness-forService." API-RP-579, 2000.

[7]. SINTAP: Structural Integrity Assessment Procedure for European Industry.Final Procedure, 1999.

[8]. Det Norske Veritas. "Submarine Pipeline Systems." DNV-OS-F101, 2007.

[9]. Det Norske Veritas. "Fracture Control for Pipeline Installation Methods Introducing Cyclic Plastic Strain." DNV-RP-F108, 2006.

[10]. American Petroleum Institute. "Recommended Practice For Preproduction Qualification For Steel Plates For Offshore Structures." APIRP 2Z, 2005.

[11]. American Petroleum Institute. "Welding of Pipeline and Related Facilities." API-1104, 2005.

[12]. Wells A.A.,"Unstable Crack Propagation in Metal: Cleavage and Fast Fracture." Proceedings Of Crack Propagation Symposium, Vol. 1, Paper 84, Cranfield, UK, 1961.

[13]. Burdekin, F. M. and Stone, D. E. W., "The Crack Opening Displacement Approach to Fracture Mechanics in Yielding Materials", Journal of Strain Analysis, Vol. 1, pp.144-153, 1966. 
[14]. Burdekin, F. M. and Dawes, M. G., "Practical Use Of Linear Elastic And Yielding Fracture Mechanics With Particular Reference To Pressure Vessels" in Proceedings of the Institute of Mechanical Engineers Conference, London, pp.28-37, 1971.

[15]. British Standards Institution, "Guidance on Some Methods For Derivation Of Acceptance Levels for Defects In Fusion Welded Joints", PD 6493, 1980.

[16]. Hadley, I., Ainsworth, B., Budden, P. and Sharples, J., "The Future of BS 7910 Flaw Assessment Procedures." In Proceedings of the ASME 2010 Pressure Vessels \& Piping Division Conference, Washington, 2010

[17]. Anderson, T. L., "Fracture Mechanics: Fundaments and Applications" 2nd Edition, CRC Press, New York, 1995.

[18]. British Standard, "Fracture Mechanics Toughness Tests", BS 7448, 1991.

[19]. American Society for Testing and Materials, "Standard Test Method for Crack-Tip Opening Displacement (CTOD) Fracture Toughness Measurement", ASTM E1290, 2008.

[20]. Tagawa, T., Kayamori, Y., Ohata, M., Handa T., Kawabata, T., Yamashita, Y., Tsutsumi, K., Yoshinari, H., Aihara, S. and Hagihara, Y., "Comparasion of CTOD Stadards: BS 7448-Part 1 and Revised ASTM1290", Engineering Fracture Mechanics 77, 2010, pp. 327-336.

[21]. Kayamori, Y., Inoue, T., Tegawa, T., "Transformation of BS7448CTOD to ASTM E1290-CTOD" in Journal of Pressured Vessel Technology, Vol. 132, 2010, pp. 041401-1-041401-7.

[22]. Griffith A. A., "The Phenomena of Rupture and Flow in Solids" Philosophical Transactions, Series A, Vol. 221, 1920, pp. 163-198

[23]. Irwin G. R., "Fracture Dynamics." Fracturing of Metals, Americam Society for Metal, Cleveland, 1948, pp. 147-166.

[24]. Irwin G. R., "Onset of Fast Crack Propagation in High Strenght Steel and Aluminum Alloys." Sagamore Research Conference Proceedings, Vol. 2, 1956, pp. 289-305.

[25]. Westergaard, H. M., "Bearing Pressure and Vessel." Journal of Applied Mechanics, Vol. 6, 1939, pp. 49-53.

[26]. Hutchinson, J. W., "A Singular Behavior at the end of a Tensile Crack Tip in a Hardening Material." Journal of the Mechanics And Physics Of Solids, Vol.16, 1968, pp. 379-386. 
[27]. Rice, J. R., E Rosengren, G. F., "Plane Strain Deformation Near The Crack Tip In A Power-Law Hardenig Material." Journal of the Mechanics And Physics of Solids, VOL.16, 1968, PP. 1-12.

[28]. Williams, M.L., "Stress Singularities Resulting from Various Boundary Conditions in Angular Corner Plates in Extension." Journal of Applied Mechanics Vol. 19, 1952, pp. 526-528.

[29]. Cravero S., "Metodologia Biparamétrica para Análise de Efeitos de Restrição sobre a Fratura de Componentes Estruturais e Aplicações à Avaliação de Defeitos em Dutos." Dissertação de Mestrado, Escola Politécnica da Universidade de São Paulo, 2007.

[30]. Williams, M.L., "On the Stress Distribution at the Base of Stationary Crack." Journal of Applied Mechanics Vol. 24, 1957, pp. 109-114.

[31]. Irwin, G.R., "Analysis Os Stresses and Strains Near the End of Crack Traversing Plate." Journal of Applied Mechanics Vol. 24, 1957, pp. 361-364.

[32]. American Society for Testing and Materials, "Standard Test Method For Plane Strain Fracture Toughness Of Metalic Materials", ASTM E399, Philadelphia, 1991.

[33]. Donato, G. H. B, "Efeitos de Heterogeneidades Mecânicas Sobre Forças Motrizes de Trinca em Juntas Soldadas: Determinação Experimental de Tenacidade e Extensão de Metodologias de Avaliação de Criticidade de Defeitos", Tese de Doutorado, Escola Politécnica da Universidade de São Paulo, 2008.

[34]. Rice, J.R., "A Path Independent Integral And The Approximate Analysis of a Strain Concentration by Notches And Cracks.", Journal Of Applied Mechanics, Vol. 35, 1968, pp. 379-386.

[35]. Irwin, G. R., "Plastic Zone Near a Crack and Fracture Toughness." Sagamore Research Conference Proceedings, Vol. 4, 1961.

[36]. Dugdale, D. S., "Yielding in Steel Sheets Containing Slits" Journal of the Mechanics and Physics Of Solids, Vol. 8, pp. 100-104.

[37]. Barenblatt, G. I., "The Mathematical Theory of Equilibrium Crack In Brittle Fracture." Advances in Applied Mechanics, Vol. VII, Academic Press, 1962, pp. 55-129.

[38]. Ruggieri C., "FRACTUS 2D: Cálculo Numérico de Parâmetros de Mecânica da Fratura em Componentes Estruturais 2D Contendo Trincas." Escola Politécnica da Universidade de São Paulo, Departamento de Engenharia Naval e Oceânica, 2010.

[39]. Shih C.F., "Relationship Between the $J$-Integral and the Crack Opening Displacement for Stationary and Extending Cracks" Journal of The Mechanics and Physics of Solids, vol. 29, 1981, pp. 305-326. 
[40]. Kirk, M. T., Doods, R.H., "J and CTOD Estimation Equations fort Shallow Craks in Single Edge Notch Bend Specimens," Journal of Testing and Evaluation, Vol. 21, 1993, pp 228-238,

[41]. Kulkarni, D. M., Prakash R., Talan, P., Kumar, A. N.," The Effect of Specimen Thickness on the Experimental and Finite Element Characterization of CTOD in Extra Deep Drawn Steel Sheets," Sadhana, Vol. 29, Part 4, 2004, pp. 365-380.

[42]. R6, "Assessment of the Integrity of Structures Containing Defects", Report R6 revision 4, British Energy Generation, Gloucester, UK, 2000.

[43]. Sumpter J. D. G., E Turner C. E., "Method For Laboratory Determination Of $J_{\mathrm{c}}$ " Crack and Fracture, ASTM STP 601, American Society or Testing and Materials, 1976, PP. 3-18.

[44]. American Society for Testing and Materials, "Standard Test Method for Measurement of Fracture Toughness." ASTM E1820, 1996.

[45]. International Organization for Standardization, "Metallic Materials Unified Method of Test for the Determination of Quasistatic Fracture Toughness", ISO 12135, 2002.

[46]. Silva, L. A. L, "Avaliação De Defeitos Em Dutos e Risers Utilizando Corpos-de-Prova Mecanicamente Similares: Extensão 3D da Metodologia $J$ Q", Dissertação de Mestrado, Escola Politécnica da Universidade de São Paulo, 2006.

[47]. O'Dowd, N.P., and Shih, C.F., "Family of Crack-Tip Fields Characterized by a Triaxiality Parameter: Part I - Structure of Fields," Journal of the Mechanics and Physics of Solids, Vol. 39, pp. 989-1015, 1991.

[48]. O'Dowd, N.P., and Shih, C.F., "Family Of Crack-Tip Fields Characterized By A Triaxiality Parameter: Part II - Fracture Applications." Journal of the Mechanics and Physics of Solids, Vol. 40, pp. 939-963, 1992.

[49]. AMERICAM WELDING SOCIETY, "AWS D1.1 STRUCTURAL WELDING CODE", 2010

[50]. Koppenhoefer, K., Gullerud, A., Ruggieri, C., Dodds, R. and Healy, B., "WARP3D: Dynamic Nonlinear Analysis of Solids Using a Preconditioned Conjugate Gradient Software Architecture," Structural Research Series (SRS) 596, UILU-ENG-94-2017, University Of Illinois at Urbana-Champaign, 1994.

[51]. MSC PATRAN Reference Manual, Disponível em: HTTP://MSCSOFTWARE.COM.

[52]. Panontin, T. L., Makino, A. and Williams J. F., "Crack Tip Opening Displacement Estimation Formulae for $\mathrm{C}(\mathrm{T})$ Specimen" Engineering Fracture Mechanics, Vol. 67, 2000, pp. 293-301. 
[53]. Y. J. Kim, P. J. Budden, "Plastic $\eta$ Factor Solutions of Homogeneous and BiMaterial SE(T) Specimens for Toughness and Creep Crack Growth Testing" Fatigue Fracture Engineering Material Structure, Vol 24, 2001, pp 751-760.

[54]. Helene, O.," Método dos Mínimos Quadrados: com Formalismo Matricial," $1^{\circ}$ Ed., Livraria da Física, 2006. 


\section{APÊNDICE A - FATORES ETA OBTIDOS NO TRABALHO}

Nas tabelas 9 - 13 encontram-se os valores numéricos dos fatores eta utilizados para gerar os gráficos da seção de resultados. Primeiramente são apresentados os valores para os fatores eta 2D (dimensão 1T) em seguida são apresentados os valores para os fatores eta tridimensionais com as dimensões $1 \mathrm{~T}$ e $0.5 \mathrm{~T}$.

Tabela 9: Fatores $\eta$ 2D utilizados para gerar os gráficos da seção 6.2.2 para o espécime 1T com largura de cordão de solda $2 h=10 \mathrm{~mm}$.

\begin{tabular}{|c|c|c|c|c|c|c|c|c|}
\hline & \multicolumn{8}{|c|}{$2 h=10 \mathrm{~mm}$} \\
\hline & & & $a / W=0.45$ & $a / W=0.5$ & $a / W=0.55$ & $a / W=0.6$ & $a / W=0.65$ & $a / W=0.7$ \\
\hline \multirow{12}{*}{$2 \mathrm{D}$} & \multirow{3}{*}{$M_{y}=1.0$} & $\eta_{J}^{C M O D}$ & 1.749 & 1.812 & 1.806 & 1.787 & 1.753 & 1.707 \\
\hline & & $\eta_{\delta}^{C M O D}$ & 0.667 & 0.675 & 0.673 & 0.672 & 0.663 & 0.648 \\
\hline & & $\eta_{J}^{L L D}$ & 2.461 & 2.490 & 2.442 & 2.386 & 2.315 & 2.227 \\
\hline & \multirow{3}{*}{$M_{y}=1.1$} & $\eta_{J}^{C M O D}$ & 1.705 & 1.769 & 1.766 & 1.755 & 1.724 & 1.682 \\
\hline & & $\eta_{\delta}^{C M O D}$ & 0.721 & 0.729 & 0.729 & 0.728 & 0.717 & 0.695 \\
\hline & & $\eta_{J}^{L L D}$ & 2.398 & 2.426 & 2.383 & 2.338 & 2.274 & 2.192 \\
\hline & \multirow{3}{*}{$M_{y}=1.2$} & $\eta_{J}^{C M O D}$ & 1.660 & 1.721 & 1.721 & 1.713 & 1.687 & 1.649 \\
\hline & & $\eta_{\delta}^{C M O D}$ & 0.756 & 0.777 & 0.784 & 0.785 & 0.772 & 0.743 \\
\hline & & $\eta_{J}^{L L D}$ & 2.333 & 2.359 & 2.320 & 2.280 & 2.222 & 2.147 \\
\hline & \multirow{3}{*}{$M_{y}=1.3$} & $\eta_{J}^{C M O D}$ & 1.616 & 1.672 & 1.679 & 1.666 & 1.639 & 1.607 \\
\hline & & $\eta_{\delta}^{C M O D}$ & 0.796 & 0.824 & 0.835 & 0.840 & 0.826 & 0.794 \\
\hline & & $\eta_{J}^{L L D}$ & 2.272 & 2.292 & 2.260 & 2.215 & 2.157 & 2.091 \\
\hline
\end{tabular}

Tabela 10: Fatores $\eta$ 2D utilizados para gerar os gráficos da seção 6.2.2 para o espécime 1T com largura de cordão de solda $2 h=15 \mathrm{~mm}$.

\begin{tabular}{|c|c|c|c|c|c|c|c|c|}
\hline & \multicolumn{8}{|c|}{$2 h=15 \mathrm{~mm}$} \\
\hline & & & $a / W=0.45$ & $a / W=0.5$ & $a / W=0.55$ & $a / W=0.6$ & $a / W=0.65$ & $a / W=0.7$ \\
\hline \multirow{12}{*}{$2 \mathrm{D}$} & \multirow{3}{*}{$M_{y}=1.0$} & $\eta_{J}^{C M O D}$ & 1.749 & 1.812 & 1.806 & 1.787 & 1.753 & 1.707 \\
\hline & & $\eta_{\delta}^{C M O D}$ & 0.667 & 0.675 & 0.673 & 0.672 & 0.663 & 0.648 \\
\hline & & $\eta_{J}^{L L D}$ & 2.461 & 2.490 & 2.442 & 2.386 & 2.315 & 2.227 \\
\hline & \multirow{3}{*}{$M_{y}=1.1$} & $\eta_{J}^{C M O D}$ & 1.670 & 1.757 & 1.759 & 1.750 & 1.725 & 1.690 \\
\hline & & $\eta_{\delta}^{C M O D}$ & 0.716 & 0.724 & 0.720 & 0.714 & 0.699 & 0.677 \\
\hline & & $\eta_{J}^{L L D}$ & 2.348 & 2.410 & 2.374 & 2.333 & 2.276 & 2.204 \\
\hline & \multirow{3}{*}{$M_{y}=1.2$} & $\eta_{J}^{C M O D}$ & 1.584 & 1.688 & 1.707 & 1.709 & 1.691 & 1.670 \\
\hline & & $\eta_{\delta}^{C M O D}$ & 0.747 & 0.769 & 0.769 & 0.756 & 0.732 & 0.702 \\
\hline & & $\eta_{J}^{L L D}$ & 2.225 & 2.313 & 2.300 & 2.276 & 2.230 & 2.178 \\
\hline & \multirow{3}{*}{$M_{y}=1.3$} & $\eta_{J}^{C M O D}$ & 1.509 & 1.603 & 1.640 & 1.658 & 1.655 & 1.649 \\
\hline & & $\eta_{\delta}^{C M O D}$ & 0.777 & 0.808 & 0.814 & 0.799 & 0.766 & 0.723 \\
\hline & & $\eta_{J}^{L L D}$ & 2.120 & 2.199 & 2.208 & 2.204 & 2.180 & 2.150 \\
\hline
\end{tabular}


Tabela 11: Fatores $\eta$ 2D utilizados para gerar os gráficos da seção 6.2.2 para o espécime 1T com largura de cordão de solda $2 h=20 \mathrm{~mm}$.

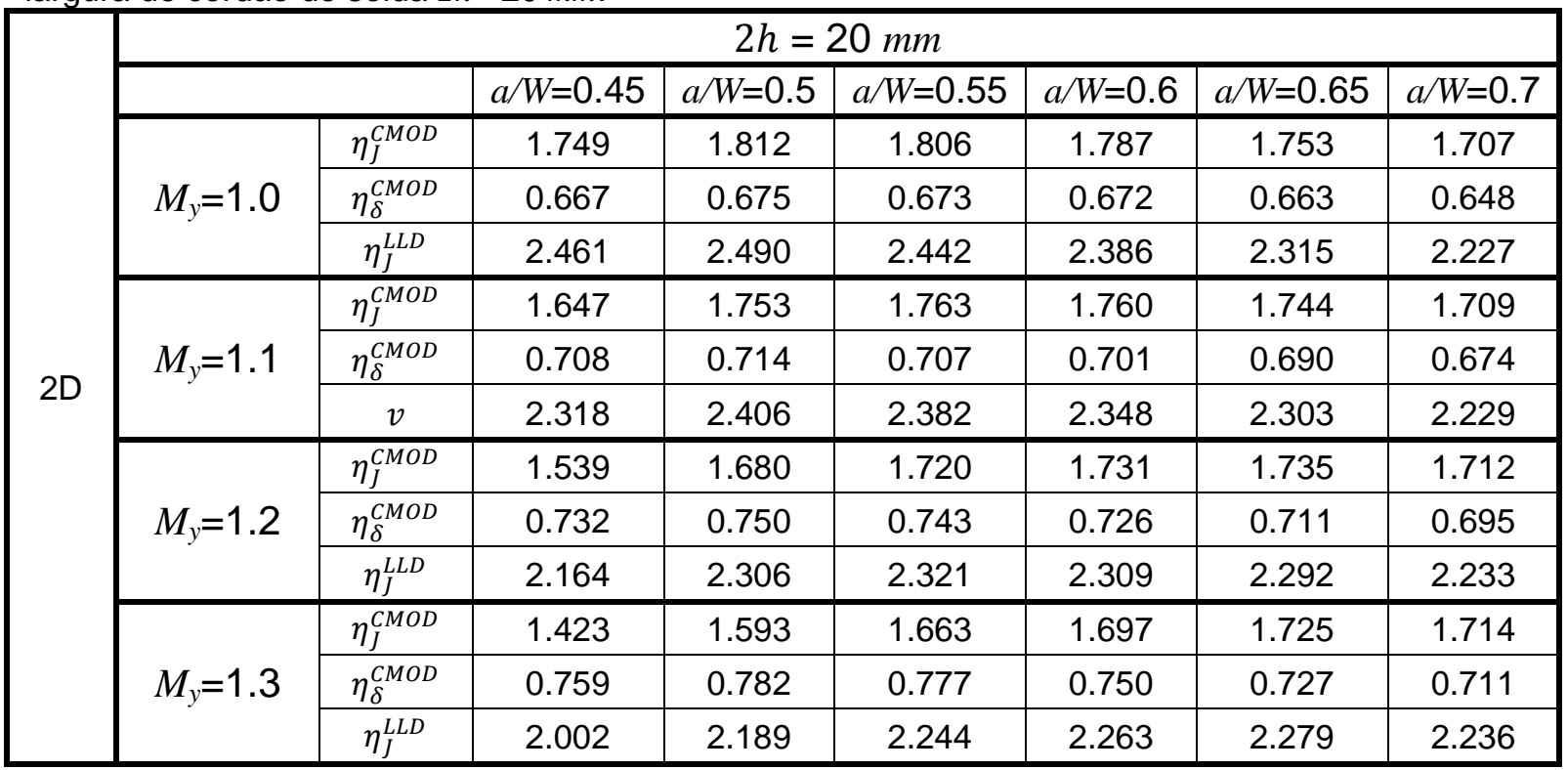

Tabela 12: Fatores $\eta$ tridimensionais utilizados para gerar os gráficos da seção 6.4 para o espécime 1T com largura de cordão de solda $2 h=15 \mathrm{~mm}$.

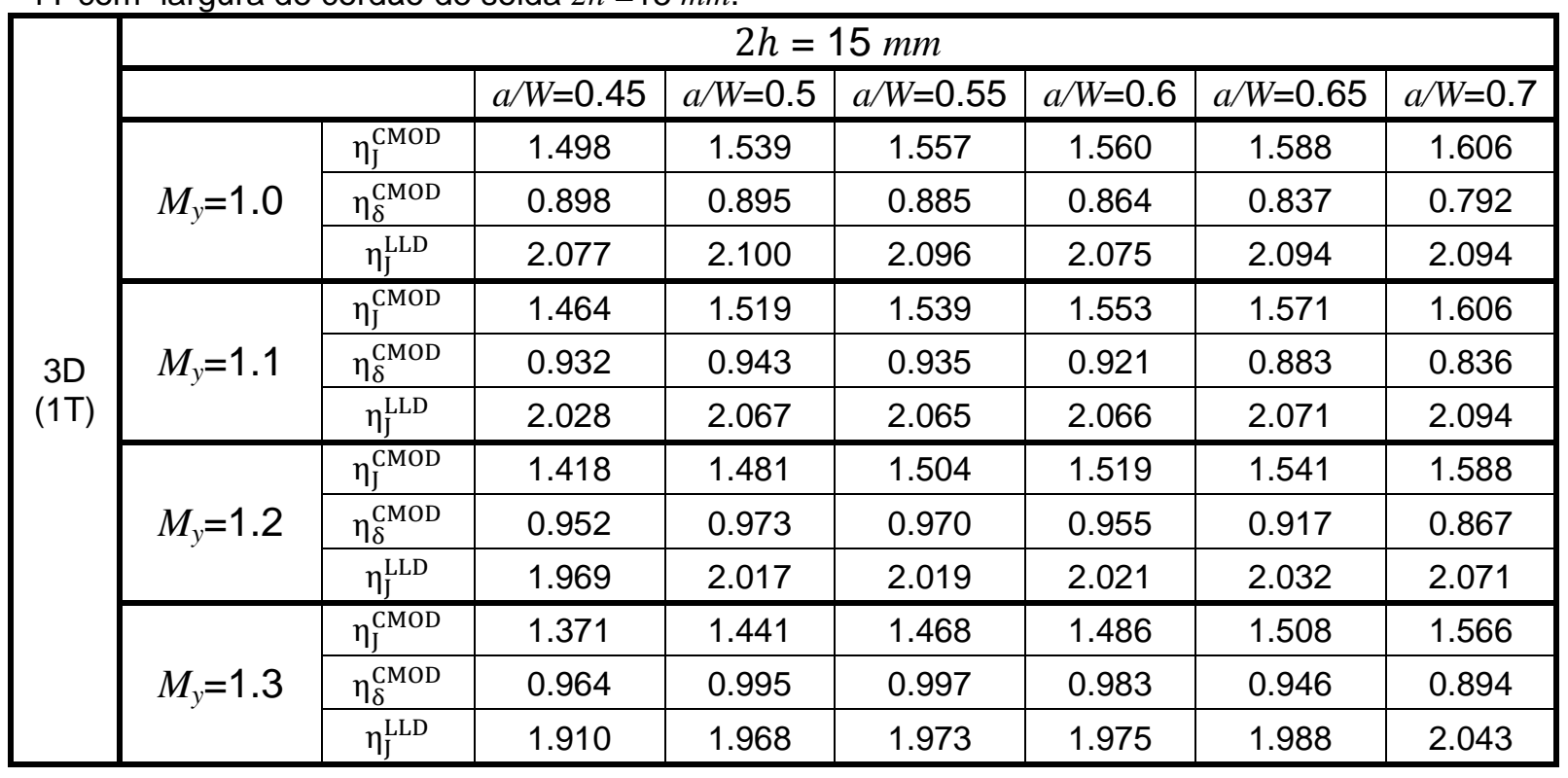


Tabela 13: Fatores $\eta$ tridimensionais utilizados para gerar os gráficos da seção 6.4 para o espécime $0.5 \mathrm{~T}$ com largura de cordão de solda $2 h=15 \mathrm{~mm}$.

\begin{tabular}{|c|c|c|c|c|c|c|c|c|}
\hline & \multicolumn{8}{|c|}{$2 h=15 \mathrm{~mm}$} \\
\hline & & & $a / W=0.45$ & $a / W=0.5$ & $a / W=0.55$ & $a / W=0.6$ & $a / W=0.65$ & $a / W=0.7$ \\
\hline \multirow{12}{*}{$\begin{array}{c}3 \mathrm{D} \\
(0.5 \mathrm{~T})\end{array}$} & \multirow{3}{*}{$M_{y}=1.0$} & $\eta_{J}^{C M O D}$ & 1.533 & 1.593 & 1.606 & 1.616 & 1.621 & 1.625 \\
\hline & & $\eta_{\delta}^{C M O D}$ & 0.802 & 0.815 & 0.800 & 0.771 & 0.739 & 0.709 \\
\hline & & $\eta_{J}^{L L D}$ & 2.089 & 2.140 & 2.134 & 2.134 & 2.127 & 2.118 \\
\hline & \multirow{3}{*}{$M_{y}=1.1$} & $\eta_{J}^{C M O D}$ & 1.485 & 1.558 & 1.578 & 1.596 & 1.609 & 1.622 \\
\hline & & $\eta_{\delta}^{C M O D}$ & 0.822 & 0.845 & 0.835 & 0.805 & 0.770 & 0.738 \\
\hline & & $\eta_{J}^{L L D}$ & 2.028 & 2.095 & 2.101 & 2.108 & 2.112 & 2.115 \\
\hline & \multirow{3}{*}{$M_{y}=1.2$} & $\eta_{J}^{C M O D}$ & 1.433 & 1.518 & 1.550 & 1.575 & 1.597 & 1.620 \\
\hline & & $\eta_{\delta}^{C M O D}$ & 0.832 & 0.863 & 0.861 & 0.831 & 0.794 & 0.761 \\
\hline & & $\eta_{J}^{L L D}$ & 1.964 & 2.045 & 2.065 & 2.081 & 2.097 & 2.112 \\
\hline & \multirow{3}{*}{$M_{y}=1.3$} & $\eta_{J}^{C M O D}$ & 1.381 & 1.473 & 1.519 & 1.551 & 1.583 & 1.616 \\
\hline & & $\eta_{\delta}^{C M O D}$ & 0.835 & 0.872 & 0.882 & 0.854 & 0.813 & 0.779 \\
\hline & & $\eta_{J}^{L L D}$ & 1.898 & 1.987 & 2.024 & 2.049 & 2.079 & 2.108 \\
\hline
\end{tabular}

